\title{
Helping Nature:
}

The Impact of Exposure to Nature on Prosociality and Sustainability

by

\section{Colin A. Capaldi}

A thesis submitted to the Faculty of Graduate and Postdoctoral Affairs in partial fulfillment of the requirements for the degree of

\author{
Master of Arts
}

in

Psychology

\section{Carleton University \\ Ottawa, Canada}

(C) 2014

Colin A. Capaldi 


\begin{abstract}
The biophilia hypothesis states that humans have an innate need to connect with nature because it was evolutionarily adaptive for our survival. Research shows that nature exposure provides many physical and psychological benefits, and that nature relatedness is positively associated with environmentalism and well-being. Preliminary evidence suggests that nature exposure may also be linked to increased prosociality and sustainable behaviours. Study 1 found that viewing videos of pleasant and unpleasant nature had a similar positive impact on connectedness to nature, concern for others, and willingness to engage in proenvironmental behaviours. In contrast, participants exposed to nature in Study 2 were less likely to volunteer to help someone and results concerning interest in sustainability were inconclusive. Multiple methodological and theoretical explanations were discussed to account for these ambiguous findings. Meta-analyses of relevant studies suggested that, on average, nature exposure does cause increased prosociality and sustainability.
\end{abstract}




\section{Acknowledgements}

First and foremost, I would like to thank my supervisor Dr. John Zelenski for providing me with consistent support and feedback during my time as a master's student. His thoughtful comments and questions pushed me to be a better writer and researcher, and his openness to ideas and intellectual curiosity allowed and motivated me to pursue various research questions of interest. I also want to thank the Carleton University Happy Lab members who were always willing to help and offer guidance and support. I am looking forward to continue working with such a great group of individuals.

Thank you to my parents for the unconditional love and support. I will forever appreciate the opportunities they provided to me and the values of hard work, dedication, and curiosity they instilled in me. Thank you to Jonathan, who is an up-and-coming psychology student himself, for being a solid brother. I want to thank my girlfriend Daphne for her never-ending love, complete acceptance, and for putting up with my unorthodox work hours. Thank you to all my close friends for being there whenever I needed a laugh or a night off from work. Last but not least, I have to acknowledge Harley, my dog, for being right by my side throughout the writing of this thesis, providing me with restorative breaks, and reminding me to connect with nature.

This research was supported through scholarships from the Social Sciences and Humanities Research Council, the Government of Ontario, and Carleton University. 


\section{Table of Contents}

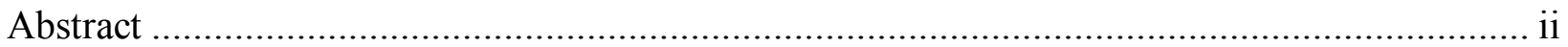

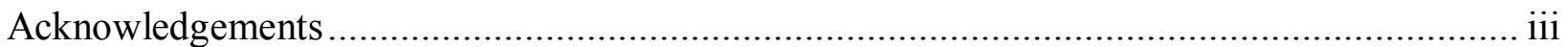

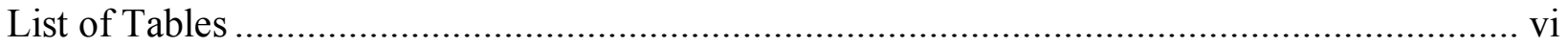

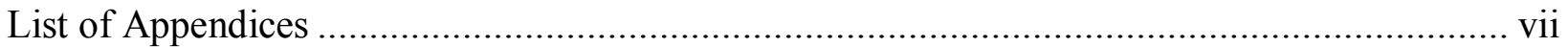

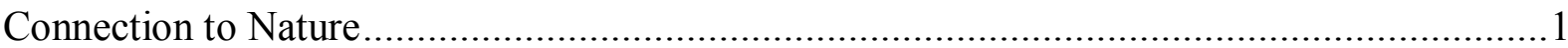

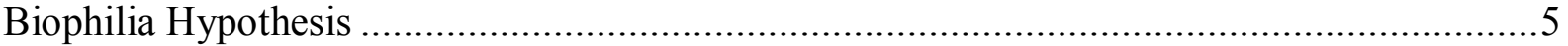

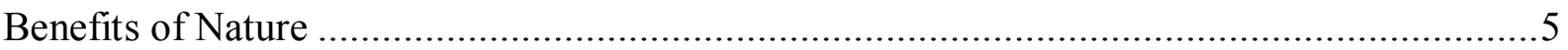

Subjective Nature Relatedness ......................................................................................

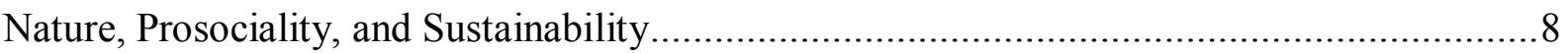

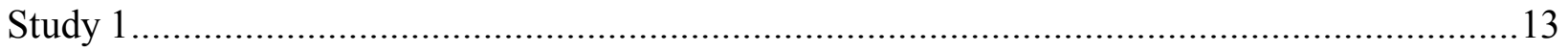

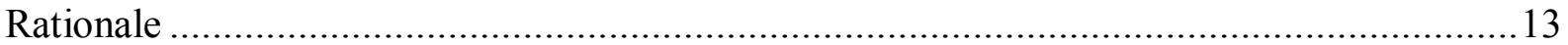

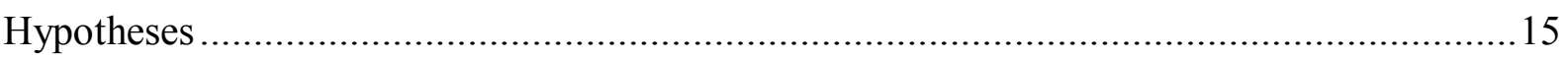

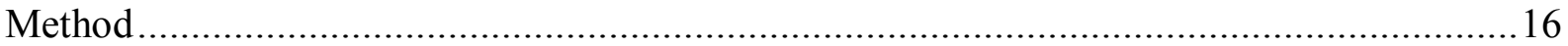

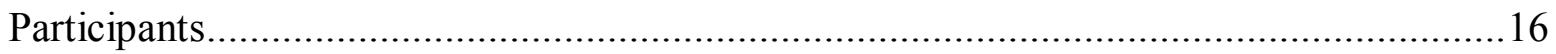

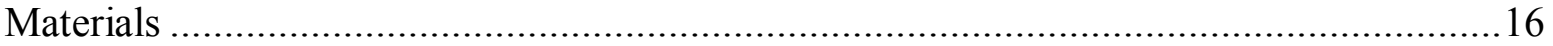

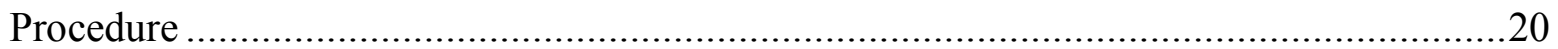

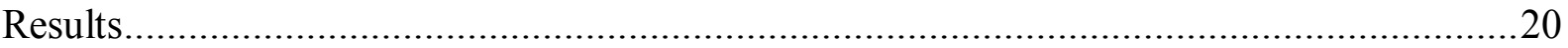

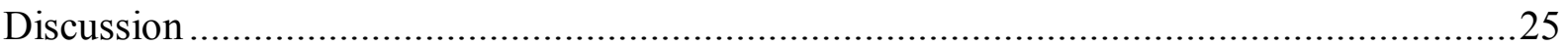

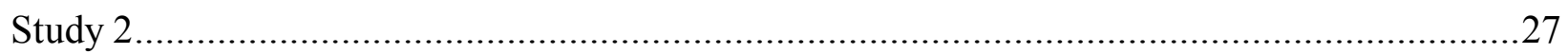

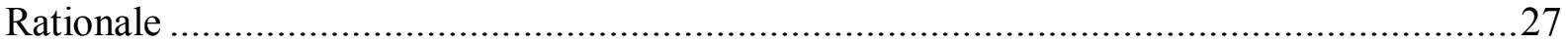

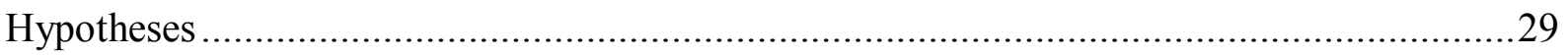

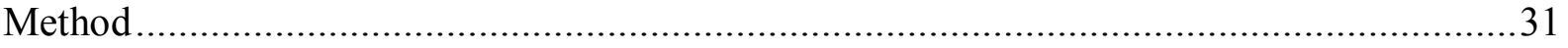




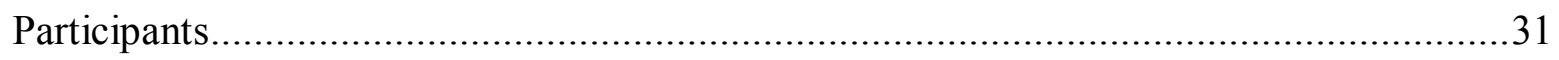

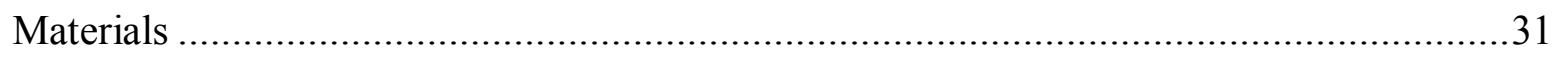

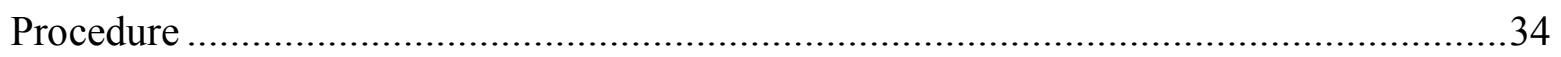

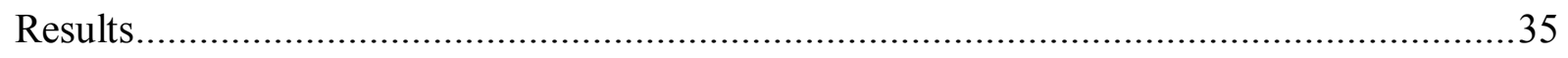

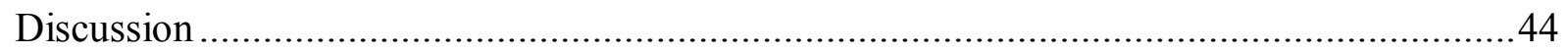

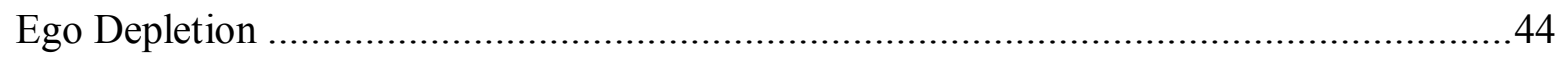

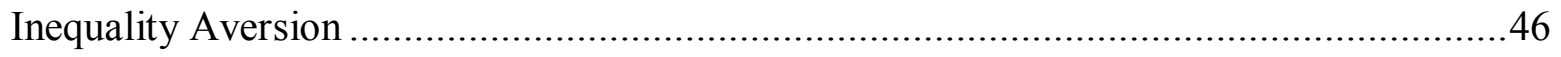

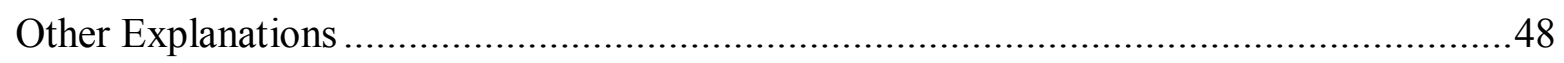

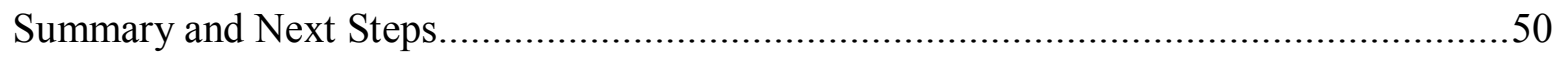

Nature Exposure and Prosociality Meta-Analysis .............................................................51

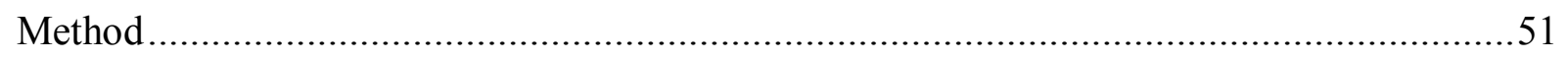

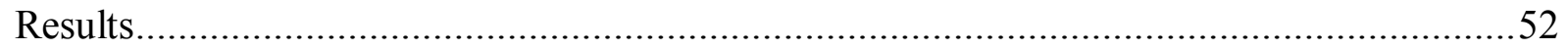

Nature Exposure and Sustainability Meta-Analysis …….......................................................5

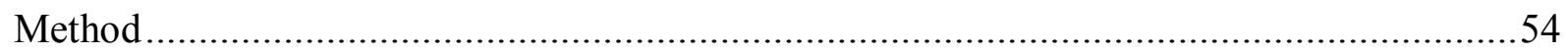

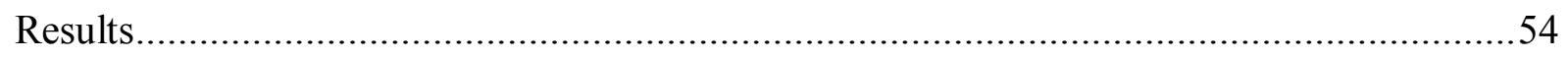

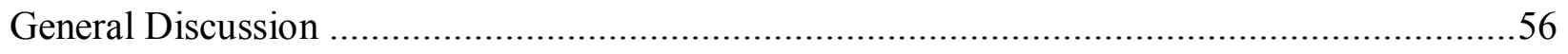

Why Does Nature Exposure Increase Prosociality and Sustainability? .................................57

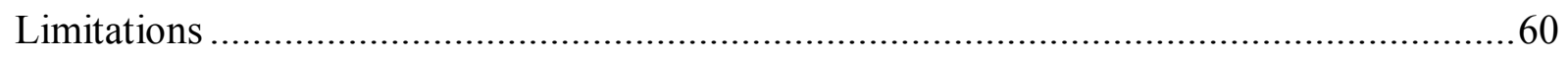

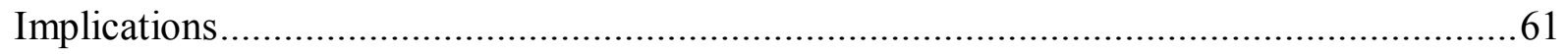

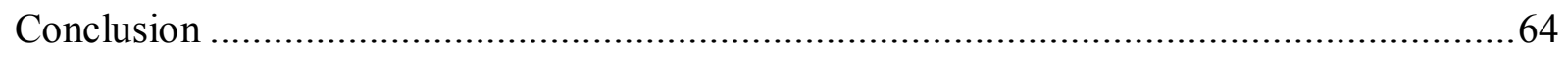

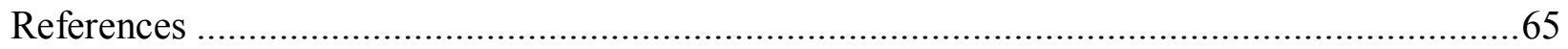




\section{List of Tables}

Table 1 Means (Standard Deviations) by Condition for Study 1 Outcomes ...........................21

Table 2 Study 1 Correlation Coefficients ......................................................................26

Table 3 Study 1 Statistical Mediation Analyses of Location to SVO and WPSB via INS ...........26

Table 4 Means (Standard Deviations) and Effect Sizes by Condition for Video Impression

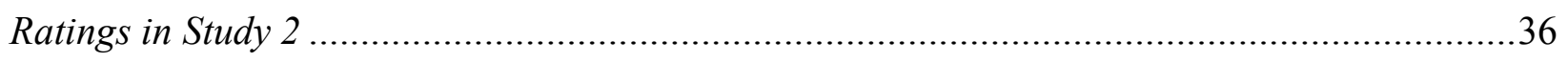

Table 5 Study 2 Correlation Coefficients .........................................................................43

Table 6 Descriptive Information for Samples Included in the Nature Exposure and Prosociality

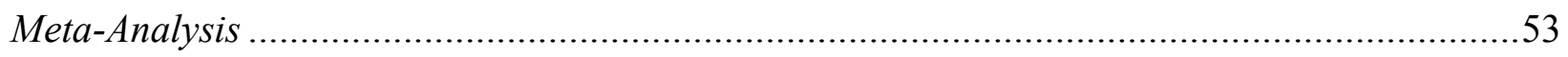

Table 7 Descriptive Information for Samples Included in the Nature Exposure and Sustainability

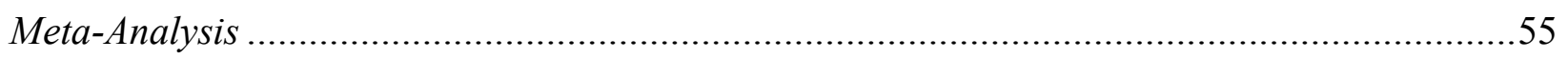




\section{List of Appendices}

Appendix A: Nature Relatedness Scale \& IPIP Representation of Five NEO Domains .............86

Appendix B: Positive and Negative Affect Schedule (PANAS) \& Vitality Scale .....................89

Appendix C: Inclusion of Nature in Self Scale (INS) .............................................. 90

Appendix D: Social Value Orientation Slider Measure (SVO) ........................................ 91

Appendix E: Willingness to Perform Sustainable Behaviours (WPSB) ................................93

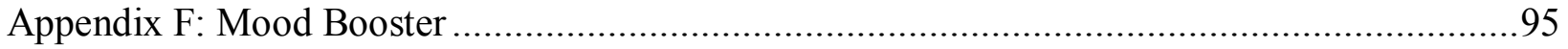

Appendix G: Nature Relatedness Scale (Short-Form) ............................................. 96

Appendix H: Video Impressions Questionnaire .....................................................97

Appendix I: Player Experience of Need Satisfaction Physical Presence Scale (Modified) ..........98

Appendix J: PANAS \& Fascination....................................................................... 99

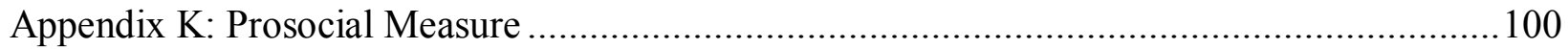

Appendix L: Additional Questionnaire \#1 Curiosity and Exploration Inventory (CEI-II)......... 101

Appendix M: Additional Questionnaire \#2 Emotion Regulation Questionnaire (ERQ) ............ 102

Appendix N: Additional Questionnaire \#3 Short Test Of Music Preferences (STOMP) ........... 103

Appendix O: Additional Questionnaire \#4 Ten-Item Personality Inventory (TIPI)..................104

Appendix P: Additional Questionnaire \#5 Time of Day Scale ........................................... 105

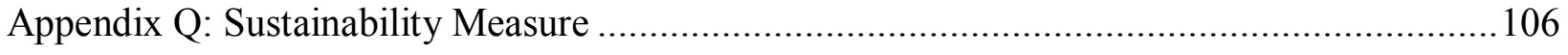

Appendix R: Coding Manual for Meta-Analyses ..................................................... 108 


\section{Helping Nature:}

The Impact of Exposure to Nature on Prosociality and Sustainability

\section{Colin A. Capaldi}

Although the idea of nature as a promoter of physical, psychological, and societal wellbeing is not a new one (Rohde \& Kendle, 1997), a growing body of scientific research from a variety of academic fields in the past couple of decades have increasingly provided support for this proposition (e.g., Frumkin, 2001). A relatively novel line of research in this area has begun to investigate nature's impact on interpersonal relations and proenvironmental behaviours. Specifically, recent studies have found that nature exposure promotes other-focused orientations, generosity, and cooperative sustainable behaviour in a commons dilemma (Dopko, 2012; Weinstein, Przybylski, \& Ryan, 2009). With two studies, I attempted to extend these findings and test their generalizability with novel methodologies and dependent measures. In Study 1, the valence of nature and built videos was manipulated to examine whether the beneficial impact of nature exposure on prosociality and sustainability extended to its more unpleasant aspects as well (i.e., natural disasters and predators). In Study 2, participants were randomly assigned to view nature or built photographs and cover stories were employed to discreetly measure helping behaviour and interest in sustainability. In order to quantitatively summarize the limited research on this topic, meta-analyses were conducted on nature exposure's impact on prosociality and sustainability.

\section{Connection to Nature}

In an era of history where the majority of the world population lives in urban instead of rural areas (United Nations Population Division [UNPD], 2011), it may appear at first glance that humans are more disconnected from the natural environment than they have ever been. Some 
trends provide support for this proposition. For instance, there is evidence to suggest that youth are spending less time outdoors compared to previous generations (Clements, 2004; England Marketing, 2009; Louv, 2005). In fact, a recent survey by the David Suzuki Foundation (2012) found that most Canadian youth (70\%) spend an hour or less of their time outdoors each day. In general, it has been estimated that individuals from developed nations are spending close to $90 \%$ of their time indoors (Evans \& McCoy, 1998; MacKerron \& Mourato, 2013). Moreover, the declining visitation rates to national parks in multiple countries during the past two decades (Pergams, Czech, Haney, \& Nyberg, 2004; Schultis \& More, 2011) is representative of a more general downward trend in nature-based recreation that has been observed (Pergams \& Zaradic, 2008). Among the many possible reasons, some argue that the rise of electronic media partially explains these trends (Louv, 2005; Pergams \& Zaradic, 2006) and that the substitution of time spent outdoors with time spent indoors in front of screens is likely contributing to the increased prevalence rates of obesity across age groups (Cleland et al., 2008; Skinner \& Skelton, 2014; Twells, Greogry, Reddigan, \& Midodzi, 2014). Globally, urbanization is expected to continue into the foreseeable future, with the urban population in 2050 projected to be the same size as the overall world population at the beginning of the twenty-first century (UNPD, 2011). Lastly, despite the warnings about the negative impacts of climate change (e.g., Intergovernmental Panel on Climate Change [IPCC], 2014), carbon dioxide continues to be released into the atmosphere at an ever-increasing rate (Carrington, 2013), sea levels continue to rise (Chen, Wilson, \& Tapley, 2013), and more species are becoming extinct with every day that passes (Chivian \& Bernstein, 2008). Based on these trends, one may be tempted to posit that we have become and will increasingly continue to be more disconnected from the natural environment.

This physical and psychological distance from the natural world has likely led to a 
decreased identification with and concern for the environment, as well as a diminished understanding and consideration of how our behaviour impacts the planet (Nisbet, Zelenski, \& Murphy, 2009). In fact, childhood experiences in nature predict proenvironmental behaviours and time spent in nature as an adult (Cheng \& Monroe 2012; Thompson, Aspinall, \& Montarzino, 2008). Thus, the reduction in nature contact during development may be decreasing the future likelihood of individuals having proenvironmental attitudes, engaging in sustainable behaviours, and connecting with nature as adults. In addition, having a strong attachment to natural spaces is associated with proenvironmental behaviours and climate change engagement (Scannell \& Gifford, 2010, 2013). If individuals are spending almost all of their time indoors, they may not be forming a connection to the natural spaces around them and may be less motivated to engage in place-protective behaviours (Scannell \& Gifford, 2010). As environmental problems, including climate change, are often attributable to human actions (IPCC, 2013) and their solutions require changes in behaviour, a disconnection from nature may impede progress on these issues.

According to some, the gradual movement of populations from rural to urban areas has and will likely continue to bring changes to cultural values as well. Greenfield's (2009) theory of social change and human development posits that certain values are adaptive in specific ecological contexts. One aspect of this theory argues that more collectivist values and behaviours are associated with rural environments and more individualistic values and behaviours are associated with urban environments. To support this proposition, Greenfield (2013) illustrated that as American and British populations became more urbanized during the past two centuries, the use of individualistic and materialistic words (e.g., self and get) in published books became more popular in usage while collectivistic and other-oriented words became less so (e.g., 
authority and give). This is consistent with other research that shows increases in narcissism ${ }^{1}$ and materialism $^{2}$ among college students over more recent time periods (Twenge, Campbell, Hoffman, \& Lance, 2010; Twenge, Konrath, Foster, Campbell, \& Bushman, 2008). With the continuing urbanization of the world's population into the foreseeable future, this suggests not only a further disengagement from the natural world, but from one another as well. Greenfield's (2009) theory of social change and human development asserts that these sociodemographic changes have and will continue to have an impact on how we relate to others and the environment around us.

Yet beyond these trends that suggest a disconnection, there are also indications that human kind's connection to nature perseveres in many ways. For instance, more than half of North American households have at least one pet and, in the US alone, money spent on pets has consistently increased over the years to reach an all-time high of $\$ 55.7$ billion in 2013 (American Pet Products Association, 2013; Perrin, 2009). Over 175 million people visit zoos and aquariums each year (Association of Zoos \& Aquariums, n.d.), which is more than the total annual number of individuals who attend all sporting events in North America's major baseball, basketball, football, hockey, and soccer leagues (Gaines, 2012). Furthermore, \$286 million was donated to Canadian environmental charities in 2010 (Charity Intelligence Canada, 2013) and \$8.3 billion was given to environmental, conservation, and animal-related causes by Americans in 2012 (Giving USA Foundation, 2013). These statistics illustrate that interest in and concern for the

\footnotetext{
${ }^{1}$ It should be noted that the increased narcissism among newer generations finding has generated a lot of debate. For instance, after including newer data on this topic and conducting an updated meta-analysis, Roberts, Edmonds, and Grijalva (2010) did not observe an increase in narcissism and argued that changes in narcissism across the lifespan are more important than generational changes.

${ }^{2}$ Interestingly, consistent with another aspect of Greenfield's (2009) theory of social change and human development (i.e., that people are more collectivistic and less individualistic in poorer ecological contexts), high school seniors during the recent economic recession showed more concern for others and the environment, and did not show the same increase in some aspects of materialism compared to high school seniors measured before the downturn (Park, Twenge, \& Greenfield, 2014). This illustrates the importance of other societal forces, beyond urbanization, that can influence cultural values.
} 
natural world remain prevalent. Moreover, this attraction to nature is evident even at an early age. For instance, almost a third of children books contain an animal as its central character (McCabe, Fairchild, Grauerholz, Pescosolido, \& Tope, 2011), half of children report that animals are their favorite subject matter to read about (Pearson Foundation, 2010), and veterinarian remains one of the most commonly aspired to career for children (Trice \& Hughes, 1995).

\section{Biophilia Hypothesis}

In line with these observations, Wilson's (1984) biophilia hypothesis posits that people have an innate need to connect with other living entities. Considering that it was only relatively recent that people started living in cities detached from the rest of nature, we have spent the vast majority of our evolutionary history living and evolving within the context of the natural environment. It follows that it was evolutionarily adaptive and necessary for our ancestors to be connected to nature in order to survive because individuals who were more connected to nature would have an advantage finding food and shelter, avoiding predators, orienting themselves in space and time, predicting weather and seasonal patterns, etc., compared to those who were less connected with the environment. Consequently, although most of the global population finds themselves inhabiting urban regions, it is thought that we remain biologically and psychologically hardwired to exist in and connect with the natural world (Kellert \& Wilson, 1993).

\section{Benefits of Nature}

A growing body of scientific literature has risen over the past couple of decades that has provided support for the biophilia hypothesis. For instance, research shows that exposure to nature can provide a wide array of physical health benefits (Frumkin, 2001). Employees who had views of nature from their office indicated that they experienced fewer headaches than those 
without a view of nature (Kaplan, 1992). Postoperative patients whose room windows overlooked trees had shorter hospitalizations and a decreased need for pain medications than those patients whose windows faced a brick wall (Ulrich, 1984). Similarly, dental patients who were exposed to a nature mural in the waiting room had significantly lower blood pressure compared to dental patients who were not exposed to it (Heerwagen, 1990). Greater exposure to green space has also been found to reduce the income-inequality gap in mortality (Mitchell \& Popham, 2008).

Interacting with and being in the presence of animals appears to be physically beneficial as well. Patients at a clinic who were pet owners were at a decreased risk for cardiovascular disease (Anderson, Reid, \& Jennings, 1992) and of those who had a heart attack already, people who owned dogs were more likely to be living one year after suffering a heart attack compared to non-dog owners (Friedmann \& Thomas, 1995). Furthermore, participants had a lower stress response when they were exposed to a stressful stimulus in the presence of a dog compared to when they were alone or with a friend (Allen, 1997). Lastly, individuals in an outpatient clinic for pain management had a significant decrease in pain when a therapy dog was present in the waiting room compared to when it was absent (Marcus et al., 2012).

Besides the many physical health benefits that have been discovered, exposure to the natural world also leads to a plethora of psychological improvements. For example, taking brief walks in nature has been found to cause significant increases in positive affect, relaxation, fascination, attentional capacity and restoration, ability to reflect on personal problems, and connection to nature compared to taking brief walks in indoor or urban settings (Berman, Jonides, \& Kaplan, 2008; Mayer, Frantz, Bruehlman-Senecal, \& Dolliver, 2009; Nisbet \& Zelenski, 2011). These improvements in mood and cognition also appear to endure when 
exposure is limited to videos and photographs of nature (Berman et al., 2012; Mayer et al., 2009). Experiencing nature not only enhances normal functioning, but it can also alleviate negative psychological states. As an example, individuals with major depressive disorder who took a walk in nature showed improved mood and short-term memory span compared to when they took a walk in an urban setting (Berman et al., 2012). Moreover, a meta-analysis found that exposure to natural environments can lead to decreased anger, sadness, and fatigue (Bowler, Buyung-Ali, Knight, \& Pullin, 2010). Finally, living near green spaces in urban areas is associated with decreased mental distress and increased satisfaction with life (White, Alcock, Wheeler, \& Depledge, 2013).

\section{Subjective Nature Relatedness}

Beyond the physical and psychological benefits that come from experiencing nature, researchers have identified between-person and within-person differences in how connected people feel to the natural world. On a trait level, many measures have been developed to assess individual differences in people's subjective nature relatedness (see Tam, 2013). One of these is the Nature Relatedness Scale, which assesses stable trait-like differences in people's physical, cognitive, and affective connection to the natural world (Nisbet et al., 2009). Those who are higher in trait nature relatedness identify more with nature, are more concerned about the impact of human behaviour on the environment, and are more comfortable and have more of a desire to be in nature. Not surprisingly, nature relatedness is a strong predictor of proenvironmental attitudes and behaviours, as well as time spent outdoors (Nisbet et al., 2009; Tam, 2013). In terms of personality traits, nature relatedness has been found to be positively associated with extraversion, agreeableness, conscientiousness, and openness to experience (Nisbet et al., 2009; Tam, 2013). Subjective nature relatedness can also be measured at the state level. For instance, 
exposure to natural environments increases momentary feelings of nature relatedness (Nisbet \& Zelenski, 2011). State nature relatedness is commonly measured by the state version of the Inclusion of Nature in Self scale, which asks individuals to indicate how interconnected they are with nature at that moment (Schultz, 2002)

Just as exposure to nature leads to the multitude of psychological benefits discussed above, being higher in subjective nature relatedness is also associated with positive outcomes. In particular, trait nature relatedness has been shown to be positively correlated with life satisfaction, positive affect, vitality, autonomy, personal growth, and purpose in life (Nisbet, Zelenski, \& Murphy, 2011). Thus, being connected to nature is linked to better overall subjective well-being in both the hedonic and eudaimonic conceptions of happiness.

\section{Nature, Prosociality, and Sustainability}

Prosociality can be considered an umbrella term for altruism, generosity, and cooperation as it generally refers to other-oriented values and behaviours, without making any assumptions about the context, motives, or costs involved (Wilson, O’Brien, \& Sesma, 2009). As prosociality is a broad construct, it can be operationalized in a variety of ways. Social value orientation - how people choose to distribute resources between themselves and others - is one way researchers assess prosociality (Balliet, Parks, \& Joireman, 2009). In situations where interdependent decisions must be made, some people tend to have a more altruistic or prosocial value orientation where they take other people's interests and welfare into account when allocating resources, while others have a more individualistic or competitive value orientation where they only consider their own interests and show little to no concern about others (Balliet at al., 2009). Although social value orientation is commonly regarded as a relatively stable trait-like characteristic (Bogaert, Boone, \& Declerck, 2008), within-person changes across situations and 
the lifespan have been observed (Van Lange, Otten, De Bruin, \& Joireman, 1997). Beyond the countless self-report questionnaires, other operationalizations of prosociality include behavioural measures where scenarios are presented to individuals that involve the opportunity to help others by donating time, effort, money, etc. (e.g., Aderman, 1972). Not surprisingly, social value orientation is associated with these behavioural measures of prosociality (McClintock \& Allison, 2006; Van Lange, Bekkers, Schuyt, \& Van Vugt, 2007).

As previously mentioned, a promising new line of research in this area has begun to investigate the link between exposure to nature and prosociality. For instance, participants who viewed images of natural environments valued intrinsic aspirations more and extrinsic aspirations less compared to those who viewed images of human-made environments (Weinstein et al., 2009). This relates to prosociality as intrinsic aspirations tended to be prosocial and otherfocused, whereas extrinsic aspirations tended to be self-focused. In other words, participants in the nature condition placed higher personal importance on relationships and community and lower personal importance on fame and fortune compared to those in the built condition. Moreover, Weinstein et al. (2009) found that participants were more generous and trusting when exposed to nature versus built environments (i.e., they were more likely to give money to another participant who may return an equal amount to them or may keep it all for themselves). More than two decades prior, Witman (1987) found that adolescents with a variety of mental health issues who went on a wilderness experience were subsequently more cooperative and trusting compared to a control group and a group that participated in a traditional social recreation program. Moreover, a meta-analysis by Steblay (1987) found that people are more likely to be helpful in rural versus urban contexts.

In terms of nature relatedness, there are many reasons to posit that it will be related to and 
predict prosocial values and behaviours. As an example, individual differences in modesty, fairness, cooperativeness, and genuineness versus selfishness, greediness, slyness, and pompousness have been found to be associated with environmentalism (Hilbig, Zettler, Moshagen, \& Heydasch, 2013). More specifically, those who are more prosocial tend to have more proenvironmental attitudes and tend to engage in more ecologically responsible behaviours. As nature relatedness is a strong predictor of environmental attitudes and behaviours, it follows that this association with prosociality will likely extend to subjective connectedness to nature. As mentioned previously, nature relatedness has been found to be positively associated with the personality traits of agreeableness and extraversion (Nisbet et al., 2009), which in turn have also been correlated with prosocial behaviours (Carlo, Okun, Knight \& Guzman, 2005; Graziano \& Eisenberg, 1997; Kosek, 1995). Lastly, scores on a measure of humanitarianism, which assessed concern for others' well-being and willingness to help, showed a significant positive correlation with nature relatedness (Nisbet et al., 2009).

One potential mechanism by which nature exposure may influence prosociality is through mood. As discussed above, exposure to nature leads to increased positive affect (Nisbet \& Zelenski, 2011). Relatedly, people are more likely to help others when they are in a positive emotional state (Salovey, Mayer, \& Rosenhan, 1991). As an example, individuals who had a positive mood induced by a confederate giving them a cookie were significantly more likely to volunteer to help run a psychology study when asked by an experimenter compared to those who were not given a cookie (Isen \& Levin, 1972). Thus, there is the possibility that people who are experiencing nature are expressing more prosocial orientations and behaviours simply because they are happier. It should also be noted that negative affect has been associated with increased prosociality in some circumstances too (e.g., Manucia, Baumann, \& Cialdini, 1984). Generally, 
the negative state relief hypothesis claims that people will be more likely to behave prosocially when they are experiencing negative emotions, such as sadness or guilt, in order to reduce unpleasant affect and feel better (Cialdini, Darby, \& Vincent, 1973). These two findings have lead some to suggest that there is a U-shaped relationship between mood and prosociality, with higher levels of positive and negative affect leading to increased prosociality compared to more neutral states (Cialdini, Darby, \& Vincent, 1973). For these reasons, it is important that mood is taken into account and controlled for in investigations of the impact of nature exposure on prosociality.

Nature exposure may also indirectly increase prosociality by enhancing self-regulatory resources. The executive function of self-regulation involves the ability of bringing one's behaviour in line with certain standards, often in the face of conflicting motivations and impulses, such as studying for an upcoming test when one is tempted to peruse Facebook or forgoing a highly desired but less nutritional dish and choosing a healthier option on the menu (Baumeister, Schmeichel, \& Vohs, 2007; DeWall, Baumeister, Gailliot, \& Maner, 2008). Research shows that self-regulation requires energy that is in a limited supply and our ability to self-regulate in the present can be impaired following prior self-regulatory activities that have depleted this finite resource (Muraven, Tice, \& Baumeister, 1998; Vohs \& Heatherton, 2000). This deficit in self-regulatory resources is called ego depletion (Baumeister, Bratslavsky, Muraven, \& Tice, 1998). There is some evidence that suggests that nature exposure can have a restorative effect on fatigued executive functions (see Kaplan \& Berman, 2010, for a review). For instance, after having participants engage in mentally taxing tasks and then exposing them to natural or built environments, Berman et al. (2008) found that individuals in the nature conditions performed better on subsequent cognitive tasks compared to those in the built 
conditions. Similarly, after inducing cognitive fatigue in participants and randomly assigning them to take a walk in nature, in an urban environment, or remain indoors in the laboratory, those in the nature condition showed the greatest restoration in cognitive abilities (Hartig, Mang, \& Evans, 1991). This relates to prosociality as research indicates that when people are in an ego depleted state, they are less likely to help others (DeWall et al., 2008). It is thought by some that helping requires self-regulatory resources in order to overcome selfish impulses and behave in a more prosocial manner (DeWall et al., 2008; Xu, Bègue, \& Bushman, 2012). It should be noted that there is contradictory evidence which suggests that prosociality is actually an intuitive and automatic impulse (see review by Zaki \& Mitchell, 2013). This remains an ongoing debate, with some researchers failing to replicate original intuitive-cooperation effects and others offering alternative explanations for why the effect has disappeared over time (Rand, Greene, \& Nowak, 2012; Rand et al., 2014; Tinghög et al., 2013; Verkoeijen \& Bouwmeester, 2014). Nevertheless, it is plausible that nature exposure may be promoting prosocial orientations and behaviours due to its greater ability to restore self-regulatory resources compared to urban environments.

The link between prosociality and nature is an important one for a variety of reasons. When one views environmental issues as a commons dilemma where self-interested behaviour in the short-term comes at the detriment of others and results in the degradation of shared group resources over the long-term, the promotion of prosocial orientations and behaviour can be seen as a nudge in the right direction to minimize the tragedy of the commons (Hardin, 1968). In other words, individuals acting purely in their own immediate self-interest may avoid engaging in more sustainable behaviours because of the financial or temporal personal costs in the present, which they might tolerate with a more prosocial and other-oriented focus that benefits everyone, including themselves, in the long-term. Interestingly, utilizing a simulated fishing commons 
dilemma and conceptualizing sustainable behaviour as cooperative, Dopko (2012) found that participants who viewed a nature video caught less fish per round and sustained the common resource pool for a longer period of time compared to those who viewed a video of urban settings. This suggests that along with prosociality, nature exposure might also promote sustainability. Being exposed to nature stimuli might trigger individuals' biophilic tendencies and increase people's valuing of and concern for the natural world. It is also plausible that nature exposure might increase proenvironmental attitudes and behaviours by restoring self-regulatory resources. In fact, Crelley (2013) found that participants who were more ego depleted were less sustainable in a simulated foresting social commons dilemma compared to those who had more self-regulatory energy available. Exposure to nature may restore self-regulatory resources and allow individuals' to more easily inhibit selfish and habitual behaviours that are harmful to the environment in favour of ones that may be more costly in the present but more beneficial to the well-being of environment and to a greater number of people in the future. Connecting with nature in the moment (i.e., nature exposure) and in general (i.e., nature relatedness) may nudge people to behave in more other-oriented and proenvironmental ways. It is for these reasons that prosociality and sustainability were the primary outcomes of interest in this thesis.

\section{Study 1}

\section{Rationale}

The vast majority of studies that have examined the effects of nature exposure on psychological functioning have only employed stimuli that contain the pleasant aspects of natural environments. The unpleasant and threatening aspects of the natural world have largely been ignored. Bruni, Chance, Schultz, and Nolan (2012) did manipulate the valence of nature and built stimuli in an implicit association test and found that people generally show stronger associations 
between the self and nature compared to the self and built, regardless of valence. From a terror management theory perspective, Koole and Van den Berg (2005) found that wilderness is associated with more thoughts about death compared to cultivated nature and urban environments. Beyond these studies, how the valence of nature stimuli influences explicit measures of state nature relatedness, prosociality, and environmentalism remains an unanswered question. This is an especially pertinent issue given the unique relationship between mood and prosocial behaviours (Eisenberg, 1991). Do we feel more connected to the natural world when we are reminded of its unpleasant and threatening characteristics? Are we more concerned and willing to help others when natural disasters and predators are salient? Are we still willing to "save the planet" when we are reminded that Mother Nature can be dangerous and harmful? Relatedly, does the extent to which we feel connected to the natural world at a trait-level influence how we respond to pleasant and unpleasant aspects of nature and built environments? For example, being exposed to aversive features of the natural world may have a more detrimental interpersonal, attitudinal, and emotional impact on individuals who are low in nature relatedness as those who are more connected to nature understand the importance of even the most unpleasant parts of nature (Nisbet et al., 2009).

In order to extend previous findings beyond pleasant to unpleasant aspects of nature and control for mood as a potential mediator of prosociality, Study 1 manipulated the pleasantness of nature and built videos in a $2 \times 2$ experimental design. Participants were randomly assigned to view one of these videos and then complete questionnaires that assessed their mood, state nature relatedness, social value orientation, and willingness to perform sustainable behaviours. As a related focus of Study 1 was whether individual differences in nature relatedness moderate emotional, prosocial, and proenvironmental responses to pleasant and unpleasant aspects of 
natural and built environments, participants completed the Nature Relatedness Scale before watching the video.

Investigating these questions is important in the modern context as the public is increasingly bombarded with negative new stories about the environment and as the damaging consequences of climate change become more salient. How our environmental attitudes and behaviours, as well as our social relations, change in response to the transformations we see and will see in the natural and built environments we are exposed to is a research question worthy of investigation.

\section{Hypotheses}

Hypothesis 1: Participants who viewed the nature videos would be higher in state nature relatedness compared to those who viewed the built videos, regardless of pleasantness. Hypothesis 2: Participants who viewed the nature videos would show a more prosocial value orientation compared to those who viewed the built videos, regardless of pleasantness. Hypothesis 3: Participants who viewed the nature videos would be more willing to perform sustainable behaviours compared to those who viewed the built videos, regardless of pleasantness.

Hypothesis 4: Trait nature relatedness would interact with location and valence in predicting positive affect, state nature relatedness, social value orientation, and willingness to perform sustainable behaviours. It was thought that participants low in trait nature relatedness might respond less favourably to the unpleasant aspects of nature, while those high in trait nature relatedness might respond similarly to both pleasant and unpleasant aspects of nature. It should be noted that this hypothesis was exploratory in nature. 


\section{Method}

\section{Participants}

Two hundred seventy-one undergraduate students from Carleton University consented to participate in an online study titled "Personality, Videos, Moods and Attitudes" for partial course credit in their first or second year psychology or neuroscience class. Participants were excluded if they only partially completed the study, finished in less than 10 minutes, and did not comply with two requests to leave items blank. These exclusion criteria left a remaining sample size of 228 participants.

\section{Materials}

Trait nature relatedness. This variable was measured using the 21 -item Nature Relatedness Scale (Nisbet et al., 2009; Appendix A). A 5-point Likert scale ranging from 1 (disagree strongly) to 5 (agree strongly) was used to answer statements like "I enjoy being outdoors, even in unpleasant weather", "I always think about how my actions affect the environment", and "The state of non-human species is an indicator of the future for humans". After the appropriate items were reverse-scored, an overall score on trait nature relatedness was calculated by taking the average of all the items, with higher scores indicating higher connectedness to nature. Items in this scale were internally consistent at a Cronbach's alpha of 0.90. To make the focus of the current study less discernible, the instructions and the items of the Nature Relatedness Scale were slightly reworded so they could be embedded seamlessly within the following questionnaire.

Five-factor personality. The five-factor model of personality identifies five broad dimensions that best account for and describe individual differences in personality: extraversion, neuroticism, agreeableness, conscientiousness, and openness to experience (Costa \& McCrae, 
1985). These five factors were measured using the 100-item International Personality Item Pool (IPIP) representation of Costa and McCrae's (1992) five NEO domains (Appendix A). A 5-point Likert scale ranging from 1 (disagree strongly) to 5 (agree strongly) was used to answer statements like "I make friends easily", "I have frequent mood swings", "I trust what people say", "I am always prepared", and "I enjoy hearing new ideas". In order to identify inattentive and careless responding, two requests to leave items blank were inserted into this questionnaire.

Videos clips. Videos were created that varied location and pleasantness in a 2 × 2 experimental design. Exposure to positively and negatively valenced nature and built stimuli was manipulated by randomly assigning participants to watch one of five possible video clips. More specifically, a video of an abandoned decrepit house was used for the negatively valenced built stimulus (http://vimeo.com/86481554) ${ }^{3}$, while a video of a pack of wolves (http://vimeo.com/86481556) and a video of a flood (http://vimeo.com/86481555) were used for the negatively valenced nature stimuli. These two videos were chosen as the negatively valenced nature stimuli in order to examine whether participant responses to subsequent questionnaires depended on being exposed to different unpleasant aspects of nature (i.e., a predator versus a natural disaster). The two videos were also chosen in order to account for confounds in the natural disaster video as it included images of floods in built environments. Overall, responses were quite similar across these two video conditions so they were combined into one general unpleasant nature condition. A video of Las Vegas was used for the positively valenced built stimulus (http://vimeo.com/86511096), while a video of an old-growth forest was used for the positively valenced nature stimulus (http://vimeo.com/86481553). Each of the videos were originally found and downloaded from YouTube. The audio from the videos were removed and

\footnotetext{
${ }^{3}$ As the videos in Study 1 contained copyrighted content, they were made private and password-protected so they could only be accessed and used for research purposes. To watch these videos, enter the password "psychology".
} 
replaced with either ominous or upbeat music in order to further augment the valence of the videos. Each of the video clips was edited to around two minutes in length.

Positive and negative mood. These variables were measured using the 20 -item Positive and Negative Affect Schedule (PANAS; Watson, Clark, and Tellegen, 1988; Appendix B). Participants answered how much certain words described how they were feeling at that moment on a 5-point Likert scale ranging from 1 (very slightly or not at all) to 5 (extremely). Overall measures of positive and negative affect were obtained by averaging the items for each of the subscales. Items in the Positive Affect and Negative Affect subscales were both internally consistent at Cronbach's alphas of 0.91. Embedded within the PANAS were 6-items measuring vitality (Ryan \& Frederick, 1997).

State nature relatedness. This variable was measured using the Inclusion of Nature in Self scale (INS; Schultz, 2002; Appendix C). This 1-item measure has seven pairs of circles with one of the circles in the pair labeled nature and the other labeled self. The seven pairs of circles differ in how much they overlap - from no overlap at all to complete overlap. The overlapping circles represent the extent to which nature is incorporated into someone's identity and how connected that person is to nature. Participants were asked to select the pair of circles that best described their relationship with the natural environment at that moment. Because this scale was used to measure state nature relatedness, 'at this moment' and 'right now' were included in the instructions. To make the interest of the study less obvious, participants were also asked how connected they were to their family and to society.

Prosociality. This variable was measured using the Social Value Orientation Slider Measure (SVO; Murphy, Ackermann, \& Handgraaf, 2011; Appendix D). Within each of the six items, participants were asked to allocate resources (i.e., imaginary money) to themselves and an 
imaginary other. Every item had nine outcomes participants could choose from that varied in how beneficial it was to the participant or the hypothetical other. Participants were asked to choose the distribution they preferred the most for each of the six items. Overall SVO scores were calculated using the formula outlined in Murphy et al. (2011). Higher overall scores represent a more prosocial allocation of resources, while lower overall scores represent a more individualistic allocation of resources.

Willingness to perform sustainable behaviours. This variable was measured using the 30-item willingness to perform sustainable behaviour measure from Ferguson, Branscombe, and Reynolds (WPSB; 2011; Appendix E). On a 7-point Likert scale ranging from 1 (extremely unwilling) to 7 (extremely willing), participants were asked how willing they would be to engage in a variety of sustainable behaviours like "Ride a bicycle or moped", "Reduce the amount of warm and hot water used", "Attend a peaceful demonstration promoting awareness of climate change", "Support a $\$ 50$ per year federal tax increase to support research to reduce climate change", and "Support a regulation requiring new buildings to meet higher energy-efficiency standards". These aforementioned statements are examples of items respectively measuring willingness to perform five types of sustainable behaviours: transportation choices, energy-water use, social advocacy, tax support, and regulatory support. Overall scores were obtained by taking the average of all the items, with higher scores indicating higher willingness to engage in proenvironmental behaviours. This questionnaire was chosen specifically because it is sensitive to experimental manipulations (Ferguson et al., 2011). Items in this scale were internally consistent at a Cronbach's alpha of 0.94 .

Mood booster. Since some participants were exposed to negatively valenced videos, a mood booster was employed to counteract any lingering negative emotions (Appendix F). 
Participants imagined themselves as they read two scenarios that described being asked out on a date by someone they were romantically interested in and reading a letter that offered them their ideal job.

\section{Procedure}

Participants were recruited online through the experiment management system of the Department of Psychology at Carleton University. After reading a recruitment notice and signing up to participate, individuals were automatically given a link to the online study being hosted on Qualtrics. Once participants read the informed consent form and indicated their consent to participate, they completed the Nature Relatedness Scale embedded within the IPIP representation of Costa and McCrae's (1992) five NEO domains. Participants were then randomly assigned to view one of the five video clips and instructed to turn on their audio, make the video full screen, and pay close attention to the video as they watched it. Next, they completed the PANAS, INS, SVO, and WPSB. After the mood booster, participants read the debriefing form and were given 0.5 course credit for participating. The median time for completing the study was 21 minutes.

\section{Results}

See Table 1 for descriptive statistics associated with the following tests. As a manipulation check, a two-way between-subjects analysis of variance (ANOVA) was conducted with valence (pleasant vs. unpleasant) and location (nature vs. built) as the independent variables and positive affect as the dependent variable. If the experimental manipulation was done correctly then one should observe a main effect of valence. Furthermore, positive affect should not differ based on location and there should not be a valence $\mathrm{x}$ location interaction. As expected, there was a main effect of valence, $F(1,224)=12.61, p<.001, \eta_{p}^{2}=.053$. Participants in the 
Table 1

Means (Standard Deviations) by Condition for Study 1 Outcomes

\begin{tabular}{|c|c|c|c|c|}
\hline & \multicolumn{2}{|c|}{ Built } & \multicolumn{2}{|c|}{ Nature } \\
\hline & $\begin{array}{l}\text { Unpleasant } \\
(n=48)\end{array}$ & $\begin{array}{l}\text { Pleasant } \\
(n=46)\end{array}$ & $\begin{array}{l}\text { Unpleasant } \\
(n=89)\end{array}$ & $\begin{array}{l}\text { Pleasant } \\
(n=45)\end{array}$ \\
\hline \multicolumn{5}{|c|}{ PANAS } \\
\hline PA & $2.34(0.82)$ & $2.69(0.93)$ & $2.26(0.86)$ & $2.79(1.02)$ \\
\hline NA & $2.19(0.96)$ & $1.55(0.61)$ & $1.96(0.80)$ & $1.39(0.50)$ \\
\hline VS & $2.39(0.84)$ & $2.67(1.02)$ & $2.21(0.81)$ & $2.67(1.02)$ \\
\hline INS & $3.06(1.39)$ & $2.78(1.32)$ & $3.38(1.54)$ & $3.22(1.61)$ \\
\hline SVO & $27.23(16.67)$ & $25.75(16.24)$ & 30.37 (13.44) & $31.41(12.09)$ \\
\hline WPSB & $4.81(0.85)$ & $4.42(1.07)$ & $4.82(1.03)$ & $4.98(0.85)$ \\
\hline \multicolumn{5}{|c|}{$\begin{array}{l}\text { Note. PANAS = Positive and Negative Affect Schedule; PA = Positive Affect; NA = Negative } \\
\text { Affect; VS = Vitality Scale; INS = Inclusion of Nature in Self; SVO = Social Value Orientation; } \\
\text { WPSB = Willingness to Perform Sustainable Behaviours. }\end{array}$} \\
\hline \multicolumn{5}{|c|}{ positively valenced conditions experienced significantly more positive affect $(M=2.74$, } \\
\hline \multicolumn{5}{|c|}{$S D=0.97)$ compared to participants in the negatively valenced conditions $(M=2.29$} \\
\hline \multicolumn{5}{|c|}{$S D=0.85)$. There was not a significant main effect for location, $F(1,224)=0.01, p=.92$, } \\
\hline \multicolumn{5}{|c|}{$\eta_{p}^{2}<.001$. There also was not a significant interaction between valence and location, } \\
\hline$F(1,22$ & $=.47, \eta_{p}^{2}=$ & & & \\
\hline
\end{tabular}

As a second manipulation check, a two-way between-subjects ANOVA was conducted with valence and location as the independent variables and negative affect as the dependent

\footnotetext{
${ }^{4}$ The same pattern was found for vitality. There was a significant main effect of valence, $F(1,224)=8.71$, $p=.004, \eta_{p}^{2}=.037$, but the main effect for location, $F(1,224)=0.49, p=.49, \eta_{p}^{2}=.002$, and the interaction, $F(1,224)=0.56, p=.45, \eta_{p}^{2}=.003$, were not significant.
} 
variable. The main effect of valence was significant, $F(1,224)=33.70, p<.001, \eta_{p}^{2}=.131$.

Participants in the negatively valenced conditions experienced significantly more negative affect $(M=2.04, S D=0.86)$ compared to participants in the positively valenced conditions $(M=1.47$, $S D=0.56)$. There was also a marginally significant main effect for location, $F(1,224)=3.49$, $p=.06, \eta_{p}^{2}=.015$. Participants in the built conditions experienced marginally more negative affect $(M=1.88, S D=0.87)$ compared to participants in the nature conditions $(M=1.77$, $S D=0.76)$. There was not a significant interaction between valence and location, $F(1,224)=0.09, p=.76, \eta_{p}^{2}<.001$. Overall, it appears as though the experimental manipulation mostly had its desired effect. To account for the marginally significant main effect of location on negative affect, analyses were presented without and with negative affect as a covariate.

Participants who viewed the nature videos, regardless of pleasantness, were expected to identify with nature more than those who viewed the built videos. In order to test this hypothesis, a two-factor between-subjects ANOVA was conducted with valence and location as the independent variables and state nature relatedness (i.e., INS score) as the dependent variable. A marginally significant main effect was found for location, $F(1,224)=3.46, p=.06 \eta_{p}^{2}=.015$. Regardless of valence, participants felt marginally more connected to nature in the nature conditions $(M=3.33, S D=1.56)$ compared to the built conditions $(M=2.93, S D=1.35)$. There was not a significant main effect for valence, $F(1,224)=1.16, p=.28, \eta_{p}^{2}=.005$, nor was there a significant valence by location interaction, $F(1,224)=0.09, p=.77, \eta_{p}^{2}<.001$. When an ANCOVA was conducted with negative affect as a covariate, the main effect of location became significant, $F(1,223)=4.43, p=.04, \eta_{p}^{2}=.019$, while the main effect of valence, $F(1,223)=0.08, p=.78, \eta_{p}^{2}<.001$, and the valence by location interaction, $F(1,223)=0.65$, $p=.80, \eta_{p}^{2}<.001$, remained nonsignificant. 
Participants who viewed the nature videos, regardless of pleasantness, were expected to show a more prosocial value orientation compared to those who viewed the built videos. In order to test this hypothesis, a two-factor between-subjects ANOVA was conducted with valence and location as the independent variables and prosociality (i.e., overall SVO score) as the dependent variable. A significant main effect was found for location, $F(1,224)=4.82, p=.03, \eta_{p}^{2}=.021$. Participants in the nature conditions had a more prosocial value orientation $(M=30.72$, $S D=12.97)$ than participants in the built conditions $(M=25.75, S D=16.23)$. There was not a significant main effect for valence, $F(1,224)=0.01, p=.91, \eta_{p}^{2}<.001$, nor was there a significant valence by location interaction, $F(1,224)=0.40, p=.53, \eta_{p}^{2}=.002$. When an ANCOVA was conducted with negative affect as a covariate, the main effect of location remained significant, $F(1,223)=3.78, p=.05, \eta_{p}^{2}=.017$, while the main effect of valence, $F(1,223)=0.70, p=.41, \eta_{p}^{2}=.003$, and the valence by location interaction, $F(1,223)=0.45$, $p=.50, \eta_{p}^{2}=.002$, remained nonsignificant

Participants who viewed the nature videos, regardless of pleasantness, were expected to be more willing to perform sustainable behaviours compared to those who viewed the built videos. In order to test this hypothesis, a two-factor between-subjects ANOVA was conducted with valence and location as the independent variables and willingness to engage in proenvironmental behaviours (i.e., overall WPSB score) as the dependent variable. A significant main effect was found for location, $F(1,224)=4.51, p=.04, \eta_{p}^{2}=.020$. Individuals in the nature conditions were more willing to engage in proenvironmental behaviours $(M=4.88, S D=0.98)$ than individuals in the built conditions $(M=4.62, S D=0.98)$. No main effect was found for valence, $F(1,224)=0.73, p=.39, \eta_{p}^{2}=.003$. Interestingly, a significant valence by location interaction was found, $F(1,224)=3.96, p=.05, \eta_{p}^{2}=.017$. When an ANCOVA was conducted 
with negative affect as a covariate, the main effect of location remained significant, $F(1,223)=4.76, p=.03, \eta_{p}^{2}=.021$, the main effect of valence remained nonsignificant, $F(1,223)=0.33, \eta^{2}=.003, p=.57, \eta_{p}^{2}=.001$, and the valence by location interaction remained significant, $F(1,223)=3.90, p=.05, \eta_{p}^{2}=.017$.

Post hoc analyses revealed that the simple effect of location was significant in the pleasant conditions, $F(1,224)=7.31, p=.01, \eta_{p}^{2}=.032$, but not significant in the unpleasant conditions, $F(1,224)=0.01, p=.92, \eta^{2}<.001$. Thus, participants who were exposed to the pleasant nature stimulus (i.e., a video clip of the old growth forest) were more willing to engage in proenvironmental behaviours $(M=4.98, S D=0.85)$ than participants who were exposed to the pleasant built stimulus (i.e., a video clip of Las Vegas; $M=4.42, S D=1.08$ ). Individuals who were exposed to the unpleasant nature stimulus (i.e., a video clip of a pack of wolves or a flood; $M=4.82, S D=1.03$ ) were not significantly different in their willingness to engage in proenvironmental behaviours compared to individuals who were exposed to the unpleasant built condition (i.e., an abandoned decrepit house; $M=4.81, S D=0.85$ ).

When I investigated this significant interaction from a second perspective, post hoc analyses revealed that the simple effect of valence was marginally significant in the built conditions, $F(1,224)=3.61, p=.06, \eta_{p}^{2}=.016$, but nonsignificant in the nature conditions, $F(1,224)=0.73, p=.39, \eta_{p}^{2}=.003$. Participants who were exposed to the pleasant built condition were marginally less willing to engage in proenvironmental behaviours compared to those who were exposed to the unpleasant built condition, while there was no significant difference between participants in the pleasant nature and unpleasant nature conditions.

I also hypothesized that trait nature relatedness would interact with location and valence in predicting positive affect, state nature relatedness, prosociality, and willingness to perform 
sustainable behaviours. In general, trait nature relatedness did not interact significantly with valence or location. ${ }^{5}$ Across conditions, trait nature relatedness was significantly and positively correlated with positive affect, $r(226)=.23, p<.001$, social value orientation, $r(226)=.27$, $p<.001$, and willingness to perform sustainable behaviours, $r(226)=.64, p<.001$. Thus, those who are more subjectively connected to nature tend to experience more positive emotions, be more prosocial, and be more willing to engage in proenvironmental behaviours compared to those who are not as subjectively connected to nature. See Table 2 for the correlation coefficients between the variables of interest from Study 1.

Exploratory statistical mediation analyses were conducted to investigate state nature relatedness (i.e., INS) as the potential mechanism underlying the effect of location (collapsed across valence) on social value orientation and willingness to engage in proenvironmental behaviours. As one can see from Table 3, there appears to be some evidence for the indirect effect of state nature relatedness. It appears that an increased connection to nature following nature exposure partially mediates its effect on prosociality and proenvironmental willingness. ${ }^{6}$

\section{Discussion}

Overall, this study provided further evidence for the beneficial effect nature exposure has on prosociality. Regardless of the pleasantness of the videos, participants in the nature conditions were more likely to allocate resources in a prosocial manner compared to those in the built conditions. This is a promising finding because it suggests that even when the natural environment is threatening or unpleasant, nature exposure continues to promote concern for others. Furthermore, both state and trait nature relatedness were positively associated with

\footnotetext{
${ }^{5}$ The one exception to this general pattern was a significant interaction between trait nature relatedness and valence in predicting positive affect, $B=0.47, S E=0.19, \beta=0.21, t(221)=2.54, p=.01$. Only in the pleasant conditions were increases in nature relatedness significantly associated with increases in positive affect.

${ }^{6}$ For the purposes of this thesis, if the path between the independent variable and the outcome variable was nonzero after controlling for a significant indirect effect, then it was classified as partial mediation (Kenny, 2014).
} 
Table 2

Study 1 Correlation Coefficients

\begin{tabular}{lcccccc}
\hline Measure & 1 & 2 & 3 & 4 & 5 & 6 \\
\hline $1 . \mathrm{NR}$ & - & - & - & - & - & - \\
$2 . \mathrm{PA}$ & $.23 * * *$ & - & - & - & - & - \\
3. NA & .12 & .03 & - & - & - & - \\
4. VS & $.23 * * *$ & $.87 * * *$ & .01 & - & - & - \\
$5 . \mathrm{INS}$ & $.61 * * *$ & $.32 * * *$ & $.14 *$ & $.31 * * *$ & - & - \\
$6 . \mathrm{SVO}$ & $.27 * * *$ & -.02 & $-.13 *$ & .01 & $.21 * *$ & $.29 * *$ \\
$7 . \mathrm{WPSB}$ & $.64 * * *$ & $.18 * *$ & .05 & $.13 *$ & $.45 * * *$ & \\
\hline
\end{tabular}

Note. NR = Nature Relatedness; PA = Positive Affect; NA = Negative Affect; VS = Vitality Scale; INS = Inclusion of Nature in Self; SVO = Social Value Orientation; WPSB = Willingness to Perform Sustainable Behaviours.

$* p<.05, * * p<.01, * * * p<.001$.

Table 3

Study 1 Statistical Mediation Analyses of Location to SVO and WPSB via INS

\begin{tabular}{rccc}
\hline DVependent Variable & $95 \%$ CI (Bootstrapping) & Sobel $Z$ & Sobel $p$ \\
\hline WPSB & $.07,1.68$ & 1.60 & .11 \\
\hline
\end{tabular}

Note. INS = Inclusion of Nature in Self; $\mathrm{SVO}=$ Social Value Orientation; WPSB = Willingness to Perform Sustainable Behaviours.

prosociality. Relatedly, statistical mediation analyses suggested that state nature relatedness may partially mediate the effect of nature exposure on prosociality. This is consistent with previous 
findings from Weinstein et al. (2009). Overall, the link between nature and prosociality has been strengthened and extended beyond the pleasant aspects of the natural world to the more unpleasant and threatening facets of nature as well.

In terms of environmental attitudes and behaviours, hypotheses were somewhat supported. Participants in the nature conditions were more willing to engage in sustainable behaviours compared to those in the built conditions. But this main effect was qualified by an interaction with valence - with participants who viewed the pleasant built video being especially low on willingness and participants who viewed the unpleasant built video being similar in willingness to those in the nature conditions. This may have been due to Las Vegas priming attitudes about materialism, consumption, waste, or some other confounding variable. It may have also been due to participants perceiving the abandoned house as decaying and being overtaken by nature or returning to a more natural state. Nevertheless, state and trait nature relatedness were both significantly associated with willingness. Moreover, statistical mediation analyses suggested that state nature relatedness may partially mediate the effect of nature exposure on willingness to behave sustainably as well.

\section{Study 2}

\section{Rationale}

As Study 1 suggests, nature exposure itself, and not its valence, is impacting prosociality. Because the valence of built and nature stimuli was not having any discernible effect on prosociality, pleasantness was not experimentally manipulated in a 2 x 2 design in the subsequent study. Rather, Study 2 proceeded in a related but new direction from Study 1. Namely, it attempted to conceptually replicate and further test the generalizability and limitations of nature exposure's impact by employing different experimental manipulations and novel 
operationalizations of prosociality and sustainability.

Studies that have investigated the benefits of exposure to nature on social interactions have mainly utilized resource allocation paradigms (e.g., commons dilemmas and social value orientation) as measures of prosocial behaviour (Dopko, 2012; Weinstein et al., 2009). For example, Dopko (2012) used a simulated fishing commons dilemma game and operationalized cooperation as fishing in a sustainable manner. Weinstein et al. (2009) employed a funds distribution task in some of their studies where participants were given $\$ 5$ and presented them with the choice to either (a) keep the money for themselves and leave with $\$ 5$ or (b) give the money to another anonymous participant, where it would be doubled, and the other person could decide whether to keep the $\$ 10$ all for themselves or give $\$ 5$ back to them. Study 1 of this thesis also operationalized prosociality by employing a resource allocation task (i.e., the SVO Slider Measure). Thus, the examination of nature's impact on prosocial behaviour has been somewhat restricted. Furthermore, these resource allocation paradigms may be attenuating the effect of nature exposure as there is evidence that being primed with reminders of money promotes selfsufficiency and leads to reduced helping behaviour (Vohs, Mead, \& Goode, 2006).

Study 2 attempted to extend previous findings beyond resource allocation as the dependent variable to a more general form of prosociality by employing a behavioural measure of helping behaviour. In addition, nature exposure's impact on sustainability was expanded beyond self-report ratings of willingness in Study 1 to a behavioural measure of interest in Study 2. More specifically, participants were informed that the study was concerned with people's ability to immerse themselves in photographs. Although this was used mainly as a cover story, immersion was expected to be a moderating variable. Weinstein et al. (2009) found that individuals who were more immersed in the nature stimuli had more prosocial and other-focused 
orientations, while individuals who were more immersed in the built stimuli had more individualistic and self-focused orientations. In terms of the experimental manipulation, participants were randomly assigned to view photographs of nature or built environments. After completing questionnaires assessing their mood, how immersed they were in the photographs, and their perception of the video, participants were informed that the study was over but were asked if they would volunteer to complete some additional questionnaires to help another graduate student. Whether participants agreed to help and the number of questionnaires participants volunteered to complete was how prosociality was operationalized in Study 2. This operationalization was different from previous research in this area as the prosocial behaviour of interest involves sacrificing one's time and effort to aid someone in need and was not in the context of an economic exchange or commons dilemma. Similar operationalizations of prosocial behaviour have been used successfully in psychological research outside of this topic area (e.g., Twenge, Baumeister, DeWall, Ciarocco, \& Bartels, 2007). A behavioural measure of interest for sustainability was employed by discreetly recording how much time participants spent reading a variety of tips on ways they could be more environmentally friendly in their daily lives. By measuring sustainable interest behaviourally, it removed the problem of participants responding in a socially desirable manner to items asking about their prospective likelihood and motivation for engaging in sustainable behaviours.

\section{Hypotheses}

Hypothesis 1: Participants who viewed the nature photographs would be more likely to engage in prosocial behavior by agreeing to fill out additional questionnaires compared to participants who viewed the built photographs.

Hypothesis 2: Participants in the nature condition would volunteer to complete more additional 
questionnaires on average compared to participants in the built condition.

Hypothesis 3: Participants who viewed the nature photographs would spend more time on average reading about the ways in which they could be more sustainable compared to participants who viewed the built photographs.

Hypotheses 4: Immersion and condition would interact in predicting prosociality. Individuals in the nature condition who were more immersed in the photographs were predicted to be more likely to agree to help and would volunteer to complete more additional questionnaires compared to those in the nature condition who were not as immersed. In contrast, individuals in the built condition who were more immersed in the photographs were predicted to be less likely to agree to help and would volunteer to complete fewer additional questionnaires compared to those in the built condition who were not as immersed.

Hypothesis 5: Immersion and condition would interact in predicting interest in sustainability. Individuals in the nature condition who were more immersed in the photographs were predicted to spend more time reading the eco-tips compared to those in the nature condition who were less immersed. In contrast, individuals in the built condition who were more immersed in the photographs were expected to spend less time reading the eco-tips compared to those in the built condition who were not as immersed.

Hypothesis 6: Trait nature relatedness would be positively associated with the number of additional questionnaires participants volunteered to complete. Hypothesis 7: Trait nature relatedness would be positively associated with the amount of time participants spent reading about the ways in which they could be more sustainable. 


\section{Method}

\section{Participants}

Two hundred eight undergraduate students from Carleton University consented to participate in an online study titled "Immersion in Photographs" for partial course credit in their first or second year psychology or neuroscience class. Participants were excluded if they only partially completed the study, watched less than half of the video, or did not consent to the use of their data after being debriefed. Of those remaining, an additional seven participants (five from the nature condition and two from the built condition) were excluded for indicating doubt about either of the cover stories when asked what they thought the study was about (e.g., explicitly linking the content of the video to willingness to help or the eco-tips) ${ }^{7}$. These exclusion criteria left a remaining sample size of 146 participants. In terms of demographics, the vast majority of participants were female $(n=125)$ and the average age of the sample was $20.24(S D=4.62)$.

\section{Materials}

Nature relatedness. This variable was measured using the 6-item short-form version of the Nature Relatedness Scale (Nisbet \& Zelenski, 2013; Appendix G). Similar to the 21-item version used in Study 1, participants rated statements about their connectedness to nature on a 5point Likert scale ranging from 1 (disagree strongly) to 5 (agree strongly). Items in this scale were internally consistent at a Cronbach's alpha of 0.88 .

Photographs. Photographs were found by searching for nature and architecture-related pictures on Google Image that were labeled for reuse with modification. Thirty photographs were identified for both the nature and built conditions and slideshow videos were created for each. Because each of the photographs was presented for 10 seconds, both of the videos were five minutes in length. The nature and the built slideshow videos can be viewed at

\footnotetext{
${ }^{7}$ The pattern of results remained practically the same when analyses were run with these participants included.
} 
http://vimeo.com/73052195 and http://vimeo.com/73052194, respectively. The amount of time participants spent viewing the videos was measured discreetly to ensure that they were being exposed to the nature and built stimuli for the desired amount of time. In order to assess and minimize differences between the two video slideshows, pilot studies asked participants to rate the videos using an 18 -item video impressions questionnaire that I created for this research (Appendix H). A 5-point Likert scale ranging from 1 (not at all) to 5 (extremely) was used to rate the videos on adjectives like "pleasant", "interesting", and "vibrant". Throughout the pilot studies, certain photographs were included or excluded in an attempt to make the video slideshows as similar to each other as possible. As some differences remained despite multiple rounds of pilot studies, a 17-item version of the questionnaire was used in Study 2 in order to statistically control for any significant differences between the videos. As the following scale measured the construct more in-depth, the "immersive" item was excluded from the video impressions questionnaire in Study 2.

Immersion. This variable was measured using an 8-item modified version of the Player Experience of Need Satisfaction Physical Presence Scale (Ryan, Rigby, \& Przybylski, 2006; Appendix I). Although the original version was developed to assess immersion in interactive environments (i.e., video games), researchers have modified the items in order to measure immersion in non-interactive environments (i.e., photographs; Weinstein et al., 2009). I had to modify the items from the original version myself as attempts to locate the adapted scale used in Weinstein et al. (2009) were unsuccessful. A 5-point Likert scale ranging from 1 (not at all) to 5 (very much) was used to assess statements like "All my senses were engaged", "I felt transported to another place", and "I reacted to the environments as if they were real". After reverse scoring one of the items, overall scores on immersion were calculated by taking the average of all the 
items. Higher scores indicated greater immersion. Items in this scale were internally consistent at a Cronbach's alpha of 0.90 .

Mood. In order to further examine any differential effects the videos might have had on mood, a 23-item modified PANAS was included (Appendix J). Beyond the original 20 items used in Study 1 to assess positive affect and negative affect, three additional items were included that tap the "soft fascination" commonly associated with nature in the research literature (i.e., "curious", "in awe", and "fascinated"; Kaplan \& Berman, 2010). The positive affect $(\alpha=.92)$, negative affect $(\alpha=.84)$, and fascination $(\alpha=.81)$ subscales all exhibited high internal reliability.

Prosociality. A behavioural measure of prosociality was used in Study 2 (Appendix K). Participants were told that the study they signed up for was complete and they were asked if they would be willing to help another graduate student by completing additional questionnaires. They were repeatedly asked after completing each additional questionnaire if they would be willing to complete another, with the possibility of completing up to a total of five additional questionnaires. The five additional questionnaires, which were presented to participants in a randomized order, were the Curiosity and Exploration Inventory (CEI-II; Kashdan et al., 2009; Appendix L), Emotion Regulation Questionnaire (ERQ; Gross \& John, 2003; Appendix M), the Short Test Of Music Preferences (STOMP; Rentfrow \& Gosling, 2003; Appendix N), the TenItem Personality Inventory (TIPI; Gosling, Rentfrow, \& Swan, 2003; Appendix O), and the Time of Day Scale (Richmond \& McCroskey, 1995; Appendix P). These particular questionnaires were included because they were similar in length, relatively brief, and were not expected to have an impact on helping behaviour. Whether the participant decided to help out at all was a categorical measure of prosocial behaviour and the number of additional questionnaires they 
volunteered to complete, ranging from 0 to $6^{8}$, was a continuous measure of prosocial behaviour. Those who indicated that they did not want to help, that they did not want to complete any more additional questionnaires, or who completed all five questionnaires were immediately directed to the measure below.

Sustainability. Interest in engaging in sustainable behaviours was measured by the amount of time participants spent viewing a variety of eco-tips on ways they could protect and preserve the earth, energy, air, and water (Environment Canada, 2013; Appendix Q). Participants were informed that the eco-tips were being included in the study in order to support the university's efforts toward a more sustainable and green campus and to raise awareness among students.

\section{Procedure}

Similar to Study 1, participants were recruited online through the Department of Psychology's experiment management system. Participation was originally restricted to those who had previously completed mass testing because it included the short-form version of the Nature Relatedness Scale. But in order to reach the desired number of participants in the limited amount of time, this requirement was removed in the middle of data collection. Nevertheless, overall nature relatedness scores were obtained from over half of the participants as $57.53 \%$ of the sample $(n=84)$ had completed mass-testing. Throughout the entire data collection period, individuals who participated in the pilot studies were not eligible to participate in Study 2 as they had already been exposed to the stimuli and were debriefed about the purpose of this line of research. Participants who signed up to participate were automatically provided a link to the

\footnotetext{
${ }^{8}$ Although there were only five questionnaires, participants were asked whether they would be willing to complete another questionnaire after the fifth and final questionnaire. This was necessary in order to ensure that the questionnaires were presented in a randomized order. Thus, participants were able to volunteer to complete 0 to 6 additional questionnaires.
} 
online study that was being hosted on Qualtrics. Individuals were informed that the research was interested in examining individual differences in people's ability to immerse and imagine themselves in photographic locations. After reading the consent form and indicating their consent to participate, participants were randomly assigned to watch the video slideshow of the nature photographs or the built photographs. They were asked to immerse themselves in the photographs as much as possible. After watching the five minute videos, participants completed the immersion questionnaire, followed by the video impressions questionnaire and the PANAS. Participants were then asked if they would be willing to help another graduate student by completing additional questionnaires. If they indicated that they would like to help, they were asked to fill out one of the five additional questionnaires and were asked after each if they would be willing to complete another. Once they indicated that they would not be willing or once they had completed all five questionnaires, they were presented with the eco-tips. Before being debriefed and informed of the true purpose of the study, participants answered a couple questions about their demographic characteristics (i.e., gender and age) and were asked to briefly describe what they thought the study was about. Because deception was involved, participants were given the option of withdrawing their data. After all this, participants were given 0.25 course credit for participating. The median amount of time taken to complete the study was just under 15 minutes.

\section{Results}

In order to assess whether the nature and built videos differed on any important characteristics, independent samples t-tests were conducted that compared the ratings of items on the video impressions questionnaire for participants in the nature and built conditions. As one can see in Table 4, the nature video was rated as more pleasant, relaxing, vibrant, colourful, repetitive, familiar, and attractive than the built video. When possible, the results associated with 
Table 4

Means (Standard Deviations) and Effect Sizes by Condition for Video Impression Ratings in Study 2

\begin{tabular}{|c|c|c|c|c|}
\hline & \multicolumn{2}{|c|}{ Condition } & \multirow[b]{2}{*}{$t$} & \multirow[b]{2}{*}{$d$} \\
\hline & Built & Nature & & \\
\hline Pleasant & $3.36(0.97)$ & $3.94(1.05)$ & $-3.47 * * *$ & -0.57 \\
\hline Interesting & $3.51(0.91)$ & $3.33(1.16)$ & 1.04 & 0.17 \\
\hline Impressive & $3.64(0.99)$ & $3.49(1.08)$ & 0.87 & 0.15 \\
\hline Thought Provoking & $3.04(1.05)$ & $2.96(1.23)$ & 0.44 & 0.07 \\
\hline Inspiring & $3.09(1.15)$ & $3.23(1.19)$ & -0.67 & -0.12 \\
\hline Exciting & $2.80(1.07)$ & $2.64(1.19)$ & 0.85 & 0.14 \\
\hline Relaxing & $3.03(0.99)$ & $4.07(0.93)$ & $-6.52 * * *$ & -1.08 \\
\hline Vibrant & $3.03(1.01)$ & $3.50(1.16)$ & $-2.63 * *$ & -0.43 \\
\hline Colourful & $3.18(0.98)$ & $3.58(0.95)$ & $-2.54^{*}$ & -0.41 \\
\hline Repetitive & $2.62(0.98)$ & $3.18(1.16)$ & $-3.16^{* *}$ & -0.52 \\
\hline Familiar & $2.99(0.85)$ & $3.51(1.06)$ & $-3.31 * *$ & -0.54 \\
\hline Attractive & $3.57(0.98)$ & $3.99(0.99)$ & $-2.55^{*}$ & -0.43 \\
\hline Distressing & $1.24(0.57)$ & $1.45(0.89)$ & -1.68 & -0.28 \\
\hline Upsetting & $1.12(0.37)$ & $1.06(0.29)$ & 1.19 & 0.18 \\
\hline Boring & $2.28(1.08)$ & $2.24(1.11)$ & 0.26 & 0.04 \\
\hline Irritating & $1.31(0.68)$ & $1.24(0.57)$ & 0.72 & 0.11 \\
\hline Quality & $2.88(1.01)$ & $3.07(1.03)$ & -1.14 & -0.19 \\
\hline
\end{tabular}


each of the hypotheses were presented without and with these non-equivalencies statistically controlled for.

In order to determine whether the nature and built videos elicited different affective responses in participants, independent samples t-tests were conducted with condition as the independent variable and positive affect, negative affect, and fascination as the dependent variables. No significant differences were found between conditions on positive affect, $t(141)=-0.92, p=.36, d=-0.15$, negative affect, $t(139)=0.39, p=.70, d=0.07$, or fascination, $t(143)=-0.43, p=.67, d=-0.07$, following exposure. As Study 2 was not attempting to manipulate mood in any way (unlike Study 1), these null results were expected and desired.

The last manipulation check concerned whether participants differed in how immersed they were in the nature and built photographs. An independent samples t-test with condition as the independent variable and overall immersion score as the dependent variable was conducted. A significant difference was found, $t(139)=-2.72, p=.01, d=-0.46$, as participants who viewed the nature photographs were more immersed $(M=3.12, S D=0.95)$ than those who viewed the photographs of built environments $(M=2.71, S D=0.82)$. Because of this, results associated with each of the hypotheses were presented without and with immersion statistically controlled for (along with the other non-equivalencies discussed above).

Participants who viewed the nature photographs were predicted to be more willing to volunteer to fill out additional questionnaires compared to those who viewed the built photographs. In order to test this hypothesis, a chi-square test of homogeneity was conducted with condition and decision to volunteer (no vs. yes) as the categorical variables. Willingness to volunteer was found to significantly differ between the conditions, $\chi^{2}(1, N=146)=5.37, p=.02$. Contrary to expectations, $66.22 \%$ of participants in the built condition agreed to fill out 
additional questionnaires, while only $47.22 \%$ agreed in the nature condition. Even when the nonequivalencies between videos were controlled for using hierarchical logistic regression, condition was a significant predictor, $B=-0.22, S E=0.10, \beta=-0.22, t(128)=-2.16, p=.03$, and people in the nature condition were still less likely to agree to help compared to those in the built condition. Thus, this hypothesis was not supported.

It was hypothesized that participants in the nature condition would volunteer to complete more additional questionnaires on average compared to participants in the built condition. As this variable was not normally distributed (i.e., its distribution was binomial with high frequencies of people volunteering to complete either zero or six additional questionnaires), parametric and non-parametric statistics were both used in order to test this hypothesis. An independent samples t-test with condition as the independent variable and number of questionnaires volunteered for as the dependent variable was conducted and a marginally significant difference was found, $t(144)=1.75, p=.08, d=0.29$. Contrary to expectations, participants who were exposed to the built environments volunteered for more questionnaires $(M=2.62, S D=2.60)$ than those exposed to nature $(M=1.89, S D=2.46)$. When the non-equivalencies between the videos were controlled for using hierarchical multiple linear regression, condition was a marginally significant predictor, $B=-1.05, S E=0.53, \beta=-0.21, t(128)=-1.96, p=.05$, and participants in the nature condition still volunteered to complete fewer additional questionnaires than those in the built condition. A non-parametric Mann-Whitney test also found that participants in the nature condition volunteered to complete fewer additional questionnaires $(M d n=0)$ compared to those in the built condition $(M d n=1.5), U=2177, Z=-2.01, p=.04$. Interestingly though, this significant difference disappeared when I restricted analyses to only include those who had originally agreed to help fill out additional questionnaires. With this restriction, an independent 
samples t-test found that participants who viewed the photographs of the built environments $(M=3.96, S D=2.21)$ volunteered for a similar number of questionnaires as those who viewed the photographs of nature $(M=4.00, S D=2.07), t(81)=-0.09, p=.93, d=-0.02$. In addition, condition was no longer a significant predictor when non-equivalencies were controlled for using hierarchical multiple linear regression, $B=0.03, S E=0.62, \beta=0.01, t(67)=0.05, p=.96$. A non-parametric Mann-Whitney test also found no significant difference when this restriction was applied, $U=814, Z=-0.19, p=.85$. It appears that although participants in the built condition were more likely to agree to fill out questionnaires initially, persistence in this prosocial task (i.e., continuing to volunteer to complete additional questionnaires) by those who decided to help was not influenced by condition. Overall, this hypothesis was not supported and results remained consistent regardless of whether parametric or non-parametric statistics were used or the nonequivalencies between the videos were accounted for.

Participants in the nature condition were predicted to spend more time reading the ecotips compared to those in the built condition. As this dependent variable exhibited considerable positive skew and extreme scores, parametric statistics excluding five outliers ${ }^{9}$ and nonparametric statistics with no exclusions were used to test this hypothesis. When the five outliers were excluded, an independent samples t-test with condition as the independent variable and seconds spent on the eco-tips page as the dependent variable found a marginally significant difference, $t(139)=1.70, p=.09, d=0.29$. Contrary to expectations, participants who viewed the photographs of built environments spent more time on the eco-tips page $(M=20.74$,

\footnotetext{
${ }^{9}$ Outliers were identified as scores that were \pm 3 standard deviations from the mean. It should be noted that four out of the five outliers came from the nature condition and ranged from 3.05 to 4.10 minutes. When an independent samples t-test was conducted with no outliers excluded, participants in the nature condition spent more time on the eco-tips page $(M=26.12, S D=51.59)$ than those in the built condition $(M=22.59, S D=28.53)$, but it was not statistically significant, $t(144)=-0.51, p=.61, d=-0.09$. When non-equivalencies between videos were statistically controlled for using hierarchical multiple linear regression, the direction of the effect remained but condition became a marginally significant predictor, $B=14.77, S E=8.86, \beta=0.18, t(128)=1.67, p=.098$.
} 
$S D=23.85)$ than those who viewed the photographs of nature $(M=14.58, S D=18.67)$. But when the non-equivalencies between the videos were controlled for using hierarchical multiple linear regression, condition was not a significant predictor of time spent on the eco-tips page, $B=-4.58, S E=4.74, \beta=-0.10, t(123)=-0.97, p=.34 .^{10}$ In contrast, a non-parametric MannWhitney test found that participants in the built condition spent marginally more time on the ecotips page $(M d n=12.76)$ compared to those in the nature condition $(M d n=8.84), U=2239$, $Z=-1.66, p=.096$. Unlike the second hypothesis, results for the third hypothesis appeared to vary considerably depending on how the data was analyzed.

Immersion and condition were expected to interact in predicting prosociality. It was hypothesized that being more immersed in the nature photographs would lead people to be more likely to agree to help and volunteer for more additional questionnaires, while the opposite was expected in the built condition. First, logistic regression was conducted with condition, immersion, and their interaction as predictors of agreeing to help initially. Condition, $B=-0.24$, $S E=0.08, \beta=-0.24, t(137)=-2.87, p=.01$, and immersion, $B=0.15, S E=0.07, \beta=0.27$, $t(137)=2.11, p=.04$, were both significant predictors, but their interaction was not, $B=-0.14$, $S E=0.09, \beta=-0.19, t(137)=-1.45, p=.15$. When the non-equivalencies between the videos were statistically controlled for, condition, $B=-0.22, S E=0.10, \beta=-0.22, t(127)=-2.19$, $p=.03$, and immersion, $B=0.16, S E=0.08, \beta=0.29, t(127)=1.96, p=.05$, were significant and marginally significant predictors of willingness to help, respectively, and their interaction was still not a significant predictor, $B=-0.12, S E=0.10, \beta=-0.15, t(127)=-1.13, p=.26$. To assess the continuous measure of prosociality, multiple linear regression was conducted with

\footnotetext{
${ }^{10}$ This result was also found when time spent on the eco-tips page was log transformed to make its distribution more normal. The independent samples t-test did not show a significant difference between conditions, $t(144)=1.03$, $p=.31, d=0.17$. Similarly, when the non-equivalencies between the videos were statistically controlled for, condition was not significant a predictor, $B=0.07, S E=0.21, \beta=0.33, t(128)=0.32, p=.75$.
} 
condition, immersion, and their interaction as predictors and number of additional questionnaires volunteered for as the criterion variable. Similar to previous analyses, condition, $B=-1.07$, $S E=0.43, \beta=-0.21, t(137)=-2.51, p=.01$, and immersion, $B=0.95, S E=0.36, \beta=0.34$, $t(137)=2.62, p=.01$, were significant predictors of the number of questionnaires volunteered for, while their interaction was not, $B=-0.78, S E=0.48, \beta=-0.21, t(137)=-1.63, p=.11^{11}$ When the non-equivalencies between the videos were statistically controlled for, the same pattern emerged with condition, $B=-1.07, S E=0.53, \beta=-0.21, t(127)=-2.02, p=.045$, and immersion, $B=1.03, S E=0.43, \beta=0.36, t(127)=2.39, p=.02$, significantly predicting number of questionnaires volunteered for, while their interaction did not, $B=-0.88, S E=0.53$, $\beta=-0.22, t(127)=-1.66, p=.10$. When analyses were restricted to only those who agreed to help initially, condition, $B=-0.34, S E=0.71, \beta=-0.08, t(76)=-0.47, p=.64$, immersion, $B=0.46, S E=0.36, \beta=0.20, t(76)=1.28, p=.20$, and their interaction, $B=-0.20, S E=0.54$, $\beta=-0.07, t(76)=-0.37, p=.71$, did not significantly predict the number of questionnaires volunteered for. In sum, this hypothesis was not supported.

Immersion and condition were also expected to predict time spent reading the eco-tips. It was hypothesized that being more immersed in the nature photographs would lead people to spend more time reading the eco-tips, while the opposite was expected in the built condition. In order to test this hypothesis, multiple linear regression analyses were conducted excluding the aforementioned outliers and using the log transformed variable with no exclusions, respectively. When the five outliers were excluded, condition was a marginally significant predictor, $B=-11.88, S E=6.01, \beta=-0.27, t(132)=-1.98, p=.05$, but immersion, $B=3.10, S E=3.22$,

\footnotetext{
${ }^{11}$ As the interaction was on the verge of marginal significance, I analyzed the simple slopes and found that immersion was not significantly associated with the number of additional questionnaires volunteered for in the nature condition, $B=0.17, S E=0.31, t(137)=0.55, p=.58$, but was significantly associated with the number of questionnaires volunteered for in the built condition, $B=0.95, S E=0.36, t(137)=2.61, p=.01$. The more immersed individuals were in the built condition, the more additional questionnaires they tended to volunteer for.
} 
$\beta=0.13, t(132)=0.97, p=.34$, and their interaction were not, $B=-4.25, S E=4.26, \beta=-0.15$, $t(132)=-1.00, p=.32$. When the non-equivalencies between the videos were statistically controlled for, condition, $B=-10.42, S E=6.88, \beta=-0.07, t(123)=-1.51, p=.13$, immersion, $B=1.10, S E=3.78, \beta=0.05, t(123)=0.29, p=.77$, and their interaction, $B=-5.50, S E=4.70$, $\beta=-0.19, t(123)=-1.17, p=.24$, were all not significant predictors of time spent on the eco-tips page. ${ }^{12}$ When log transformed time spent on the eco-tips page was the criterion variable, condition, $B=-0.23, S E=0.18, \beta=-0.11, t(137)=-1.29, p=.20$, immersion, $B=0.20$, $S E=0.15, \beta=0.18, t(137)=1.34, p=.18$, and their interaction, $B=-0.25, S E=0.20, \beta=-0.17$, $t(137)=-1.28, p=.20$, were not significant predictors. This same pattern remained when the non-equivalencies were statistically controlled for as condition, $B=0.06, S E=0.21, \beta=0.03$, $t(127)=0.28, p=.77$, immersion, $B=0.18, S E=0.17, \beta=0.15, t(127)=1.02, p=.31$, and their interaction, $B=-0.27, S E=0.21, \beta=-0.18, t(127)=-1.28, p=.20$, still did not significantly predict log transformed time spent on the eco-tips page. ${ }^{13}$ In sum, this hypothesis was not supported.

The final hypotheses were that trait nature relatedness would be positively associated with measures of prosociality and sustainability. As one can see from Table 5, trait nature relatedness was not significantly associated with initially agreeing to volunteer, $r(82)=-.03$, $p=.82$, or the number of questionnaires volunteered for, $r(82)=-.04, p=.75$. Thus, this

\footnotetext{
${ }^{12}$ The interaction between condition and immersion remained a nonsignificant predictor of non-transformed time spent on the eco-tips page when the outliers were included in the analyses as well, $B=-9.49, S E=8.17, \beta=-0.15$, $t(137)=-1.16, p=.25$. The same was true when the non-equivalencies between videos were controlled for, $B=-11.78, S E=8.84, \beta=-0.18, t(127)=-1.33, p=.19$.

${ }^{13}$ To further illustrate that this hypothesis was not supported, correlation coefficients were obtained to assess the relationship between time spent on the eco-tips page and immersion scores in the built and nature conditions. The pattern was fairly similar to the simple slope analyses in the previous hypothesis. In the built condition there was a positive but nonsignificant association between immersion and time spent on the eco-tips page for the transformed, $r(68)=.17, p=.16$, and non-transformed data $r(68)=.14, p=.25$. In contrast, in the nature condition the relationship was in the opposite direction and closer to zero for the transformed, $r(69)=-.05, p=.70$, and nontransformed data $r(69)=-.08, p=.50$.
} 
Table 5

Study 2 Correlation Coefficients

\begin{tabular}{|c|c|c|c|c|c|c|c|}
\hline Measure & 1 & 2 & 3 & 4 & 5 & 6 & 7 \\
\hline 1. NR & - & - & - & - & - & - & - \\
\hline 2. PA & .15 & - & - & - & - & - & - \\
\hline 3. NA & -.11 & .01 & - & - & - & - & - \\
\hline 4. FA & $.27 *$ & $.73 * * *$ & -.09 & - & - & - & - \\
\hline 5. IH & -.03 & $.17^{*}$ & $.14^{\dagger}$ & $.16^{\dagger}$ & - & - & - \\
\hline 6. NQV & -.04 & $.18 *$ & $.17^{*}$ & $.19 *$ & $.78 * * *$ & - & - \\
\hline 7. TRET & $.22 *$ & -.09 & -.08 & -.10 & $.14^{\dagger}$ & $.25 * *$ & - \\
\hline $\begin{array}{l}\text { 8. TRET } \\
\text { (log) }\end{array}$ & .14 & -.06 & -.09 & -.03 & $.22 * *$ & $.32 * * *$ & $.83 * * *$ \\
\hline
\end{tabular}

Note. $\mathrm{NR}=$ Nature Relatedness; $\mathrm{PA}=$ Positive Affect; NA = Negative Affect; FA = Fascination; $\mathrm{IH}=$ Initial Help; NQV = Number of Questionnaires Volunteered; TRET = Time Reading EcoTips.

${ }^{\dagger} p<.10, * p<.05, * * p<.01, * * * p<.001$.

hypothesis was not supported. There was partial support for the last hypothesis as nature relatedness was positively and significantly correlated with time spent on the eco-tips page, $r(82)=.22, p=.045$, but not when the latter variable was $\log$ transformed, $r(82)=.14, p=.20$. Mood appeared to have a significant impact on people's helping behaviour. Positive affect, $r(141)=.17, p=.047$, negative affect, $r(139)=.14, p=.09$, and fascination, $r(143)=.16$, $p=.06$, were all positively correlated with initially agreeing to volunteer to complete additional questionnaires. In addition, positive affect, $r(141)=.18, p=.04$, negative affect, $r(139)=.17$, $p=.04$, and fascination, $r(143)=.19, p=.02$, were also all positively associated with the number 
of questionnaires volunteered for. In contrast, no significant associations were found between mood and time spent reading the eco-tips. Interestingly, prosociality and sustainability were consistently positively correlated, indicating that those who volunteered to complete additional questionnaires also tended to spend more time reading the eco-tips.

\section{Discussion}

Study 2 produced considerably different results compared to Study 1 and previous research. Instead of nature exposure causing people to be more prosocial, individuals in the nature condition were less likely to agree to help when propositioned and were no different from those in the built condition in their persistence in a helping task. The effect of nature exposure on interest in sustainability was inconclusive as results differed substantially depending on how the data was analyzed. Study 2 did not replicate the immersion by condition interaction on prosociality found in Weinstein et al. (2009) and this interaction was also not extended to a measure of interest in sustainability. Lastly, individuals higher in nature relatedness were no different in whether and the degree to which they helped compared to those less connected to nature, but there was some evidence that they were more interested in reading about sustainability. There are numerous plausible explanations for why these anomalous results were observed in Study 2.

\section{Ego Depletion}

First, a unique aspect of the procedure in Study 2 compared to previous studies may have lead to a difference in ego depletion prior to being exposed to nature and built environments. Specifically, participants were immediately exposed to natural or built stimuli after giving their informed consent in Study 2, while all the previous studies on this topic have had participants spend time and effort filling out questionnaires before exposure. For instance, in Study 1 
individuals completed a 121-item questionnaire which assessed their personality before being randomly assigned to watch one of the nature or built videos. Similarly, Dopko (2012) and all of the studies in Weinstein et al. (2009) consistently had participants fill out multiple questionnaires prior to being exposed to nature or built stimuli. Presumably, some amount of self-regulatory energy is required to stay focused while reading each item, repeatedly choosing an appropriate response, suppressing impulses, etc. In fact, there is evidence that shows that having to repetitively make decisions reduces self-control and leads to decision fatigue (Vohs et al., 2008). Thus, it is possible that previous studies may have inadvertently placed participants in a more ego depleted state prior to being exposed to nature and built stimuli in comparison to Study 2 . As there is evidence to indicate that nature has a restorative effect on cognitive abilities following fatigue (Berman et al., 2008; Hartig et al., 1991) and willingness to help others depends on having a sufficient amount of self-regulatory resources available (DeWall et al., 2008; Xu et al., 2012), nature's influence on prosociality may solely or more prominently occur when self-control is low. In other words, increased self-regulatory energy may mediate the relationship between nature exposure and other-oriented values and behaviours, but only when a state of ego depletion is present. When individuals are not in an ego depleted state and already have enough self-regulatory resources available to suppress selfish impulses and act in accordance to socially ascribed standards, there may be no deficit for nature to restore and its beneficial impact on prosociality may disappear or be minimized. Of course, more research is needed to test this idea. As an example, researchers could have some participants engage in a mentally fatiguing task before being randomly exposed to a natural or built environment and then measure prosociality to see if this restorative effect of nature is supported. 


\section{Inequality Aversion}

Another distinctive feature of Study 2's methodology that may account for its lack of expected findings was how prosociality was operationalized. One of the purposes of Study 2 was to test the generalizability of nature's effect on prosocial behaviour. Previous studies that have examined this research question have primarily tested prosocial behaviour using resource allocation tasks. For instance, prosocial behaviour was assessed in Study 1 using the SVO Slider Measure (Murphy et al., 2011) which asked individuals to distribute hypothetical amounts of money to themselves and another hypothetical person. Similarly, the behavioural measure of prosociality used in Weinstein et al. (2009) involved having individuals decide whether or not to distribute money to another participant. Dopko (2012) used a simulated fishing commons dilemma, observed how people chose to harvest resources for money, and conceptualized it as a measure of cooperation. In contrast, Study 2 employed a qualitatively different measure of prosocial behaviour as it did not involve making any strategic economic decisions about how material resources should be allocated and shared, but rather how willing individuals would be to expend their time and effort helping a stranger.

The results of study 2 suggest that nature exposure's beneficial impact on interpersonal functioning may not extend to all aspects of prosociality. A more nuanced perspective based on this set of findings might be that nature exposure leads to more prosocial actions because it promotes an aversion to inequality. Returning to the biophilia hypothesis and examining the predominant social structures that were present during our evolutionary history helps shape the theoretical foundation for this proposition. Up until the Neolithic Revolution which brought the advent of agriculture around 12,000 years ago, humans had primarily lived in small nomadic bands as hunter-gatherers (Bellwood, 2004; Diamond, 1999). Based on observations by 
anthropologists of modern hunter-gathers, these societies are and most likely were exceptionally egalitarian in their beliefs, values, and social structures (Gray, 2013; Ingold, 1999; Wiessner, 1996). As examples of this egalitarianism, hunter-gatherer societies lack formal leadership, economic specialization, and social stratification (Diamond, 1999). They make decisions through group consensus, cooperate on a daily basis to obtain food which is then shared communally, and exhibit high levels of allomaternal care of children (Gurven, 2004; Hill, 2002; Ivey, Morelli, \& Tronick, 2005). Furthermore, it has been observed that individuals within hunter-gatherer societies are astutely sensitive to instances where the behaviour of others violates egalitarian principles (e.g., bragging) and in order to discourage such behaviour the band actively ridicules, shuns, and even expels the offending member following repeated transgressions (Boehm, 1993; Lee, 1988). The natural environment would have been the situational background in which this egalitarian ethos would have developed and occurred in. Just as modern humans exhibit an increased likelihood of developing particular phobias (e.g., snakes; Öhman, 2009), we may be more biologically prepared to respond to and associate specific stimuli in our environment based on the evolutionary history of our species (Seligman, 1970). Given the correspondence between the dominant norms and structure of hunter-gatherer societies and the natural environments in which they would have lived in, exposure to nature may readily trigger egalitarian values and, in particular, an aversion to inequality in our modern minds.

Future research is necessary to test this expanded version of the biophilia hypothesis. For instance, researchers could expose individuals to natural environments to see whether they become more bothered by societal income inequality and more supportive of interventions to minimize it. Relatedly, this expanded hypothesis would predict that after being exposed to nature individuals would be more punitive toward others who exhibit narcissistic and selfish attitudes 
and behaviours. Conducting a study with the 15-item expanded version of the SVO Slider Measure would be one other way to test these predictions as the additional items can distinguish aversion to inequality from other prosocial motivations (Murphy et al., 2011). Subsequent studies using novel measures of prosociality would also help define the generalizability of nature's impact on interpersonal functioning.

\section{Other Explanations}

There are other features of Study 2 which may explain its unexpected results. In particular, there may have been something about the content of the videos used as the experimental manipulations which account for these unanticipated findings. Although some of the characteristics of the slideshows were assessed and controlled for using the video impressions questionnaire, the videos could have also differed on other attributes (e.g., see Reber, Schwarz, \& Winkielman, 2004) which might have systematically influenced participants' impressions of the photographs and their subsequent behaviour. Relatedly, the videos may have been similar on important characteristics that typically vary in natural and built environments and normally account for their differential effect on helping and sustainable behaviour. One feature of the urban video's content that could have impacted results was the inclusion of photographs of government buildings (e.g., the Canadian Parliament). Although these were initially included in order to increase the low familiarity ratings of the urban compared to the nature photographs in the pilot studies, they could have primed participants to act more prosocially. Past research has found that subtlety priming individuals with secular concepts related to morality, justice, and a social contract (e.g., court) promotes prosocial behaviour in a similar manner as religious primes (Shariff \& Norenzayan, 2007). Thus, exposure to photographs of government buildings may have unduly increased other-oriented behaviours in the urban 
condition compared to previous experimental manipulations without this secular prime.

The cover story concocted to measure prosociality in Study 2 could have interacted unexpectedly with the experimental manipulation to produce a result that was in the opposite direction of what was hypothesized. In particular, the photographs of urban locales may have made the positive outcomes of modernization more salient and primed participants to value scientific progress and technological innovation more, causing those in the built condition to be more willing to complete additional questionnaires in the name of research. ${ }^{14}$ In other words, willingness to complete additional questionnaires as a measure of prosocial behaviour may have been confounded. Unfortunately, intentions behind individuals' decisions to complete additional questionnaires were not assessed so this explanation remains speculative. Fortunately, participants' perceptions of the cover stories were gauged by asking them to indicate what they thought the study was about before reading the debriefing form. The cover stories appear to have been believable by the vast majority of participants as only seven of them indicated any doubt about their veracity. As the analyses were reported without these seven participants and because their inclusion did not seem to considerably vary the findings, the peculiar results were unlikely due to participants guessing the purpose or hypotheses of Study 2 and changing their behaviour in response.

Finally, one could question the validity of the measures of prosociality and sustainability used in Study 2. Unlike previous research which employed more established and validated measures, this study used relatively novel ways of assessing these dependent variables. Although they appear to be face valid, it is possible that prosociality and sustainability were not accurately

\footnotetext{
${ }^{14}$ Nevertheless, it is also plausible that being exposed to nature could produce an increased valuing of science and research. This has been noted anecdotally (e.g., Wilson, 1984) and is at least tangentially suggested by research as nature exposure tends to increase curiosity (Kaplan \& Berman, 2010) and those who are more connected to nature tend to think with a more innovative cognitive style (Leong, Fischer, \& McClure, in press).
} 
assessed by these measures. This may have caused the inconsistent findings from Study 2. For instance, participants generally spent very little time reading the eco-tips. Almost half of the participants spent less than 10 seconds on the eco-tips page $(n=71)$, causing its distribution to exhibit considerable positive skew. This overall low interest may have been due to participants being familiar with or thinking that they already knew about the ways in which they can be sustainable or not seeing new information after a quick initial glance. The lack of interest may have also been due to the fact that this measure was included at the very end of the study and was explicitly presented as completely voluntary and supplementary. By the time the eco-tips were presented to the participants, they may have been eager to finish the study and unwilling to read about the ways in which they could be more sustainable when they were not required to. In addition, one might have expected that those who had spent more time and energy filling out the additional questionnaires would have been the most eager to reach the end of the study and spend the least amount of time on the eco-tips page. Contrary to this expectation but consistent with results from Study 1, prosociality and sustainability were positively correlated. Individuals who agreed to help and who volunteered for more questionnaires also tended to spend more time reading about ways in which they could be more sustainable.

\section{Summary and Next Steps}

Although the results from Study 2 were mostly unexpected and inconsistent with previous research, numerous plausible explanations suggest that they may be valid. The results may be attributable to methodological issues, confounding variables, and unintended effects which future researchers could benefit from taking into consideration when setting up and conducting research in this area. Moreover, the results suggest that there may be certain contexts where nature's beneficial effect on prosocial and proenvironmental values and behaviour does 
not extend. The constructs of interest may be too broad and the effect may be more nuanced than previously conceived. For example, it might depend on how the dependent variables are operationalized, what takes place before/after exposure, whether individuals are mentally fatigued, etc. The ideas discussed throughout this section outline the instances where nature exposure would and would not be predicted to promote prosociality and sustainability. To further understand the robustness, limits, and generalizability of these effects, future research is necessary.

With the ambiguous findings from Study 1 and Study 2, what can one conclude, in general, about the impact of nature exposure on prosociality and sustainability? Due to the inevitable sampling and measurement error that can cause considerable variability in study results even under the most ideal circumstances, single studies and replication attempts can rarely be taken as definitive (Cumming, 2014; Stanley \& Spence, 2014). Along with the growing awareness of the problems associated with null hypothesis testing and the accompanied calls for a more cumulative estimation-based approach to psychological science, meta-analyses have become increasingly attractive and recommended by numerous researchers in order to obtain more accurate answers to research questions (Cumming, 2014; Stanley \& Spence, 2014). Following these recent discussions and recommendations, meta-analyses were conducted to integrate all the research on this topic and provide an estimate of nature exposure's impact on prosociality and sustainability.

\section{Nature Exposure and Prosociality Meta-Analysis}

\section{Method}

For a sample to be included in this meta-analysis, there had to be random assignment of participants to a nature or built/non-nature condition, followed by an assessment of prosocial 
values or behaviours. Samples were identified for this meta-analysis based on an earlier literature review done in the process of writing this thesis. Promising references from these papers were investigated further and unpublished results from the Carleton University Happy Lab were considered. A brief coding manual was created that outlined the specific coding rules, planned statistical analyses, conventions used to interpret results, and rules employed to identify outliers (see Appendix R).

\section{Results}

Eight samples were found that met the inclusion criteria (see Table 6), resulting in a total sample size of 972 . The range of the samples sizes was from 72 to 228 participants $(M=121.38$, $S D=48.53)$. Of the samples in which participant demographics were assessed $(n=7)$, the samples ranged in average age from 20 to 21 years old $(M=20.31, S D=0.42)$ and the percent of females in the samples ranged from $56.94 \%$ to $85.62 \%(M=67.71, S D=9.52)$. Half of the samples were conducted by researchers in the United States, while the remaining half were conducted by Canadian researchers. Relatedly, only $50 \%$ of the samples came from a published source.

A fixed-effect meta-analysis showed that within these samples nature exposure tended to lead to increases in prosociality $(d=.17,95 \%$ CI $[.05, .30], k=8, n=971)$. This small difference between conditions in prosociality can be considered significant because the confidence interval did not include zero. There was also a significant $(Q=22.27, d f=7, p=.002)$ and moderate-tohigh amount of variability across samples $\left(I^{2}=68.57\right)$. As Study 2 contained the lowest effect size in the meta-analysis, the variability across samples was significant, and its effect size contributed to more than $50 \%$ of Cochran's $Q$, it could be considered an outlier. Another fixedeffect meta-analysis was conducted excluding Study 2 which found a significant but larger mean 
Table 6

Descriptive Information for Samples Included in the Nature Exposure and Prosociality MetaAnalysis

\begin{tabular}{|c|c|c|c|c|c|}
\hline $\begin{array}{c}\text { Sample } \\
\#\end{array}$ & Source & $N$ & $\begin{array}{l}\text { Experimental } \\
\text { Manipulation }\end{array}$ & $\begin{array}{l}\text { Measure(s) of } \\
\text { Prosociality }\end{array}$ & $\begin{array}{l}\text { Effect Size } \\
\text { (Cohen's } d \text { ) }\end{array}$ \\
\hline 1.1 & $\begin{array}{l}\text { Weinstein et } \\
\text { al. }(2009)\end{array}$ & 98 & $\begin{array}{l}\text { Nature vs. Built } \\
\text { Photographs }\end{array}$ & $\begin{array}{l}\text { Aspiration Index } \\
\text { (Kasser \& Ryan, 1993) }\end{array}$ & 0.29 \\
\hline 1.2 & $\begin{array}{l}\text { Weinstein et } \\
\text { al. }(2009)\end{array}$ & 112 & $\begin{array}{l}\text { Nature vs. Built } \\
\text { Photographs }\end{array}$ & Aspiration Index & 0.37 \\
\hline 1.3 & $\begin{array}{l}\text { Weinstein et } \\
\text { al. }(2009)\end{array}$ & 85 & $\begin{array}{l}\text { Nature vs. Built } \\
\text { Photographs }\end{array}$ & $\begin{array}{l}\text { Aspiration Index \& } \\
\text { Adapted Trust Game } \\
\text { (Berg, Dickhaut, \& } \\
\text { McCabe, 1995) }\end{array}$ & 0.52 \\
\hline 1.4 & $\begin{array}{l}\text { Weinstein et } \\
\text { al. }(2009)\end{array}$ & 72 & $\begin{array}{l}\text { Plants Present vs. } \\
\text { Not Present in Lab }\end{array}$ & $\begin{array}{l}\text { Aspiration Index \& } \\
\text { Adapted Trust Game }\end{array}$ & 0.58 \\
\hline 2 & Dopko (2012) & 111 & $\begin{array}{l}\text { Nature vs. Built } \\
\text { Videos }\end{array}$ & State-Level Trust & -0.26 \\
\hline 3 & Habets (2013) & 119 & $\begin{array}{l}\text { Nature vs. Built } \\
\text { Walk }\end{array}$ & $\begin{array}{l}\text { Social Value Orientation } \\
\text { (Murphy et al., 2011) }\end{array}$ & 0.23 \\
\hline 4 & Study 1 & 228 & $\begin{array}{l}\text { Nature vs. Built } \\
\text { Videos }\end{array}$ & Social Value Orientation & 0.29 \\
\hline 5 & Study 2 & 146 & $\begin{array}{l}\text { Nature vs. Built } \\
\text { Photographs }\end{array}$ & $\begin{array}{l}\text { Agree to Help \& } \\
\text { Number of Additional } \\
\text { Questionnaires } \\
\text { Volunteered For }\end{array}$ & -0.34 \\
\hline
\end{tabular}

Note. Positive effect sizes indicate greater prosociality in the nature condition, while negative effect sizes indicate greater prosociality in the built/non-nature condition.

weighted effect size $(d=.27,95 \%$ CI $[.13, .40], k=7, n=825)$. Not surprisingly, excluding this extreme value decreased the variability across samples $\left(I^{2}=45.64\right)$ which was marginally 
significant $(Q=11.04, d f=6, p=.09)$.

In conclusion, even when one included an outlier (i.e., Study 2), the difference in prosocial values and behaviours between the two conditions was significant. Within these observed samples, it appears that nature exposure increases prosociality.

\section{Nature Exposure and Sustainability Meta-Analysis}

\section{Method}

For a sample to be included in this meta-analysis, there had to be random assignment of participants to a nature or built/non-nature condition, followed by an assessment of sustainable willingness, interest, or behaviours. Samples were identified in a similar manner as the previous meta-analysis. In addition, the same conventions, coding procedure, and statistical analyses were used in this meta-analysis (see Appendix R).

\section{Results}

Five samples were found that met the inclusion criteria (see Table 7), resulting in a total sample size of 663. The range of the samples sizes was from 78 to 228 participants $(M=132.60$, $S D=58.42)$. Of the samples in which participant demographics were assessed $(n=4)$, the samples ranged in average age from 20.11 to 20.81 years old $(M=20.33, S D=0.32)$ and the percent of females in the samples ranged from $66.70 \%$ to $85.62 \%(M=73.41, S D=8.36)$. All of the samples were unpublished and conducted in Canada by researchers from the Carleton University Happy Lab.

A fixed-effect meta-analysis showed that within these samples nature exposure tended to lead to increased sustainability $(d=.19,95 \%$ CI $[.03, .34], k=5, n=663)$. This small difference between conditions in sustainability could be considered significant because the confidence interval did not include zero. There was also a significant $(Q=14.42, d f=4, p=.006)$ and 
Table 7

Descriptive Information for Samples Included in the Nature Exposure and Sustainability MetaAnalysis

\begin{tabular}{|c|c|c|c|c|c|}
\hline $\begin{array}{c}\text { Sample } \\
\#\end{array}$ & Source & $N$ & $\begin{array}{l}\text { Experimental } \\
\text { Manipulation }\end{array}$ & $\begin{array}{l}\text { Measure (s) of } \\
\text { Sustainability }\end{array}$ & $\begin{array}{l}\text { Effect Size } \\
\text { (Cohen's } d)\end{array}$ \\
\hline 1 & Dopko (2012) & 96 & $\begin{array}{l}\text { Nature vs. Built } \\
\text { Videos }\end{array}$ & $\begin{array}{l}\text { Sustainable Behaviour in a } \\
\text { Simulated Fishing } \\
\text { Commons Dilemma } \\
\text { (Gifford \& Gifford, 2000) }\end{array}$ & 0.65 \\
\hline 2 & Dopko (2013) & 78 & $\begin{array}{l}\text { Nature vs. Built } \\
\text { Videos }\end{array}$ & $\begin{array}{l}\text { Sustainable Behaviour in } \\
\text { Simulated Fishing } \\
\text { Commons Dilemma }\end{array}$ & 0.45 \\
\hline 3 & Habets (2013) & 120 & $\begin{array}{l}\text { Nature vs. Built } \\
\text { Walk }\end{array}$ & $\begin{array}{l}\text { Willingness to Perform } \\
\text { Sustainable Behaviours } \\
\text { (Ferguson et al., 2011) }\end{array}$ & 0.10 \\
\hline 4 & Study 1 & 228 & $\begin{array}{l}\text { Nature vs. Built } \\
\text { Videos }\end{array}$ & $\begin{array}{l}\text { Willingness to Perform } \\
\text { Sustainable Behaviours }\end{array}$ & 0.26 \\
\hline 5 & Study 2 & 141 & $\begin{array}{l}\text { Nature vs. Built } \\
\text { Photographs }\end{array}$ & $\begin{array}{l}\text { Time Spent Reading } \\
\text { Eco-Tips }\end{array}$ & -0.29 \\
\hline
\end{tabular}

Note. Positive effect sizes indicate greater sustainability in the nature condition, while negative effect sizes indicate greater sustainability in the built/non-nature condition.

a high amount of variability across samples $\left(I^{2}=72.26\right)$. As Study 2 contained the lowest effect size in the meta-analysis, the variability across samples was significant, and its effect size contributed to more than $50 \%$ of Cochran's $Q$, it could also be considered an outlier in this metaanalysis. Another fixed-effect meta-analysis was conducted excluding Study 2 which found a significant but larger mean weighted effect size $(d=.32,95 \%$ CI $[.15, .49], k=4$, $n=522$ ). When this extreme value was excluded, the variability across samples was no longer significant $(Q=3.46, d f=3, p=.23)$ and was much smaller in magnitude $\left(I^{2}=31.25\right)$. 
In conclusion, even when one included an outlier (i.e., Study 2), the difference in sustainable willingness, interest, and behaviours between the two conditions was significant. Within these observed samples, it appears that nature exposure increases sustainability.

\section{General Discussion}

The purpose of this thesis was to conceptually replicate and test the generalizability and limitations of nature exposure's impact on prosociality and sustainability. In Study 1, location and valence were manipulated in order to examine whether the unpleasant aspects of nature also promote prosocial values and sustainable willingness. Regardless of valence, individuals exposed to the nature videos had more prosocial value orientations compared to those who viewed the built videos. Although individuals in the nature condition were also more willing to perform proenvironmental behaviours than those in the built condition, this was qualified by an interaction where the pleasant built video produced uniquely low willingness. In general, Study 1 suggests that exposure to the more unpleasant aspects of nature has a similar effect on prosociality and sustainability as its pleasant features. State nature relatedness appeared to partially mediate the effect of nature exposure on prosociality and sustainability, while trait nature relatedness was positively associated with both. Study 2 employed novel operationalizations of prosociality and sustainability in order to test the generalizability of nature exposure's effect on these dependent variables. In particular, a non-resource allocation measure of prosocial behaviour was used, along with a discreet behavioural measure of interest in sustainability. Contrary to expectations, participants in the built condition were more likely to agree to help complete additional questionnaires compared to those in the nature condition. Of those who agreed to help, there was no difference between conditions in the number of additional questionnaires they volunteered for. The effect of condition on interest in sustainability was hard 
to interpret as the results varied considerably depending on how the data was analyzed.

Nevertheless, Study 2 suggests that nature exposure's impact on prosociality and sustainability may be more nuanced and limited than previously conceived. Although trait nature relatedness was positively associated with the measure of sustainability in Study 2, it was not correlated with prosocial behaviour. Given the inconsistent findings in Study 1 and 2, and the recent calls for a shift to a more cumulative estimation-based approach to psychological science (e.g., Cumming, 2014), fixed-effect meta-analyses were conducted to provide a quantitative summary of this research. Overall, the meta-analyses showed that, on average, nature exposure increases prosocial and proenvironmental values and behaviours. ${ }^{15}$

\section{Why Does Nature Exposure Increase Prosociality and Sustainability?}

Further research is necessary to understand the underlying mechanisms behind why nature exposure increases prosociality and sustainability. There are a variety of explanations, some of which have already been discussed. To account for the extremely dissimilar results of Study 2, the propositions that nature exposure causes individuals to be more prosocial and proenvironmental by restoring self-regulatory resources or priming an aversion to inequality were raised.

Despite previous research showing that mood can have an influence on helping behaviours (Isen \& Levin, 1972; Salovey et al., 1991) and that nature exposure has a positive impact on mood (Nisbet \& Zelenski, 2011), it is an unlikely mediator of this effect (but see Zhang, Piff, Iyer, Koleva, \& Keltner, 2014, for evidence to the contrary). Specifically, when valence was experimentally manipulated in Study 1, nature exposure led individuals to distribute

\footnotetext{
${ }^{15}$ As the impact of nature exposure on prosociality and sustainability was the primary focus of this thesis, metaanalyses were not conducted on the relationship between trait nature relatedness and these dependent variables. In addition, these meta-analyses were expected to be much larger and time-intensive. Future research quantitatively summarizing the association between these variables would be informative, especially considering the inconsistent findings between trait nature relatedness and prosociality in Study 1 and 2.
} 
resources more prosocially regardless of pleasantness. As mood was similar (or controlled for) in the respective pleasant and unpleasant nature and built conditions, another mechanism likely accounts for nature's beneficial impact on prosocial behaviour. Moreover, mediation analyses in Dopko $(2012,2013)$ did not support mood as a mediator of these effects. Likewise, controlling for post-exposure positive affect, Weinstein et al. (2009) found that other variables mediated (i.e., autonomy and nature relatedness) and moderated (i.e., immersion) nature's impact on participants' aspirations and trust of others.

Study 1 replicated and extended some of these results by finding that state nature relatedness partially mediated nature's effect on prosociality and sustainability. In other words, individuals exposed to nature were more prosocial and proenvironmental, in part, because they identified with and felt more connected to nature. ${ }^{16}$ It makes sense that people would care and be more willing to behave in ways that protect the environment when they feel more connected to it. This is consistent with previous research that shows that people higher in trait nature relatedness hold more proenvironmental attitudes, engage in more sustainable behaviours, and are more likely to identify as environmentalists (Mayer \& Frantz, 2004; Nisbet et al., 2009). In addition, research also finds that having a strong natural place attachment predicts engagement in climate change and proenvironmental behaviours (Scannel \& Gifford, 2010; Scannel \& Gifford, 2013). Increased state nature relatedness may promote prosociality by making the interconnectedness of all life, including that between individuals, more salient. Nature exposure may also trigger our biophilic tendencies and lead us to value the life and well-being of other individuals more, along

\footnotetext{
${ }^{16}$ These results should be taken with caution as the indirect effects have only been examined using statistical mediation analyses. Given the problems associated with this (see Stone-Romero \& Rosopa, 2008), employing experimental approaches to test these mediation effects would increase confidence in these results. Another reason to be cautious is because Dopko $(2012,2013)$ did not find any evidence for state nature relatedness mediating these effects.
} 
with the rest of the natural world.

Greenfield's (2009) theory of social change and human development might also help explain why nature exposure increases other-oriented and proenvironmental values and behaviours. Adapting the theory from cultural to individual values and large-scale social change to temporary changes in ecological contexts, one could deduce that nature exposure may prime collectivist values that are adaptive in rural environments, while exposure to built stimuli may prime individualistic values that are adaptive in urban environments. Weinstein et al. (2009) provided some support for this notion by finding that participants exposed to nature placed more importance on community and relationships and less importance on fame and fortune compared to those exposed to built environments. Future research is necessary to examine this theory more in-depth and to test the predictions that flow from it.

Finally, nature exposure could promote prosociality and sustainability by decreasing our tendency to discount the future. A recent paper by van der Wal, Schade, Krabbendam, and van Vugt (2013) found that individuals place more value on the future and are more likely to choose a slightly larger reward in the future instead of an immediate reward in the present when exposed to natural versus urban landscapes. Moreover, researchers have found that the tendency to be future-oriented is positively associated with sustainable behaviour and that manipulating people's mental timelines influences how much they donate to environmental charities (CorralVerdugo \& Pinheiro, 2006; Hershfield, Bang, \& Weber, 2013). Thus, individuals may be less willing and likely to act in self-interested ways that bring immediate rewards for themselves in the present but that are unsustainable, uncooperative, and harmful in the long-term when they are exposed to nature. These explanations are not necessarily mutually exclusive and may interact or be independent processes through which nature exposure can influence prosocial and 
proenvironmental values and behaviours.

\section{Limitations}

This research has several limitations. First, Study 1 and 2 both used samples that solely consisted of undergraduate students. In general, this is a common limitation of this area of research, as evidenced by the average ages in the meta-analyses. Including older samples from the community would increase the external validity of these findings and allow one to more confidently generalize across different age groups. This is especially relevant considering the research that shows that older populations tend to be more agreeable (Roberts, Walton, \& Viechtbauer, 2006; Srivastava, John, Gosling, \& Potter, 2003) and more proenvironmental on average (Grønhøj \& Thøgersen, 2009). Including younger samples would also increase external validity and allow one to observe how early in development the effects of nature exposure manifest. Similar to Witman (1987) and Berman et al. (2012), testing these hypotheses with clinical samples may help determine whether the effects are generalizable to individuals experiencing mental health issues. Research on this topic has only been conducted with North American samples. Conducting similar studies cross-culturally would test the generalizability and the universality of these effects which would be predicted by an evolutionary theory like the biophilia hypothesis.

Study 1 and 2 were both conducted online using brief virtual representations of natural and built environments. The effects may change in magnitude when individuals are immersed in actual natural and built environments or exposed to them for longer periods of time.

Additionally, the duration of nature exposure's impact on prosociality and sustainability, and whether people become habituated with repeated or prolonged exposures remain unanswered questions as only single short-term exposures were used in Study 1 and 2. Employing different 
methodologies would allow researchers to investigate these nuanced lines of research.

A final limitation is the persistent use of built stimuli as the control condition for nature exposure. In particular, this experimental design makes it unclear whether nature is leading to increases or built environments are leading to decreases in prosociality and sustainability. This is especially important considering that the urban overload hypothesis has been used to explain why helping behaviours are less likely in urban versus rural areas (Milgram, 1970). Specifically, it posits that because of the overwhelming amount of information that people are exposed to in urban environments, individuals adapt by ignoring stimuli which is not essential to their personal goals. Thus, strangers are ignored and people become less prosocial in order to limit the amount of input that needs to be processed and to conserve limited cognitive resources (Steblay, 1987). Nevertheless, there is some evidence to suggest that it is nature exposure in particular that is responsible for these effects. When Dopko (2013) added a non-built control condition (i.e., an audio grammar podcast), she found that sustainable behaviours were similar in the control and built conditions and especially high in the nature condition. The findings from Weinstein et al. (2009) and Study 1 that implicate state nature relatedness as a mediator also suggest that it is the exposure to nature which is driving these effects. Furthermore, Zhang et al. (2014) found that more beautiful versus less beautiful nature led participants to be more prosocial. Although these all insinuate that nature, not urban, exposure is the true cause of these effects, it would be beneficial for future research to add control conditions to disentangle these environmental catalysts.

\section{Implications}

Taking these limitations, unanswered questions, and avenues for future research into account, there are numerous implications of this research that one can consider. With the exodus 
of the world's population from rural to urban areas expected to continue into the foreseeable future (UNPD, 2011), this research provides just another reason why the inclusion and maintenance of green spaces within cities appears to be a wise investment. A growing body of evidence shows that living near green spaces is associated with numerous positive outcomes including increased emotional well-being (White et al., 2013), sustained improvements in mental health (Alcock, White, Wheeler, Fleming, \& Depledge, 2014), and decreased mortality (Mitchell \& Popham, 2008). More opportunities to experience the natural world within cities may promote slightly happier, healthier, friendlier, more caring, and sustainable urbanites. This proposition is consistent with research that shows that fewer property and violent crimes occur around innercity apartment buildings with greener surroundings compared to buildings surrounded by less vegetation (Kuo \& Sullivan, 2001b). Additionally, individuals who live in inner-city public housing with more nearby nature report lower aggression and violence than those living in buildings with less nearby nature (Kuo \& Sullivan, 2001a). Given the plethora of research illustrating the physical, psychological, and social benefits of nature, city planners, politicians, and government officials may want to invest in natural green spaces within the built urban environments that the majority of us reside in.

Making nature accessible in the indoor settings where we spend almost all of our time may be another way to reap these benefits in our daily lives. For instance, workplaces may want to add plants to their offices or ensure that their employees have windows which have views of nature. Nature interventions in settings like this would likely provide advantages to all the parties involved. Nature exposure boosts happiness (Nisbet \& Zelenski, 2011) and individuals tend to be more productive when they are happy (Oswald, Proto, \& Sgroi, in press). As nature exposure is also associated with increased functioning on a variety of measures of physical health (see 
Frumkin, 2001, for a review), employees would likely take fewer sick days and show up to work more often when nature is accessible within their workplace. Furthermore, the overall metaanalyses from this thesis suggest that cooperation and teamwork among employees might be improved and that the company might save money by individuals acting more sustainably if nature is incorporated into the workplace. Analyzing the impact of nature interventions in naturalistic settings on outcomes like the ones mentioned above would be a fruitful avenue of applied future research, especially considering news stories about government departments opting to remove plants from offices in order to save money (Fehling, 2014).

Individuals, organizations, and governments may gain from implementing nature imagery to nudge people to act in more prosocial and proenvironmental ways. Including representations of nature at specific stages in the decision-making process may make individuals slightly more likely to behave cooperatively and sustainably. For instance, placing images of nature within appeals for donations to charitable organizations may lead people to be somewhat more likely to donate and give more money. Likewise, individuals may be a little more likely to conserve resources and energy by inserting nature stimuli on and around objects like garbage receptacles, printers, or light switches. When purchasing material goods or services, using nature icons to label more sustainable choices among a number of possible options, similar to what some restaurant menus use to indicate vegetarian meals, may be more effective at influencing people's choices to more eco-friendly options compared to other non-nature-related labels. Furthermore, the results suggest that groups attempting to promote concern for the environment and proenvironmental behaviour change might want to continue to use imagery of nature over other lines of argument (e.g., financial) which may be less effective. Although these implications plausibly follow from this thesis, they are empirical claims for future research to examine more 
directly.

Lastly, this research has methodological implications for the field of psychology more generally. The relatively common use of nature stimuli as a control condition in experimental research may be misguided and problematic given all the effects of nature exposure that have been uncovered. Far from having a neutral impact on our psychology, nature stimuli may serve as a poor comparison condition in many areas of investigation. As an example, Borness, Proudfoot, Crawford, and Valenzuela (2013) used viewing brief nature documentaries as a control condition in a study investigating the efficacy of cognitive training (also known as brain training). To the surprise of the researchers, participants in the control condition who watched and answered questions about a series of nature documentaries showed more improvements (i.e., increased well-being) after six months compared to individuals in the cognitive training condition. This lack of awareness is not surprising, however, given that most psychology departments do not have a faculty member that identifies as an environmental psychologist (Gifford, 2014), and courses and research in this area are seldom covered in undergraduate psychology programs (Scott \& Koger, 2005). Including findings from and courses in environmental psychology within more psychology programs is needed if psychology is to help understand and solve the environmental problems we are facing (Koger \& Scott, 2007).

\section{Conclusion}

A sustainable future will likely rely, in part, on individuals overcoming selfish tendencies in favour of more cooperative behaviour that takes into account the short-term and long-term well-being of others and the environment. Nature exposure appears to be one way in which these prosocial and proenvironmental values and behaviours can be temporarily promoted in some circumstances. In summary, a happier, healthier, kinder, and greener self may be found in nature. 


\section{References}

Aderman, D. (1972). Elation, depression, and helping behavior. Journal of Personality and Social Psychology, 24, 91-101. http://dx.doi.org/10.1037/h0033366

Alcock, I., White, M. P., Wheeler, B. W., Fleming, L. E., \& Depledge, M. H. (2014).

Longitudinal effects on mental health of moving to greener and less green urban areas. Environmental Science and Technology, 48, 1247-1255. http://dx.doi.org/10.1021/es403688w

Allen, D. T. (1997). Effects of dogs on human health. Journal of American Veterinary Medical Association, 210, 1136-1139.

American Pet Products Association. (2013). 2013-2014 APPA National Pet Ownership Survey. Greenwich, CT: Author.

Anderson, W., Reid, C., \& Jennings, G. (1992). Pet ownership and risk factors for cardiovascular disease. Medical Journal of Australia, 157, 298-301.

Association of Zoos \& Aquariums. (n.d.). Visitor demographics. Retrieved from http://www.aza.org/visitor-demographics/

Balliet, D., Parks, C., \& Joireman, J. (2009). Social value orientation and cooperation in social dilemmas: A meta-analysis. Group Processes \& Intergroup Relations, 12, 533-547. http://dx.doi.org/10.1177/1368430209105040

Baumeister, R. F., Bratslavsky, E., Muraven, M., \& Tice, D. M. (1998). Ego depletion: Is the active self a limited resource? Journal of Personality and Social Psychology, 74, 12521265. http://dx.doi.org/10.1037/0022-3514.74.5.1252 
Baumeister, R. F., Schmeichel, B. J., \& Vohs, K. D. (2007). Self-regulation and the executive function: The self as controlling agent. In A. W. Kruglanski \& E. T. Higgins (Eds.), Social psychology: Handbook of basic principles (2nd ed.). New York, NY: Guilford.

Bellwood, P. (2004). First farmers: The origins of agricultural societies. Malden, MA: WileyBlackwell.

Berg, J., Dickhaut, J., \& McCabe, K. (1995). Trust, reciprocity, and social history. Games and Economic Behavior, 10, 122-142. http://dx.doi.org/10.1006/game.1995.1027

Berman, M. G., Jonides, J., \& Kaplan, S. (2008). The cognitive benefits of interacting with nature. Psychological Science, 19, 1207-1212. http://dx.doi.org/10.1111/j.14679280.2008.02225.x

Berman, M. G., Kross, E., Krpan, K. M., Askren, M. K., Burson, A., Deldin, P. J., . . Jonides, J. (2012). Interacting with nature improves cognition and affect for individuals with depression. Journal of Affective Disorders, 140, 300-305. http://dx.doi.org/10.1016/j.jad.2012.03.012

Boehm, C. (1993). Egalitarian behavior and reverse dominance hierarchy. Current Anthropology, 34, 227-254. http://dx.doi.org/10.1086/204166

Bogaert, S., Boone, C., \& Declerck, C. (2008). Social value orientation and cooperation in social dilemmas: A review and conceptual model. The British Journal of Social Psychology, 47, 453-480. http://dx.doi.org/10.1348/014466607X244970

Borenstein, M., Hedges, L. V., Higgins, L. V., Higgins, J. P. T., \&, Rothstein, H. R. (2009). Introduction to meta-analysis. Wiltshire, England: Wiley \& Sons, Ltd. 
Borness, C., Proudfoot, J., Crawford, J., \& Valenzuela, M. (2013). Putting brain training to the test in the workplace: A randomized, blinded, multisite, active-controlled trial. PLOS ONE, 8, 1-8. http://dx.doi.org/10.1371/journal.pone.0059982

Bowler, D. E., Buyung-Ali, L. M., Knight, T. M., \& Pullin, A. S. (2010). A systematic review of evidence for the added benefits to health of exposure to natural environments. $B M C$ Public Health, 10, 456. http://dx.doi.org/10.1186/1471-2458-10-456

Bruni, C. M., Chance, R. C., Schultz, P. W., \& Nolan, J. M. (2012). Natural connections: Bees sting and snakes bite, but they are still nature. Environment and Behavior, 44, 197-215. http://dx.doi.org/10.1177/0013916511402062

Carlo, G., Okun, M. A., Knight, G. P., \& Guzman, M. R. T. (2005). The interplay of traits and motives on volunteering: Agreeableness, extraversion, and prosocial value motivation. Personality and Individual Differences, 38, 1293-1305.

http://dx.doi.org/10.1016/j.paid.2004.08.012

Carrington, D. (2013, May 10). Global carbon dioxide in atmosphere passes milestone level: Climate warming greenhouse gas reaches 400 parts per million for the first time in human history. The Guardian. Retrieved from http://www.guardian.co.uk/environment/2013/may/10/carbon-dioxide-highest-levelgreenhouse-gas

Charity Intelligence Canada. (2013). Environmental charities in Canada. Retrieved from http://www.charityintelligence.ca/images/environmental_charities_in_canada.pdf

Chen, J. L., Wilson, C. R., \& Tapley, B. D. (2013). Contribution of ice sheet and mountain glacier melt to recent sea level rise. Nature Geoscience, 6, 549-552. http://dx.doi.org/10.1038/ngeo1829 
Cheng, J. C. H., \& Monroe, M. C. (2012). Connection to nature: Children's affective attitude toward nature. Environment and Behavior, 44, 31-49. http://dx.doi.org/10.1177/0013916510385082

Chivian, E., \& Bernstein, A. (Eds.). (2008). Sustaining life: How human health depends on biodiversity. New York, NY: Oxford University Press.

Cialdini, R. B., Darby, B. L., \& Vincent, J. E. (1973). Transgression and altruism: A case for hedonism. Journal of Experimental Social Psychology, 9, 502-516. http://dx.doi.org/10.1016/0022-1031(73)90031-0

Cleland, V., Crawford, D., Baur, L. A., Hume, C., Timperio, A., \& Salmon, J. (2008). A prospective examination of children's time spent outdoors, objectively measured physical activity and overweight. International Journal of Obesity, 32, 1685-1693. http://dx.doi.org/10.1038/ijo.2008.171

Clements, R. (2004). An investigation of the status of outdoor play. Contemporary Issues in Early Childhood, 5, 68-80. http://dx.doi.org/10.2304/ciec.2004.5.1.10

Cohen, J. (1988). Statistical power analysis for the behavioral sciences (2nd.). Hillsdale, NJ: Lawrence Erlbaum.

Corral-Verdugo, V., \& Pinheiro, J. Q. (2006). Sustainability, future orientation and water conservation. European Review of Applied Psychology, 56, 191-198. http://dx.doi.org/10.1016/j.erap.2005.09.002

Crelley, D. (2013). I can resist anything except temptation: Self-regulatory fatigue and ethical spending (Doctoral dissertation, University of Exeter). Retrieved from https://ore.exeter.ac.uk/repository/bitstream/handle/10871/12401/CrelleyD.pdf?sequence $=2$ 
Cumming, G. (2014). The new statistics: Why and how. Psychological Science, 25, 7-29. http://dx.doi.org/10.1177/0956797613504966

David Suzuki Foundation. (2012). Youth engagement with nature and the outdoors: A summary of key findings. Retrieved from http://www.davidsuzuki.org/publications/downloads/2012/youth\%20survey\%20findings \%20summary.pdf

DeWall, C. N., Baumeister, R. F., Gailliot, M. T., \& Maner, J. K. (2008). Depletion makes the heart grow less helpful: Helping as a function of self-regulatory energy and genetic relatedness. Personality and Social Psychology Bulletin, 34, 1653-1662. http://dx.doi.org/10.1177/0146167208323981

Diamond, J. (1999). Guns, germs, and steel: The fates of human societies. New York, NY: W. W. Norton \& Company, Inc.

Dopko, R. L. (2012). Effects of nature on cooperation in a commons dilemma: Implications for sustainability. (Master's thesis). Retrieved from ProQuest Dissertations and Theses database. (305005903).

Dopko, R. L. (2013). [Replication of master's thesis]. Unpublished raw data.

Eisenberg, N. (1991). Meta-analytic contributions to the literature on prosocial behavior. Personality and Social Psychology Bulletin, 17, 273-282. http://dx.doi.org/10.1177/0146167291173007

England Marketing. (2009). Report to Natural England on childhood and nature: A survey on changing relationships with nature across generations. Retrieved from Natural England website: http://bit.ly/1g7HRLX 
Environment Canada. (2013, May 28). Eco-Tips. Retrieved from http://www.ec.gc.ca/scecew/default.asp?lang=En\&n=5499C60D-1

Evans, G. W., \& McCoy, J. M. (1998). When buildings don't work: The role of architecture in human health. Journal of Environmental Psychology, 18, 85-94. http://dx.doi.org/10.1006/jevp.1998.0089

Fehling, A. (2014). Budget pruning leaves Canadian potted plants out to dry. The Two-Way: Breaking News from NPR. Retrieved from http://www.npr.org/blogs/thetwoway/2014/02/10/274736163/budget-pruning-leaves-canadian-potted-plants-out-to-dry

Ferguson, M. A., Branscombe, N. R., \& Reynolds, K. J. (2011). The effect of intergroup comparison on willingness to perform sustainable behavior. Journal of Environmental Psychology, 31, 275-281. http://dx.doi.org/10.1016/j.jenvp.2011.04.001

Friedmann, E., \& Thomas, S. A. (1995). Pet ownership, social support, and one-year survival after acute myocardial infarction in the cardiac arrhythmia suppression trial (CAST). American Journal of Cardiology, 76, 1213-1217. http://dx.doi.org/10.1016/S00029149(99)80343-9

Frumkin, H. (2001). Beyond toxicity: Human health and the natural environment. American Journal of Preventive Medicine, 20(3), 234-240.

Gaines, C. (2102, October 31). Sports chart of the day: Baseball attendance is greater than NFL, NHL, and NBA combined. Business Insider. Retrieved from http://www.businessinsider.com/more-people-attend-mlb-games-than-nfl-nhl-and-nbacombined-sports-chart-of-the-day-2012-10

Gifford, R. (2014). Environmental psychology matters. The Annual Review of Psychology, 65, 541-579. http://dx.doi.org/10.1146/annurev-psych-010213-115048 
Gifford, J. \& Gifford, R. (2000). FISH 3: A microworld for studying social dilemmas and resource management. Behavior Research Methods, Instruments, \& Computers, 32, 417422. http://dx.doi.org/10.3758/BF03200810

Giving USA Foundation. (2013). Giving USA 2013. Chicago, IL: Author.

Gosling, S. D., Rentfrow, P. J., \& Swann, W. B. (2003). A very brief measure of the Big-Five personality domains. Journal of Research in Personality, 37, 504-528. http://dx.doi.org/10.1016/S0092-6566(03)00046-1

Gray, P. (2014). Hunter-gatherer egalitarianism as a force for decline in sexual dimorphism. Psychological Inquiry, 24, 192-194. http://dx.doi.org/10.1080/1047840X.2013.816926

Graziano, W. G., \& Eisenberg, N. H. (1997). Agreeableness: A dimension of personality. In R. Hogan, J. Johnston, \& S. Briggs (Eds.), Handbook of personality psychology (pp. 795824). San Diego, CA: Academic Press.

Greenfield, P. M. (2009). Linking social change and developmental change: Shifting pathways of human development. Developmental Psychology, 45, 401-418. http://dx.doi.org/10.1037/a0014726

Greenfield, P. M. (2013). The changing psychology of culture from 1800 through 2000. Psychological Science, 24, 1722-1731. http://dx.doi.org/10.1177/0956797613479387

Grønhøj, A., \& Thøgersen, J. (2009). Like father, like son? Intergenerational transmission of values, attitudes, and behaviours in the environmental domain. Journal of Environmental Psychology, 29, 414-421. http://dx.doi.org/10.1016/j.jenvp.2009.05.002

Gross, J. J., \& John, O. P. (2003). Individual differences in two emotion regulation processes: Implications for affect, relationships, and well-being. Journal of Personality and Social Psychology, 85, 348-362. http://dx.doi.org/10.1037/0022-3514.85.2.348 
Gurven, M. (2004). Reciprocal altruism and food sharing decisions among hunter-gatherers. Behavioral Ecology and Sociobiology, 56, 366-380. http://dx.doi.org/10.1007/s00265004-0793-6

Habets, N. (2013). Examining the effects of exposure to natural environments as moderated by depressive symptoms (Unpublished honour's thesis). Carleton University, Ottawa, ON.

Hanson, R. K., \& Bussière, M. T. (1998). Predicting relapse: A meta-analysis of sexual offender recidivism studies. Journal of Consulting and Clinical Psychology, 66, 348-362. http://dx.doi.org/10.1037/0022-006X.66.2.348

Hardin, G. (1968). The tragedy of the commons. Science, 162, 1243-1248.

Hartig, T., Mang, M., \& Evans, G. W. (1991). Restorative effects of natural environment experiences. Environment and Behavior, 23, 3-26. http://dx.doi.org/10.1177/0013916591231001

Heerwagen, J. H. (1990). The psychological aspects of windows and window design. In K. H. Anthony, J. Choi, \& B. Orland (Eds.), Proceedings of the $21^{\text {st }}$ Annual Conference of Environmental Design Research Association (pp. 269-280). Oklahoma City, OK: EDRA.

Hershfield, H.E., Bang, H.M., \& Weber, E.U. (2013). National differences in environmental concern and performance predicted by country age. Psychological Science, 25, 152-160. http://dx.doi.org/10.1177/0956797613501522

Higgins, J. P. T., \& Thompson, S. G. (2002). Quantifying heterogeneity in a meta-analysis. Statistics in Medicine, 21, 1539-1558. http://dx.doi.org/10.1002/sim.1186

Hilbig, B. E., Zettler, I., Moshagen, M., \& Heydasch, T. (2013). Tracing the path from personality - via cooperativeness - to conservation. European Journal of Personality, 27, 319-327. http://dx.doi.org/10.1002/per.1856 
Hill, K. (2002). Altruistic cooperation during foraging by the Ache, and the evolved human predisposition to cooperate. Human Nature, 13, 105-128. http://dx.doi.org/10.1007/s12110-002-1016-3

Ingold, T. (1999). On the social relations of the hunter-gatherer band. In R. B. Lee \& R. H. Daly (Eds.), The Cambridge encyclopedia of hunters and gatherers (pp. 399-410). Cambridge, UK: Cambridge University Press.

International Panel on Climate Change. (2013). Climate change 2013: The physical science basis. Retrieved from http://www.climatechange2013.org/images/report/WG1AR5_ALL_FINAL.pdf International Panel on Climate Change. (2014). Climate change 2014: Impacts, adaptation, and vulnerability. Retrieved from http://ipccwg2.gov/AR5/images/uploads/IPCC_WG2AR5_SPM_Approved.pdf

Isen, A. M., \& Levin, P. F. (1972). Effect of feeling good on helping: Cookies and kindness. Journal of Personality and Social Psychology, 21, 384-388. http://dx.doi.org/10.1037/h0032317

Ivey, P. K., Morelli, G. A., \& Tronick, E. Z. (2005). Child caretakers among Efe foragers of the Ituri Forest. In B. Hewlett, \& M. Lamb (Eds.), Hunter-gatherer childhoods: Evolutionary, developmental and cultural perspectives (pp. 191-213). New York, NY: Transaction Publishers.

Kaplan, R. (1992). The psychological benefits of nearby nature. In D. Relf(Ed.), The role of horticulture in human well-being and social development: A national symposium (pp. 125-133). Portland, OR: Timber Press. 
Kaplan, S., \& Berman, M. G. (2010). Directed attention as a common resource for executive functioning and self-regulation. Perspectives on Psychological Science, 5, 43-57. http://dx.doi.org/10.1177/1745691609356784

Kashdan, T. B., Gallagher, M. W., Silvia, P. J., Winterstein, B. P., Breen, W. E., Terhar, D., \& Steger, M. F. (2009). The Curiosity and Exploration Inventory-II. Development, factor structure, and psychometrics. Journal of Research in Personality, 43, 987-998. http://dx.doi.org/10.1016/j.jrp.2009.04.011

Kasser, T., \& Ryan, R. M. (1993). A dark side of the American dream: Correlates of financial success as a central life aspiration. Journal of Personality and Social Psychology, 65, 410-422. http://dx.doi.org/10.1037/0022-3514.65.2.410

Kellert, S. R, \& Wilson, E. O. (Eds.). (1993). The biophilia hypothesis. Washington, DC: Island Press.

Kenny, D. A. (1987). Statistics for the social and behavioral sciences. Boston, MA: Scott Foresman \& Co.

Kenny, D. A. (2014, April 9). Mediation. Retrieved from http://davidakenny.net/cm/mediate.htm

Koger, S. M., \& Scott, B. A. (2007). Psychology and environmental sustainability: A call for integration. Teaching of Psychology, 34, 10-18. http://dx.doi.org/10.1080/00986280709336642

Koole, S. L., \& Van den Berg, A. E. (2005). Lost in the wilderness: Terror management, action orientation, and nature evaluation. Journal of Personality and Social Psychology, 88, 1014-1028. http://dx.doi.org/10.1037/0022-3514.88.6.1014

Kosek, R. B. (1995). Measuring prosocial behaviors of college students. Psychological Reports, 3, 739-742. http://dx.doi.org/10.2466/pr0.1995.77.3.739 
Kuo, F. E., \& Sullivan, W. C. (2001a). Aggression and violence in the inner city: Effects of environment via mental fatigue. Environment and Behavior, 33, 543-571. http://dx.doi.org/10.1177/00139160121973124

Kuo, F. E., \& Sullivan, W. C. (2001b). Environment and crime in the inner city: Does vegetation reduce crime? Environment and Behavior, 33, 343-367. http://dx.doi.org/10.1177/00139160121973025

Lee, R. B. (1988). Reflections on primitive communism. In T. Ingold, D. Riches, \& J. Woodburn (Eds.), Hunters and gatherers, volume 1: History, evolution and social change (pp. 252268). Oxford, UK: Berg.

Leong, C. L. Y., Fischer, R., \& McClure, J. (in press). Are nature lovers more innovative? The relationship between connectedness with nature and cognitive styles. Journal of Environmental Psychology. http://dx.doi.org/10.1016/j.jenvp.2014.03.007

Louv, R. (2005). Last child in the woods: Saving our children from Nature-Deficit Disorder. Chapel Hill, NC: Algonquin.

MacKerron, G., \& Mourato, S. (2013). Happiness is greater in natural environments. Global Environmental Change, 23, 992-1000. http://dx.doi.org/10.1016/j.gloenvcha.2013.03.010

Manucia, G. K., Baumann, D. J., \& Cialdini, R. B. (1984). Mood influences on helping: Direct effects or side effects? Journal of Personality and Social Psychology, 46, 357-364. http://dx.doi.org/10.1037/0022-3514.46.2.357

Marcus, D., Berstein, C., Constantin, J. M., Kunkel, F. A., Breuer, P., \& Hanlon, R. (2012). Animal-assisted therapy at an outpatient pain management clinic. Pain Medicine, 13, 4557. http://dx.doi.org/10.1111/j.1526-4637.2011.01294.x 
Mayer, F. S., Frantz, C. M., Bruehlman-Senecal, E., \& Dolliver, K. (2009). Why is nature beneficial? The role of connectedness to nature. Environment and Behavior, 41, 607-643. http://dx.doi.org/10.1177/0013916508319745

McCabe, J., Fairchild, E., Grauerholz, L., Pescosolido, B. A., \& Tope, D. (2011). Gender in twentieth-century children's books: Patterns of disparity in titles and central characters. Gender \& Society, 25, 197-226. http://dx.doi.org/10.1177/0891243211398358

McClintock, C. G., \& Allison, S. T. (2006). Social value orientation and helping behavior. Journal of Applied Social Psychology, 19, 353-362. http://dx.doi.org/10.1111/j.15591816.1989.tb00060.x

McCrae, R. R., \& Costa, P. T. (2003). Personality in adulthood: A five-factor theory perspective (2nd ed.). New York: Guilford.

Milgram, S. (1970). The experience of living in cities. Science, 167, 1461-1468. http://dx.doi.org/10.1126/science.167.3924.1461

Mitchell, R., \& Popham, F. (2008). Effect of exposure to natural environment on health inequalities: An observational population study. The Lancet, 372, 1655-1660.

Muraven, M., Tice, D. M., \& Baumeister, R. F. (1998). Self-control as limited resource: Regulatory depletion patterns. Journal of Personality and Social Psychology, 74, 774789. http://dx.doi.org/10.1037/0022-3514.74.3.774

Murphy, R. O., Ackermann, K. A., \& Handgraaf, M. J. J. (2011). Measuring social value orientation. Judgment and Decision Making, 6, 771-781. http://dx.doi.org/10.2139/ssrn.1804189 
Nisbet, E. K., \& Zelenski, J. M. (2011). Underestimating nearby nature: Affective forecasting errors obscure the happy path to sustainability. Psychological Science, 22, 1101-1106. http://dx.doi.org/10.1177/0956797611418527

Nisbet, E. K., \& Zelenski, J. M. (2013). The NR-6: A new brief measure of nature relatedness. Frontiers in Psychology, 4:813. doi:10.3389/fpsyg.2013.00813

Nisbet, E. K., Zelenski, J. M., \& Murphy, S. A. (2009). The nature relatedness scale: Linking individuals' connection with nature to environmental concern and behavior. Environment and Behavior, 41, 715-740. http://dx.doi.org/10.1177/0013916508318748

Nisbet, E. K., Zelenski, J. M., \& Murphy, S. A. (2011). Happiness is in our nature: Exploring nature relatedness as a contributor to subjective well-being. Journal of Happiness Studies, 12, 303-322. http://dx.doi.org/10.1007/s10902-010-9197-7

Öhman, A. (2009). Of snakes and faces: An evolutionary perspective on the psychology of fear. Scandinavian Journal of Psychology, 50, 543-552. http://dx.doi.org/10.1111/j.14679450.2009.00784.x

Oswald, A. J., Proto, E., \& Sgroi, D. (in press). Happiness and productivity. Journal of Labor Economics. Retrieved from http://www2.warwick.ac.uk/fac/soc/economics/staff/academic/proto/workingpapers/happi nessproductivity.pdf

Overton, R. C. (1998). A comparison of fixed-effects and mixed (random-effects) models for meta-analysis tests of moderator variable effects. Psychological Methods, 3, 354-379. http://dx.doi.org/10.1037//1082-989X.3.3.354 
Park, H., Twenge, J. M., \& Greenfield, P. M. (2014). The Great Recession: Implications for adolescent values and behavior. Social Psychological and Personality Science, 5, 310318. http://dx.doi.org/10.1177/1948550613495419

Pearson Foundation. (2010, October 9). Animals and nature are top page-turners for children across generations, say new reader research. Retrieved from http://www.pearsonfoundation.org/pr/20101019-animals-and-nature-are-top-pageturners-for-children-across-generations-says-new-reader-research.html

Pergams, O. R. W., Czech, B., Haney, J. C., \& Nyberg, D. (2004). Linkage of conservation activity to trends in the US economy. Conservation Biology, 18, 1617-1623. http://dx.doi.org/10.1111/j.1523-1739.2004.00411.x

Pergams, O. R. W., \& Zaradic, P. A. (2006). Is love of nature in the U.S. becoming love of electronic media? 16-year downtrend in national park visits explained by watching movies, playing video games, internet use, and oil prices. Journal of Environmental Management, 80, 387-393. http://dx.doi.org/10.1016/j.jenvman.2006.02.001

Pergams, O. R. W., \& Zaradic, P. A. (2008). Evidence for a fundamental and pervasive shift away from nature-based recreation. Proceedings of the National Academy of Sciences, 105, 2295-2300. http://dx.doi.org/10.1073/pnas.0709893105

Perrin, T. (2009). The Business of Urban Animals Survey: The facts and statistics on companion animals in Canada. The Canadian Veterinary Journal, 50, 48-52.

Rand, D. G., Greene, J. D., \& Nowak, M. A. (2012). Spontaneous giving and calculated greed. Nature, 489, 427-430. http://dx.doi.org/10.1038/nature11467 
Rand, D. G., Peysakhovich, A., Kraft-Todd, G. T., Newman, G. E., Wurzbacher, O., Nowak, M. A., \& Greene, J. D. (2014). Social heuristics shape intuitive cooperation. Nature Communications, 5, 1-12. http://dx.doi.org/10.1038/ncomms4677

Reber, R., Schwarz, N., \& Winkielman, P. (2004). Processing fluency and aesthetic pleasure: Is beauty in the perceiver's processing experience? Personality and Social Psychology Review, 8, 364-382. http://dx.doi.org/10.1207/s15327957pspr0804_3

Rentfrow, P. J., \& Gosling, S. D. (2003). The do re mi's of everyday life: The structure and personality correlates of music preferences. Journal of Personality and Social Psychology, 84, 1236-1256. http://dx.doi.org/10.1037/0022-3514.84.6.1236

Richmond, V. P., \& McCroskey, J. C. (1995). Nonverbal behavior in interpersonal relations (3rd Ed.). Boston, MA: Allyn \& Bacon.

Roberts, B. W., Edmonds, G., \& Grijalva, E. (2010). It is developmental me, not generation me: Developmental changes are more important than generational changes in narcissism. Perspectives on Psychological Science, 5, 97-102. http://dx.doi.org/10.1177/1745691609357019

Roberts, B. W., Walton, K., \& Viechtbauer, W. (2006). Patterns of mean-level change in personality traits across the life course: A meta-analysis of longitudinal studies. Psychological Bulletin, 132, 1-25. http://dx.doi.org/10.1037/0033-2909.132.1.1

Rohde, C. L. E., \& Kendle, A. D. (1992). Nature for people. In A. D. Kendle, \& S. Forbes (Eds.), Urban nature conservation - landscape management in the urban countryside (pp. 319335). London, England: E \& FN Spon. 
Ryan, R. M., \& Frederick, C. M. (1997). On energy, personality and health: Subjective vitality as a dynamic reflection of well-being. Journal of Personality, 65, 529-565. http://dx.doi.org/10.1111/j.1467-6494.1997.tb00326.x

Ryan, R. M., Rigby, C. S., \& Przybylski, A. (2006). The motivational pull of video games: A self-determination theory approach. Motivation and Emotion, 30, 347-363. http://dx.doi.org/10.1007/s11031-006-9051-8

Salovey, P., Mayer, J. D., \& Rosenhan, D. L. (1991). Mood and helping: Mood as a motivator of helping and helping as a motivator of mood. In M. S. Clark (Ed.), Prosocial behavior (pp. 215-237). Thousand Oaks, CA: Sage.

Scannell, L., \& Gifford, R. (2010). The relations between natural and civic place attachment and pro-environmental behavior. Journal of Environmental Psychology, 30, 289-297. http://dx.doi.org/10.1016/j.jenvp.2010.01.010

Scannell, L., \& Gifford, R. (2013). The role of place attachment in receptivity to local and global climate change messages. Environment and Behavior, 45, 60-85. http://dx.doi.org/10.1177/0013916511421196

Schultis, J., \& More, T. (2011). American and Canadian national park agency responses to declining visitation. Journal of Leisure Research, 43, 110-132.

Schulze, R. (2007). Current methods for meta-analysis: Approaches, issues, and developments. Zeitschrift für Psychologie, 215, 90-103. http://dx.doi.org/10.1027/0044-3409.215.2.90

Scott, B. A., \& Koger, S. M. (2005, October). Psychology in the conservation curriculum. Presentation at the Society for Human Ecology meeting, Salt Lake City, UT. Seligman, M. E. P. (1970). On the generality of the laws of learning. Psychological Review, 77, 406-418. http://dx.doi.org/10.1037/h0029790 
Shariff, A. F., \& Norenzayan, A. (2007). God is watching you: Priming God concepts increases prosocial behavior in an anonymous economic game. Psychological Science, 18, 803809. http://dx.doi.org/10.1111/j.1467-9280.2007.01983.x

Sharpe, D. (1997). Of apples and oranges, file drawers and garbage: Why validity issues in metaanalysis will not go away. Clinical Psychology Review, 17, 881-901. http://dx.doi.org/10.1016/S0272-7358(97)00056-1

Skinner, A. C., \& Skelton, J. A. (2014). Prevalence and trends in obesity and severe obesity among children in the United States, 1999-2012. JAMA Pediatrics. Advanced online publication. http://dx.doi.org/10.1001/jamapediatrics.2014.21

Srivastava, S., John, O.P., Gosling, S.D., \& Potter, J. (2003). Development of personality in early and middle adulthood: Set like plaster or persistent change? Journal of Personality and Social Psychology, 84, 1041-1053. http://dx.doi.org/10.1037/0022-3514.84.5.1041

Stanley, D. J., \& Spence, J. R. (2014). Expectations for replications: Are yours realistic? Perspectives on Psychological Science, 9, 305-318. http://dx.doi.org/10.1177/1745691614528518

Steblay, N. M. (1987). Helping behavior in rural and urban environments: A meta-analysis. Psychological Bulletin, 102, 346-356. http://dx.doi.org/10.1037/0033-2909.102.3.346

Stone-Romero, E. F., \& Rosopa, P. J. (2008). The relative validity of inferences about mediation as a function of research design characteristics. Organizational Research Methods, 11, 326-352. http://dx.doi.org/10.1177/1094428107300342

Tam, K. (2013). Concepts and measures related to connection to nature: Similarities and differences. Journal of Environmental Psychology, 34, 64-78. http://dx.doi.org/10.1016/j.jenvp.2013.01.004 
Thompson, C. W., Aspinall, P., \& Montarzino, A. (2008). The childhood factor: Adult visits to green places and the significance of childhood experience. Environment and Behavior, 40, 111-143. http://dx.doi.org/10.1177/0013916507300119

Tinghög, G., Andersson, D., Bonn, C., Böttiger, H., Josephson, C., Lundgreen, G., ... Johannesson, M. (2013). Intuition and cooperation reconsidered. Nature, 498, 427-430. http://dx.doi.org/10.1038/nature12194

Trice, A. D., \& Hughes, A. M. (1995). The origins of children's career aspirations: IV. Testing hypotheses from four theories. Career Development Quarterly, 43, 307. http://dx.doi.org/10.1002/j.2161-0045.1995.tb00436.x

Twells, L. K., Gregory, D. M., Reddigan, J., \& Midodzi, W. K. (2014). Current and predicted prevalence of obesity in Canada: A trend analysis. CMAJ Open, 2, 18-26. http://dx.doi.org/10.9778/cmajo.20130016

Twenge, J. M., Baumesiter, R. F., DeWall, C. N., Ciarocco, N. J., \& Bartels, J. M. (2007). Social exclusion decreases prosocial behavior. Journal of Personality and Social Psychology, 92, 56-66. http://dx.doi.org/10.1037/0022-3514.92.1.56

Twenge, J. M., Campbell, S. M., Hoffman, B. J., \& Lance, C. E. (2010). Generational differences in work values: Leisure and extrinsic values increasing, social and intrinsic values decreasing. Journal of Management, 36, 1117-1142. http://dx.doi.org/10.1177/0149206309352246

Twenge, J. M., Konrath, S., Foster, J. D., Campbell, W. K., \& Bushman, B. (2008). Egos inflating over time: A cross-temporal meta-analysis of the Narcissistic Personality Inventory. Journal of Personality, 76, 875-903. http://dx.doi.org/10.1111/j.14676494.2008.00507.x 
Ulrich, R. S. (1984). View through a window may influence recovery from surgery. Science, 224, 420-421. http://dx.doi.org/10.1126/science.6143402

United Nations Population Division. (2011). World Urbanization Prospects, the 2011 Revision. New York, NY: United Nations Population Division. Retrieved from http://esa.un.org/unup/pdf/WUP2011_Highlights.pdf

van der Wal, A. J., Schade, H. M., Krabbendam, L., \& van Vugt, M. (2013). Do natural landscapes reduce future discounting in humans? Proceedings of the Royal Society B: Biological Sciences, 280, 1-6. http://dx.doi.org/10.1098/rspb.2013.2295

Van Lange, P. A., Bekkers, R., Schuyt, T. N. M., \& Van Vugt, M. (2009). From games to giving: Social value orientation predicts donations to noble causes. Basic and Applied Social Psychology, 29, 375-384. http://dx.doi.org/10.1080/01973530701665223

Van Lange, P. A., Otten, W., De Bruin, E. M., \& Joireman, J. A. (1997). Development of prosocial, individualistic, and competitive orientations: Theory and preliminary evidence. Journal of Personality and Social Psychology, 73, 733-746. http://dx.doi.org/10.1037//0022-3514.73.4.733

Verkoeijen, P. P. J. L., \& Bouwmeester, S. (2014). Does intuition cause cooperation? PLOS ONE, 9, 1-8. http://dx.doi.org/10.1126/10.1371/journal.pone.0096654

Vohs, K. D., Baumeister, R. F., Schmeichel, B. J., Twenge, J. M., Nelson, N. M., \& Tice, D. M. (2008). Making choices impairs subsequent self-control: A limited-resource account of decision making, self-regulation, and active initiative. Journal of Personality and Social Psychology, 94, 883-898. http://dx.doi.org/10.1037/0022-3514.94.5.883

Vohs, K. D., \& Heatherton, T. F. (2000). Self-regulatory failure: A resource-depletion approach. Psychological Science, 11, 249-254. http://dx.doi.org/10.1111/1467-9280.00250 
Vohs, K. D., Mead, N. L., \& Goode, M. R. (2006). The psychological consequences of money. Science, 314, 1154-1156. http://dx.doi.org/10.1126/science.1132491

Watson, D., Clark, L. A., \& Tellegen, A. (1988). Development and validation of brief measures of positive and negative affect: The PANAS scales. Journal of Personality and Social Psychology, 54(6), 1063-1070.

Weinstein, N., Przybylski, A. K., \& Ryan, R. M. (2009). Can mature make us more caring? Effects of immersion in nature on intrinsic aspirations and generosity. Personality and Social Psychology Bulletin, 35, 1315-1329. http://dx.doi.org/10.1177/0146167209341649

White, M. P., Alcock, I., Wheeler, B. W., \& Depledge, M. H. (2013). Would you be happier living in a greener urban area? A fixed-effects analysis of panel data. Psychological Science, 24, 920-928. http://dx.doi.org/10.1177/0956797612464659

Wiessner, P. (1996). Leveling the hunter: Constraints on the status quest in foraging societies. In P. Wiessner \& W. Schiefenhövel (Eds.), Food and the status quest (pp. 171-191). Oxford, UK: Berghahn Books.

Wilson, D. S., O’Brien, D. T., \& Sesma, A. (2009). Human prosociality from an evolutionary perspective: Variation and correlations at a city-wide scale. Evolution and Human Behavior, 30, 190-200. http://dx.doi.org/10.1016/j.evolhumbehav.2008.12.002

Wilson, E. O. (1984). Biophilia. Cambridge, MA: Harvard University Press.

Witman, J. P. (1987). The efficacy of adventure programming in the development of cooperation and trust with adolescents in treatment. Therapeutic Recreation Journal, 21, 22-29.

Xu, H., Bègue, L., \& Bushman, B. J. (2012). Too fatigued to care: Ego depletion, guilt, and prosocial behavior. Journal of Experimental Social Psychology, 48, 1183-1186. http://dx.doi.org/10.1016/j.jesp.2012.03.007 
Zaki, J., \& Mitchell, J. P. (2013). Intuitive prosociality. Current Directions in Psychological Science, 22, 466-470. http://dx.doi.org/10.1177/0963721413492764

Zhang, J. W., Piff, P. K., Iyer, R., Koleva, S., \& Keltner, D. (2014). An occasion for unselfing: Beautiful nature leads to prosociality. Journal of Environmental Psychology, 37, 61-72. http://dx.doi.org/10.1016/j.jenvp.2013.11.008 


\section{Appendix A: \\ Nature Relatedness Scale \& IPIP Representation of Five NEO Domains}

[Note: Items were presented in a randomized order. Items 1-21 are from the Nature Relatedness Scale. Items 22-121 are from the IPIP.]

Instructions: For each of the characteristics listed below, rate how descriptive each characteristic is of you.

\begin{tabular}{|c|c|c|c|c|}
\hline $\begin{array}{c}1 \\
\text { Disagree } \\
\text { strongly }\end{array}$ & $\begin{array}{c}2 \\
\text { Disagree a little }\end{array}$ & $\begin{array}{c}3 \\
\text { Neither agree or } \\
\text { disagree }\end{array}$ & $\begin{array}{c}4 \\
\text { Agree a little }\end{array}$ & $\begin{array}{c}5 \\
\text { Agree strongly }\end{array}$ \\
\hline
\end{tabular}

I see myself as someone who/whose...

1. Enjoys being outdoors, even in unpleasant weather.

2. Believes some species are just meant to die out or become extinct.

3. Believes humans have the right to use natural resources any way we want.

4. Ideal vacation spot would be a remote, wilderness area.

5. Always think about how my actions affect the environment.

6. Enjoys digging in the earth and getting dirt on my hands.

7. Connection to nature and the environment is a part of my spirituality.

8. Is very aware of environmental issues.

9. Takes notice of wildlife wherever I am.

10. Doesn't often go out in nature.

11. Believes nothing I do will change problems in other places on the planet.

12. Believes that I am not separate from nature, but a part of nature.

13. Finds the thought of being deep in the woods, away from civilization, is frightening.

14. Feelings about nature do not affect how I live my life.

15. Believes animals, birds and plants should have fewer rights than humans.

16. Notices nature around me, even in the middle of the city.

17. Relationship to nature is an important part of who I am.

18. Believes conservation is unnecessary because nature is strong enough to recover from any human impact.

19. Believes the state of non-human species is an indicator of the future for humans.

20. Thinks a lot about the suffering of animals.

21. Feels very connected to all living things and the earth.

22. Feels comfortable around people.

23. Makes friends easily.

24. Is skilled in handling social situations.

25. Is the life of the party.

26. Knows how to captivate people.

27. Starts conversations.

28. Warms up quickly to others.

29. Talks to a lot of different people at parties.

30. Doesn't mind being the center of attention. 
31. Cheers people up.

32. Has little to say.

33. Keeps in the background.

34. Would describe my experiences as somewhat dull.

35. Doesn't like to draw attention to myself.

36. Doesn't talk a lot.

37. Avoids contacts with others.

38. Is hard to get to know.

39. Retreats from others.

40. Finds it difficult to approach others.

41. Keeps others at a distance.

42. Believes in the importance of art.

43. Has a vivid imagination.

44. Tends to vote for liberal political candidates.

45. Carries the conversation to a higher level.

46. Enjoys hearing new ideas.

47. Enjoys thinking about things.

48. Can say things beautifully.

49. Enjoys wild flights of fantasy.

50. Gets excited by new ideas.

51. Has a rich vocabulary.

52. Is not interested in abstract ideas.

53. Does not like art.

54. Avoids philosophical discussions.

55. Does not enjoy going to art museums.

56. Tends to vote for conservative political candidates.

57. Does not like poetry.

58. Rarely looks for a deeper meaning in things.

59. Believes that too much tax money goes to support artists.

60. Is not interested in theoretical discussions.

61. Has difficulty understanding abstract ideas.

62. Has a good word for everyone.

63. Believes that others have good intentions.

64. Respects others.

65. Accepts people as they are.

66. Makes people feel at ease.

67. Is concerned about others.

68. Trusts what people say.

69. Sympathizes with others' feelings.

70. Is easy to satisfy.

71. Treats all people equally.

72. Has a sharp tongue.

73. Cuts others to pieces.

74. Suspects hidden motives in others.

75. Gets back at others.

76. Insults people. 
77. Believes that I am better than others.

78. Contradicts others.

79. Makes demands on others.

80. Holds a grudge.

81. Is out for my own personal gain.

82. Is always prepared.

83. Pays attention to details.

84. Gets chores done right away.

85. Carries out my plans.

86. Makes plans and sticks to them.

87. Completes tasks successfully.

88. Does things according to a plan.

89. Is exacting in my work.

90. Finishes what I start.

91. Follows through with my plans.

92. Wastes my time.

93. Finds it difficult to get down to work.

94. Does just enough work to get by.

95. Doesn't see things through.

96. Shirks my duties.

97. Messes things up.

98. Leaves things unfinished.

99. Doesn't put my mind on the task at hand.

100. Makes a mess of things.

101. Needs a push to get started.

102. Often feels blue.

103. Dislikes myself.

104. Is often down in the dumps.

105. Has frequent mood swings.

106. Panics easily.

107. Is filled with doubts about things.

108. Feels threatened easily.

109. Gets stressed out easily.

110. Fears for the worst.

111. Worries about things.

112. Seldom feels blue.

113. Feels comfortable with myself.

114. Rarely gets irritated.

115. Is not easily bothered by things.

116. Is very pleased with myself.

117. Is relaxed most of the time.

118. Seldom gets mad.

119. Is not easily frustrated.

120. Remains calm under pressure.

121. Rarely loses my composure. 


\section{Appendix B: \\ Positive and Negative Affect Schedule (PANAS) \& Vitality Scale}

[Note: Items were presented in a randomized order. Items 1-20 are from the PANAS. Items 2126 are from the Vitality Scale.]

Instructions: Below is a scale which consists of a number of words that describe different feelings and emotions. Read each item and then indicate to what extent you feel this way right now.

\begin{tabular}{|c|c|c|c|c|}
\hline $\begin{array}{c}\text { Very slightly or } \\
\text { not at all }\end{array}$ & A little & $\begin{array}{c}3 \\
\text { Moderately }\end{array}$ & $\begin{array}{c}4 \\
\text { Quite a bit }\end{array}$ & $\begin{array}{c}5 \\
\text { Extremely }\end{array}$ \\
\hline
\end{tabular}

1. Interested

2. Distressed

3. Excited

4. Upset

5. Strong

6. Guilty

7. Scared

8. Hostile

9. Enthusiastic

10. Proud

11. Irritable

12. Alert

13. Ashamed

14. Inspired

15. Nervous

16. Determined

17. Attentive

18. Jittery

19. Active

20. Afraid

21. Alive and vital

22. So alive I want to burst

23. Full of energy and spirit

24. Looking forward to each new day

25. Alert and awake

26. Energized 


\section{Appendix C: \\ Inclusion of Nature in Self Scale (INS)}

[Note: Items were presented in a randomized order. The last two items were created and included in an attempt to mask the research interest of Study 1.]

Instructions: Please select the picture below which best describes your relationship with the natural environment at this moment. How interconnected are you with nature right now?
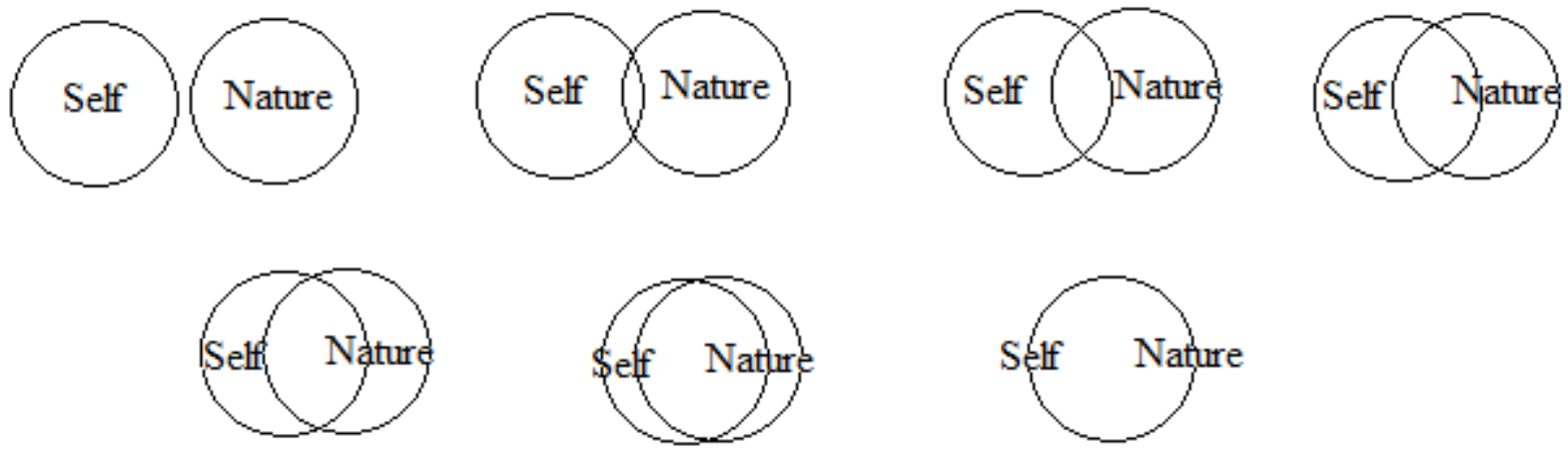

Please select the picture below which best describes your relationship with your family at this moment. How interconnected are you with your family right now?
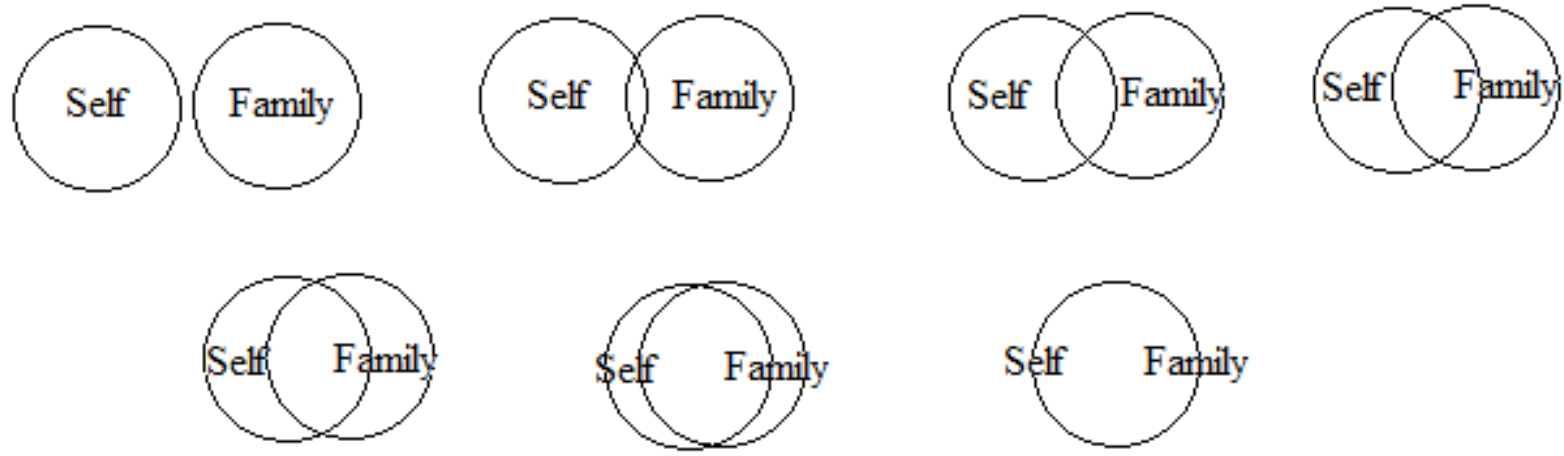

Please select the picture below which best describes your relationship with society at this moment. How interconnected are you with society right now?
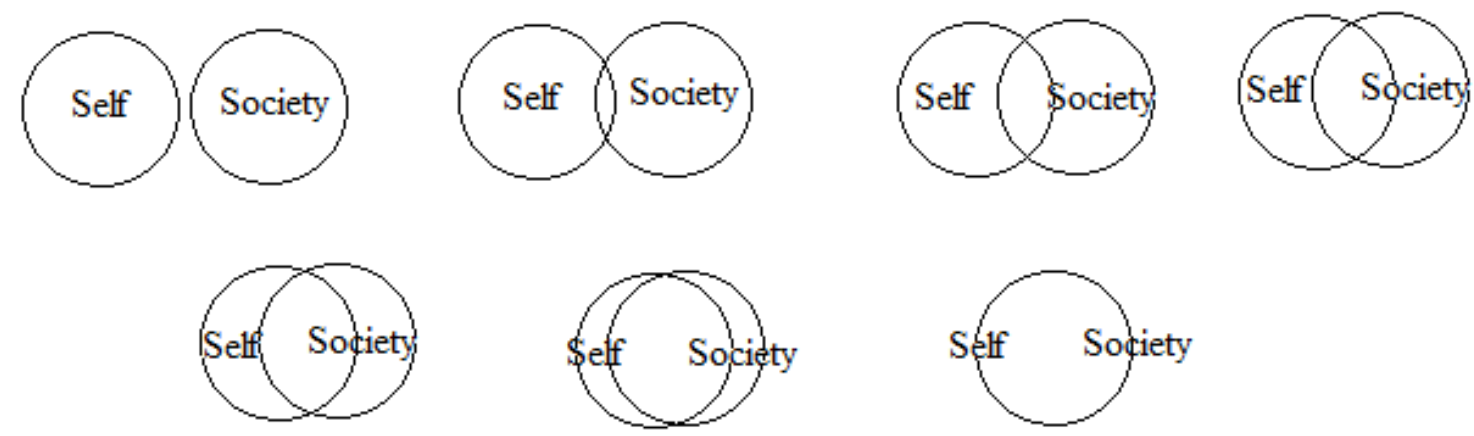


\section{Appendix D: \\ Social Value Orientation Slider Measure (SVO)}

Instructions: In this hypothetical task imagine that you have been randomly paired with another person, whom we will refer to as other. You will be making a series of decisions about allocating resources between you and this other person. For each of the following questions, please indicate the distribution you prefer most by clicking your mouse in the respective position along the midline. Please only make one mark for each question.

Imagine your decisions would yield money for both yourself and the other person. In the example below, a person has chosen to distribute money so that he/she receives 50 dollars, while the anonymous other person receives 40 dollars.

There are no right or wrong answers, this is all about personal preferences. As you can see, your choice would influence both the amount of money you receive as well as the amount of money the other receives.

\begin{tabular}{|c|c|c|c|c|c|c|c|c|c|}
\hline 8 & \multicolumn{9}{|c|}{ Example: } \\
\hline You tecoive & 30 & 35 & 40 & 45 & 50 & 55 & $\omega 0$ & 65 & 70 \\
\hline Other receives & 80 & 70 & 60 & 50 & 40 & 30 & 20 & 10 & 0 \\
\hline
\end{tabular}

In the example above, you would get 50 dollars and the other person would receive 40 dollars.

Please indicate the distribution you prefer most by clicking your mouse in the respective position along the midline. Please only make one mark.
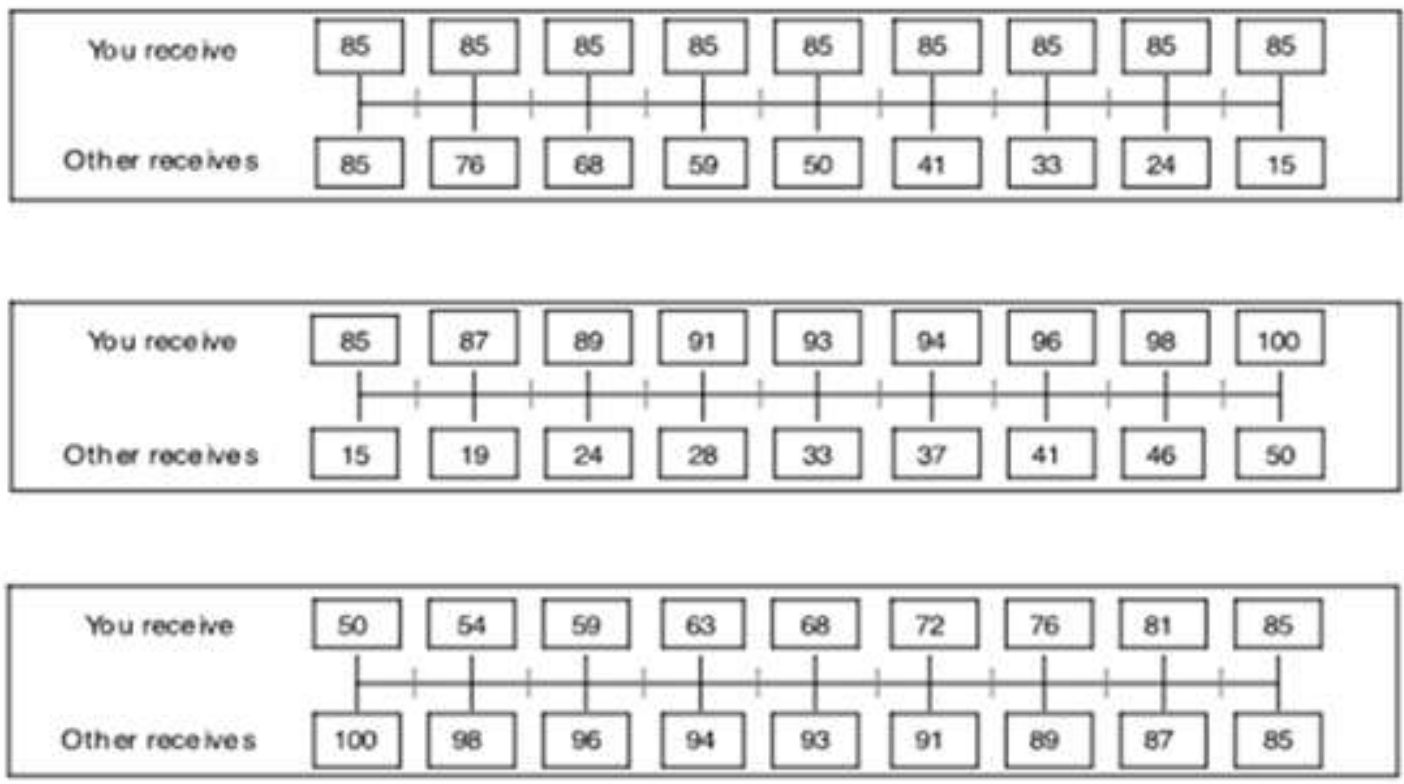


\begin{tabular}{|ll|l|l|l|l|l|l|l|l|l|l|l|l|l|}
\hline You rocolive & 50 & 54 & 59 & 63 & 68 & 72 & 76 & 81 & $\mid 85$ \\
\hline
\end{tabular}

\begin{tabular}{|c|c|c|c|c|c|c|c|c|c|}
\hline You recetvo & 100 & 94 & 88 & 81 & 75 & 69 & 63 & 56 & 50 \\
\hline Other receives & 50 & 56 & 63 & 69 & 75 & 81 & 88 & 94 & 100 \\
\hline
\end{tabular}

\begin{tabular}{|c|c|c|c|c|c|c|c|c|c|}
\hline You receive & 100 & 98 & 96 & 94 & 93 & 91 & 89 & 87 & 85 \\
\hline Other recenes & 50 & 54 & 59 & 63 & 68 & 72 & 76 & 81 & 85 \\
\hline
\end{tabular}




\section{Appendix E: \\ Willingness to Perform Sustainable Behaviours (WPSB)}

[Note: Items were presented in a randomized order.]

Instructions: Below are several examples of behaviours that are environmentally friendly. Please rate each one on how willing you are to perform these.

\begin{tabular}{|c|c|c|c|c|c|c|}
\hline 1 & 2 & 3 & 4 & 5 & 6 & 7 \\
$\begin{array}{c}\text { Extremely } \\
\text { unwilling }\end{array}$ & $\begin{array}{c}\text { Moderately } \\
\text { unwilling }\end{array}$ & $\begin{array}{c}\text { Slightly } \\
\text { unwilling }\end{array}$ & $\begin{array}{c}\text { Neutral/ } \\
\text { Unsure }\end{array}$ & $\begin{array}{c}\text { Slightly } \\
\text { willing }\end{array}$ & $\begin{array}{c}\text { Moderately } \\
\text { willing }\end{array}$ & $\begin{array}{c}\text { Extremely } \\
\text { willing }\end{array}$ \\
\hline
\end{tabular}

1. Avoid sudden starts and stops when driving a car.

2. Combine car trips to reduce the distance traveled.

3. Reduce highway speeds from $100 \mathrm{~km} / \mathrm{h}$ to $70 \mathrm{~km} / \mathrm{h}$.

4. Carpool with family, friends, or coworkers.

5. Ride a bicycle or moped.

6. Use public transportation, such as buses or trains.

7. Replace existing incandescent light bulbs with compact fluorescent bulbs.

8. Reduce the amount of electric lighting used in non-essential areas.

9. Reduce the time spent using electronics (televisions, stereos, computers).

10. Unplug electronics or appliances with lights or clocks when not in use.

11. Reduce the amount of warm and hot water used.

12. Adjust the thermostat to 20 degrees Celsius or lower in the winter.

13. Sign a petition asking the university to get more energy from renewable sources (wind or solar power).

14. Attend a peaceful student demonstration promoting awareness of climate change.

15. Put a button on my backpack to support reducing climate change.

16. Contact politicians to urge them to support policies that reduce climate change.

17. Vote against politicians who do not support policies that reduce climate change.

18. Stop purchasing from companies that oppose policies to reduce climate change.

19. Support a $\$ 50$ per year federal tax increase to support research to reduce climate change.

20. Support a $\$ 20$ per month electricity tax to promote conservation and energy-efficient construction and remodeling. 
21. Support a $\$ 400$ per year property tax on residences that do not meet higher energyefficiency standards to promote energy-efficient construction and remodeling.

22. Support a $\$ 600$ tax on vehicle purchases that do not meet higher fuel-efficiency standards to promote fuel-efficient vehicle purchases.

23. Support a $10 \notin$ per litre gasoline tax to promote conservation and fuel-efficient vehicle purchases.

24. Support a $2 \notin$ per $\mathrm{km}$ pollution tax to promote less driving each year.

25. Support a regulation requiring new buildings to meet higher energy-efficiency standards.

26. Support a regulation requiring automakers to meet higher emissions standards.

27. Support a regulation requiring energy companies to generate at least $25 \%$ of their electricity from renewable sources (wind or solar power).

28. Support a policy transferring federal energy subsidies from the fossil fuel industry to renewable energy industry.

29. Support a regulation limiting the amount of greenhouse gases that companies (power plants and factories) can produce each year without paying penalties.

30. Support a regulation creating a national "cap-and-trade" system. This system limits the amount of greenhouse gas emissions that all companies (power plants and factories) can produce each year. It requires companies to buy and sell permits to produce a portion of the total emissions without penalties. 


\section{Appendix F: Mood Booster}

[Scenario 1]

Instructions: Please read the following paragraph and imagine yourself in this scenario.

You have just spent a wonderful evening with a friend in whom you have had a growing romantic interest. You are sharing drinks in their apartment when they begin to hint that they are romantically interested in you as well. Your palms become sweaty and your heart begins to beat faster as you consider telling them how you feel. Your heart leaps when they confess that they would love to go out with you. You are ecstatic as they lean over and give you a long intimate embrace.

\section{[Scenario 2]}

Instructions: Please read the following paragraph and imagine yourself in this scenario.

Your hands tremble in anticipation as you hold the envelope. The return address indicates it is from the number one employer in your field - the place you most wanted to be. You felt the interviews had gone very well, and that it would be an excellent position for you. You rip open the envelope and discover that they have offered you the job! Your insides feel like they are going to burst. You are trembling with excitement and you want to scream "yea" and run out and tell the world. 


\section{Appendix G: \\ Nature Relatedness Scale (Short-Form)}

Instructions: For each of the following, please rate the extent to which you agree with each statement, using the scale from 1 to 5 as shown below. Please respond as you really feel, rather than how you think "most people" feel.

\begin{tabular}{|c|c|c|c|c|}
\hline $\begin{array}{c}1 \\
\text { Disagree } \\
\text { strongly }\end{array}$ & $\mathbf{2}$ & $\mathbf{3}$ & $\mathbf{4}$ & $\mathbf{5}$ \\
Disagree a little & $\begin{array}{c}\text { Neither agree or } \\
\text { disagree }\end{array}$ & Agree a little & Agree strongly \\
\hline
\end{tabular}

1. My ideal vacation spot would be a remote, wilderness area.

2. I always think about how my actions affect the environment.

3. My connection to nature and the environment is a part of my spirituality.

4. I take notice of wildlife wherever I am.

5. My relationship to nature is an important part of who I am.

6. I feel very connected to all living things and the earth. 


\section{Appendix H: \\ Video Impressions Questionnaire}

[Note: Items were presented in a randomized order. Item 11 was excluded from this questionnaire in Study 2.]

Instructions: Please indicate how well each of the adjectives below describe the video you just watched using the following scale.

\begin{tabular}{|c|c|c|c|c|}
\hline $\mathbf{1}$ & $\mathbf{2}$ & $\mathbf{3}$ & $\mathbf{4}$ & $\mathbf{5}$ \\
Not at all & A little & Moderately & Quite a bit & Extremely \\
\hline
\end{tabular}

1. Pleasant

2. Interesting

3. Impressive

4. Thought provoking

5. Inspiring

6. Exciting

7. Relaxing

8. Vibrant

9. Colourful

10. Repetitive

11. Immersive

12. Familiar

13. Attractive

14. Distressing

15. Upsetting

16. Boring

17. Irritating

18. How would you rate the quality of the video you just watched?

\begin{tabular}{|c|c|c|c|c|}
\hline 1 & 2 & 3 & 4 & 5 \\
Low quality & - & - & - & High quality \\
\hline
\end{tabular}




\section{Appendix I: \\ Player Experience of Need Satisfaction Physical Presence Scale (Modified)}

[Note: Items were presented in a randomized order.]

Instructions: Below are various statements concerning your experience while viewing the photographs in the previous part of the study. Please read each item and indicate to what extent you felt this way when you were watching the video.

\begin{tabular}{|c|c|c|c|c|}
\hline $\mathbf{1}$ & $\mathbf{2}$ & $\mathbf{3}$ & $\mathbf{4}$ & $\mathbf{5}$ \\
Not at all & Slightly & Moderately & Quite a bit & Very much \\
\hline
\end{tabular}

1. All my senses were engaged.

2. I felt that I was in the places I saw.

3. The visual aspects of the environments involved me.

4. I was immersed in the environments.

5. I reacted to the environments as if they were real.

6. I felt transported to another place.

7. I was not immersed in the places I saw.

8. The experience I had viewing the photographs resembled experiences I have had in real life. 


\section{Appendix J:}

\section{PANAS \& Fascination}

[Note: Items were presented in a randomized order. Items 1-20 were from the PANAS. Items 2123 measure fascination.]

Instructions: Below is a scale which consists of a number of words that describe different feelings and emotions. Read each item and then indicate to what extent you feel this way right now.

\begin{tabular}{|c|c|c|c|c|}
\hline $\begin{array}{c}\text { Very slightly or } \\
\text { not at all }\end{array}$ & A little & $\begin{array}{c}3 \\
\text { Moderately }\end{array}$ & $\begin{array}{c}4 \\
\text { Quite a bit }\end{array}$ & Extremely \\
\hline
\end{tabular}

1. Interested

2. Distressed

3. Excited

4. Upset

5. Strong

6. Guilty

7. Scared

8. Hostile

9. Enthusiastic

10. Proud

11. Irritable

12. Alert

13. Ashamed

14. Inspired

15. Nervous

16. Determined

17. Attentive

18. Jittery

19. Active

20. Afraid

21. Curious

22. In awe

23. Fascinated 


\section{Appendix K: \\ Prosocial Measure}

You have now completed the study you originally volunteered to participate in.

At this point, we would like for you to consider whether you would be willing to help out another graduate student in our lab by filling out some additional questionnaires. Your involvement is voluntary and you will be asked after filling out each of the questionnaires whether you would like to complete another. Each questionnaire should only take a couple minutes to complete. Thanks in advance for your help if you decide to provide it.

Are you willing to complete another questionnaire?

Yes

No 


\section{Appendix L: \\ Additional Questionnaire \#1 \\ Curiosity and Exploration Inventory (CEI-II)}

Instructions: Rate the statements below for how accurately they reflect the way you generally feel and behave. Do not rate what you think you should do, or wish you do, or things you no longer do. Please be as honest as possible.

\begin{tabular}{|c|c|c|c|c|}
\hline 1 & 2 & 3 & 4 & 5 \\
$\begin{array}{c}\text { Very slightly or } \\
\text { not at all }\end{array}$ & A little & Moderately & Quite a bit & Extremely \\
\hline
\end{tabular}

1. I actively seek as much information as I can in new situations.

2. I am the type of person who really enjoys the uncertainty of everyday life.

3. I am at my best when doing something that is complex or challenging.

4. Everywhere I go, I am out looking for new things or experiences.

5. I view challenging situations as an opportunity to grow and learn.

6. I like to do things that are a little frightening.

7. I am always looking for experiences that challenge how I think about myself and the world.

8. I prefer jobs that are excitingly unpredictable.

9. I frequently seek out opportunities to challenge myself and grow as a person.

10. I am the kind of person who embraces unfamiliar people, events, and places.

Are you willing to complete another questionnaire? Your participation is entirely voluntary and you can quit at any moment.

Yes

No 


\section{Appendix M: \\ Additional Questionnaire \#2 \\ Emotion Regulation Questionnaire (ERQ)}

Instructions: We would like to ask you some questions about your emotional life, in particular, how you control (that is, regulate and manage) your emotions. The questions below involve two distinct aspects of your emotional life. One is your emotional experience, or what you feel like inside. The other is your emotional expression, or how you show your emotions in the way you talk, gesture, or behave. Although some of the following questions may seem similar to one another, they differ in important ways. For each item, please answer using the scale below.

\begin{tabular}{|c|c|c|c|c|c|c|}
\hline $\begin{array}{c}1 \\
\text { Disagree } \\
\text { strongly }\end{array}$ & $\begin{array}{c}\mathbf{2} \\
\text { Disagree } \\
\text { moderately }\end{array}$ & $\begin{array}{c}\mathbf{3} \\
\text { Disagree a } \\
\text { little }\end{array}$ & $\begin{array}{c}4 \\
\text { Neither } \\
\text { agree nor } \\
\text { disagree }\end{array}$ & $\begin{array}{c}\mathbf{5} \\
\text { Agree a } \\
\text { little }\end{array}$ & $\begin{array}{c}\mathbf{6} \\
\text { Agree } \\
\text { moderately }\end{array}$ & $\begin{array}{c}7 \\
\text { Agree } \\
\text { strongly }\end{array}$ \\
\hline
\end{tabular}

1. When I want to feel more positive emotion (such as joy or amusement), I change what I'm thinking about.

2. I keep my emotions to myself.

3. When I want to feel less negative emotion (such as sadness or anger), I change what I'm thinking about.

4. When I am feeling positive emotions, I am careful not to express them.

5. When I'm faced with a stressful situation, I make myself think about it in a way that helps me stay calm.

6. I control my emotions by not expressing them.

7. When I want to feel more positive emotion, I change the way I'm thinking about the situation.

8. I control my emotions by changing the way I think about the situation I'm in.

9. When I am feeling negative emotions, I make sure not to express them.

10. When I want to feel less negative emotion, I change the way I'm thinking about the situation.

Are you willing to complete another questionnaire? Your participation is entirely voluntary and you can quit at any moment.

Yes

No 


\section{Appendix N: \\ Additional Questionnaire \#3 \\ Short Test Of Music Preferences (STOMP)}

Instructions: For the following items, please indicate your basic preference level for the genres listed using the scale provided.

\begin{tabular}{|c|c|c|c|c|c|c|}
\hline $\mathbf{1}$ & $\mathbf{2}$ & $\mathbf{3}$ & $\mathbf{4}$ & $\mathbf{5}$ \\
$\begin{array}{c}\text { Strongly } \\
\text { dislike }\end{array}$ & Dislike & $\begin{array}{c}\text { Somewhat } \\
\text { dislike }\end{array}$ & $\begin{array}{c}\text { Neither } \\
\text { like nor } \\
\text { dislike }\end{array}$ & $\begin{array}{c}\text { Somewhat } \\
\text { like }\end{array}$ & $\begin{array}{c}\mathbf{6} \\
\text { Like }\end{array}$ & $\begin{array}{c}\text { Strongly } \\
\text { like }\end{array}$ \\
\hline
\end{tabular}

1. Classical

2. Blues

3. Country

4. Dance/Electronica

5. Folk

6. Rap/hip-hop

7. Soul/funk

8. Religious

9. Alternative

10. Jazz

11. Rock

12. Pop

13. Heavy Metal

14. Soundtracks/theme songs

Are you willing to complete another questionnaire? Your participation is entirely voluntary and you can quit at any moment.

Yes

No 


\section{Appendix 0: \\ Additional Questionnaire \#4 \\ Ten-Item Personality Inventory (TIPI)}

Instructions: Here are a number of personality traits that may or may not apply to you. Next to each statement, please indicate the extent to which you agree or disagree with that statement. You should rate the extent to which the pair of traits applies to you, even if one characteristic applies more strongly than the other.

\begin{tabular}{|c|c|c|c|c|c|c|}
\hline $\begin{array}{c}1 \\
\text { Disagree } \\
\text { strongly }\end{array}$ & $\begin{array}{c}\mathbf{2} \\
\text { Disagree } \\
\text { moderately }\end{array}$ & $\begin{array}{c}\mathbf{3} \\
\text { Disagree a } \\
\text { little }\end{array}$ & $\begin{array}{c}\text { Neither } \\
\text { agree nor } \\
\text { disagree }\end{array}$ & $\begin{array}{c}\text { Agree a } \\
\text { little }\end{array}$ & $\begin{array}{c}\text { 6 } \\
\text { Agree } \\
\text { moderately }\end{array}$ & $\begin{array}{c}\text { Agree } \\
\text { strongly }\end{array}$ \\
\hline
\end{tabular}

I see myself as:

1. Extraverted, enthusiastic.

2. Critical, quarrelsome.

3. Dependable, self-disciplined.

4. Anxious, easily upset.

5. Open to new experiences, complex.

6. Reserved, quiet.

7. Sympathetic, warm.

8. Disorganized, careless.

9. Calm, emotionally stable.

10. Conventional, uncreative.

Are you willing to complete another questionnaire? Your participation is entirely voluntary and you can quit at any moment.

Yes

No 


\section{Appendix P: \\ Additional Questionnaire \#5 \\ Time of Day Scale}

Instructions: Below are a series of 16 statements concerning peoples' time orientations. Indicate the degree to which each of these statements apply to you using the scale below.

\begin{tabular}{|c|c|c|c|c|}
\hline $\begin{array}{c}\text { Strongly } \\
\text { disagree }\end{array}$ & $\begin{array}{c}2 \\
\text { Disagree }\end{array}$ & $\begin{array}{c}\text { 3 } \\
\text { Neutral or } \\
\text { undecided }\end{array}$ & $\begin{array}{c}4 \\
\text { Agree }\end{array}$ & $\begin{array}{c}\mathbf{5} \\
\text { Strongly } \\
\text { agree }\end{array}$ \\
\hline
\end{tabular}

1. I really dislike getting up in the mornings.

2. I like taking afternoon classes

3. I prefer morning classes.

4. I am at my worst in the mornings.

5. I really like getting up in the mornings.

6. I dislike taking afternoon classes.

7. I am very irritable in the morning.

8. I am very alert in the afternoons.

9. I am very irritable in the afternoons.

10 . I am very alert in the mornings.

11. I rarely do well on tests in morning classes.

12. I usually do very well on tests in afternoon classes.

13. I usually do very well on tests in morning classes.

14. I rarely do well on tests in afternoon classes.

15. I like to do my studying late at night.

16. I like to do my studying early in the day.

Are you willing to complete another questionnaire? Your participation is entirely voluntary and you can quit at any moment.

Yes

No 


\section{Appendix Q: Sustainability Measure}

In support of Carleton University's efforts toward a more sustainable and greener campus, we have decided to provide a list of eco-tips at the end of all our studies. This is being done in order to increase awareness among Carleton students about the ways in which they can be more sustainable. Your reading of these eco-tips is completely voluntary and you can read as much or as little as you want. If you have no interest or once you are finished, please click on the next button at the bottom of the page to be taken to the debriefing form.

\section{Eco-Tips}

There are many ways to take action on protecting and preserving our natural environment. It is important to recognize that every effort counts, big or small. Getting involved is the first step towards protecting the diversity of life on Earth. Many of the tips below will help protect our environment and save you money too!

\section{Earth}

- Trees are essential to the planet and to humans. Plant a tree and reap the many benefits!

- Get a green bin and start collecting organic waste.

- Avoid waste by using reusable cloths and rags instead of paper towels to clean.

- Instead of using chemicals and paper towels to wash your windows, try $125 \mathrm{ml}$ vinegar ( $1 / 2$ cup) and $1 \mathrm{~L}$ water ( 4 cups) and a squeegee.

- If space is limited, try growing organic vegetables in containers or window boxes.

- Have a garage sale to help recycle your unwanted items. Someone's trash is another's treasure.

- Just because you throw something away does not mean that it is gone for good. You have only just moved it to a landfill. So instead of throwing something in the garbage, recycle it instead! Old homework papers, cardboard and newspapers are examples of things you can easily recycle.

- Donate electronic equipment to specific recycling groups or recycle them. This will help reduce pressure on landfills.

- When buying wooden fencing and garden furniture, consider whether the wood is from a well-managed forest. Deforestation is a serious problem in some areas of the world, leading to loss of topsoil and flooding, among other problems.

- When boating, avoid stirring up bottom sediment with propellers. Keep personal watercraft out of shallow areas that are critical habitat for spawning fish, aquatic plants and aquatic invertebrates.

\section{Energy}

- Your appliances need a tune-up too; clean all filters and coils.

- When replacing hard-to-reach light bulbs, such as exterior porch lights, switch to energy efficient compact fluorescent bulbs. You will not have to change them for up to seven years!

- Use your window coverings to help warm or cool your house. 
- Make your home more energy-efficient through improved insulation, caulking and weather-stripping. The less energy you use, the less impact you have on the environment.

- Install and use a programmable thermostat. For every $1^{\circ} \mathrm{C}$ you lower your thermostat, you can save $2 \%$ on your heating bill. A reduction of $3^{\circ} \mathrm{C}$ at night and when you are away during the day provides optimal savings and can reduce your greenhouse gas emissions by half a tonne.

- When buying a new appliance, choose an energy-efficient one.

- Energy efficiency can be practiced at home, at school and during recreational activities in fact, practically anywhere and anytime in our day-to-day activities. This may be as simple as turning off the lights when leaving a room, or bicycling to school instead of getting a ride. Encouraging energy efficiency reduces the use of fossil fuels, thus reducing emissions of harmful pollutants into the Earth's atmosphere.

\section{Air}

- Use potpourri instead of aerosol-based sprays.

- Compost your leaves and brush. Burning them will increase carbon dioxide emissions.

- Buy a push lawn mower. It is good exercise and reduces carbon dioxide emissions.

- Do not blow your leaves - rake them instead. Your ears and your neighbours will thank you, and you will reduce carbon dioxide emissions.

- Make sure your car is properly tuned up and your tires are at the right pressure to ensure optimal fuel efficiency.

- Encourage carpooling when possible! Put a map up in the office to encourage carpooling and make it easier for riders to connect.

\section{Water}

- Use a broom rather than a water hose to clean walkways, driveways and sidewalks.

- Collect and use your rainwater for your lawn and plants. It is free and better for your plants.

- Avoid cleaners containing phosphates. When they get into rivers and lakes they cause algae blooms, robbing the water of oxygen and ultimately killing aquatic life.

- Fix that leaking hose and dripping nozzle. It will help keep your shoes and shirt dry and save water.

- Keep the septic system working smoothly! Pour $250 \mathrm{~mL}$ baking soda down any toilet or drain once a week. Baking soda creates a favourable $\mathrm{pH}$ environment for optimal bacterial action.

- Install water-saving showerheads.

- Do not run the water running when you brush your teeth, shave, wash dishes or clean vegetables. 


\section{Appendix R: Coding Manual for Meta-Analyses}

As the purpose of these meta-analyses was to investigate a difference between two groups, Cohen's $d$ was used as the primary effect size (Kenny, 1987). Following conventions, a $d$ of . 2 was considered small, a $d$ of .5 was considered medium, and a $d$ of . 8 was considered large (Cohen, 1977). If Cohen's $d$ was not reported in the original source, the results that were available (e.g., correlation coefficients) were converted into their equivalent standardized mean difference using the appropriate effect size transformation formula (Cohen, 1988). If prosociality/sustainability was assessed using more than measure, a weighted average of the effect sizes was calculated. Furthermore, effect sizes were consistently coded so that positive values indicated greater prosociality/sustainability in the nature condition and negative values indicated greater prosociality/sustainability in the built/non-nature condition. If the number of participants in each condition were not explicitly reported, the total sample size was presumed to be split evenly between conditions.

When samples contained more than two conditions (e.g., nature, built, and control conditions in Dopko, 2013), only the differences in prosociality/sustainability between the nature and built condition were included. This comparison was chosen over nature versus control because it was the overwhelmingly most common comparison in the literature and, thus, reduced commensurability. Nevertheless, a limited amount of results seem to suggest that built and control conditions tend to be similar to each other and differ from nature in how they influence prosocial/sustainable behaviours (Dopko, 2013). Lastly, when multiple statistical analyses were used to test the same hypothesis (e.g., Dopko, 2012, 2013; Study 2), the results associated with the independent t-tests with outliers excluded were used to calculate that sample's effect size.

For the prosociality meta-analysis, only studies with the direct purpose of examining the effects of nature exposure on prosociality were included; samples that investigated differences of helping behaviour in rural versus urban areas (see Steblay, 1987) or the effects of a wilderness experience on prosocial outcomes were excluded (i.e., Witman, 1987). This was done in order to minimize commensurability (i.e., combining substantively different studies and measures together) and to maintain a targeted focus on the specific research question of interest (Sharpe, 1997). As the purpose of these investigations was not to examine the impact of nature specifically, it is unlikely that the researchers experimentally controlled for important variables (i.e., natural and built features in the urban and rural environments or social interaction in the wilderness experience). Including these studies would have severely hindered confidence in the claim that it was exposure to natural environments which was causing changes in prosociality.

Fixed-effect meta-analyses were used to obtain the mean weighted effect sizes (Borenstein, Hedges, Higgins, \& Rothstein, 2009). This model assumes that all the samples are measuring one true effect size and variability represents sampling error. Although one can make generalizations beyond the included samples when a random-effects model is used, it tends to be unreliable when fewer than 30 samples are included in the meta-analysis and is a more conservative test (Overton, 1998; Schulze, 2007). As the number of samples was not expected to be that large, the fixed-effect model was chosen. In order to test whether there was a significant amount of variability between samples, Cochran's $Q$ statistic was used (Borenstein et al., 2009). 
In addition, $I^{2}$ was obtained to determine how much of the variability between samples was beyond sampling error. Following conventions, $I^{2}$ values of $25 \%, 50 \%$, and $75 \%$ were respectively considered low, moderate, and high amounts of variability (Higgins, Thompson, Deeks, \& Altman, 2003). Using the rules outlined in Hanson and Bussière (1998), samples were identified as outliers if their effect size was the highest or lowest in the meta-analysis, there was significant variability between samples, and their effect size contributed to more than $50 \%$ of Cochran's $Q$. If outliers were identified, results were presented with and without their inclusion. 